\title{
Inhabiting the threshold: the Women's Gallery as liminal space in New Zealand's feminist art history
}

Kirsty Baker

A thesis submitted to the Victoria University of Wellington in fulfilment of the requirements for the degree of Master of Arts in Art History

Victoria University of Wellington 


\section{Contents}

$\begin{array}{lll}\text { Abstract } & \text { ii }\end{array}$

Acknowledgements

List of Illustrations

Introduction 1

Chapter one: Locating the Women's Gallery 9

Chapter two: Essentialism to Poststructuralism? 36

Chapter three: Liminality and Difference 60

$\begin{array}{lr}\text { Conclusion } & 85\end{array}$

$\begin{array}{lr}\text { Illustrations } & 93\end{array}$

$\begin{array}{ll}\text { Bibliography } & 108\end{array}$

Appendix I: $\quad 118$

Exhibition history of the Wellington Women's Gallery 


\begin{abstract}
In the four years between January 1980 and January 1984, a gallery was run in Wellington by a collective of women to display the work of female artists only. This feminist space sought to provide an educational, supportive and inclusive environment, free from the obstacles which were perceived to prohibit women from displaying their work in mainstream art spaces. This thesis tackles the history of this gallery's reception and seeks to address its absence in the writing of New Zealand's art history. In reassessing its history, I assert the Women's Gallery deserves a place within critical accounts of art in New Zealand.
\end{abstract}

Chapter one locates the Women's Gallery within the cultural and political context of New Zealand society by tracing the development of the women's art movement, and feminism as a grassroots political movement. An examination of the gallery's Opening Show serves as an example of the way in which the ideology of the Women's Gallery shaped its organisational structure.

Chapter two pinpoints the time of the gallery's existence at a point of transformation within feminist thinking. This chapter problematises the evolution of feminist thought from 'essentialism' to a critique informed by poststructuralist strategies. A close analysis of artworks demonstrates that the Women's Gallery was simultaneously occupied by artists who exhibited both tendencies.

By proposing Victor Turner's model of liminality as a framework upon which to base a discussion of the Women's Gallery, chapter three reframes the gallery as a liminal space. I argue the temporary existence of the gallery allowed women a space removed from patriarchal power structures - in which to experiment both politically and creatively. 


\section{Acknowledgements}

Firstly, I would like to extend my gratitude to my supervisor, Christina Barton, for her guidance and belief.

My research process was aided by many along the way. Thanks to the following:

The staff at the Alexander Turnbull Library, Kirsty Willis in particular.

Libby Storey at Artis Gallery in Auckland

Marian Evans

Peter Nicholls

Juliet Batten

Enormous thanks to Kim Baker, Christopher Baker, Lynn Marston and Alison Beck for their constant support throughout.

Finally, Andrew Ching, I could have neither embarked upon nor completed this project without your love, encouragement and unwavering belief in me. Thanks are not enough. 


\section{List of Illustrations}

Fig. 1 Opening Show artists outside the Women's Gallery, 1980, photograph taken by Fiona Clark.

Page 93

Fig. 2 Heather McPherson, Goddess Figure, 1980, mixed media, (temporary installation).

Photograph of the artist with mixed media installation at the Women's Gallery Opening Show.

Page 94

Fig. 3 Juliet Batten, Roses, 1980, watercolour on paper, (artist's collection). Photograph taken during the installation of Opening Show.

Also visible: Heather McPherson, Goddess Figure, 1980, mixed media, (temporary installation).

Page 95

Fig. 4 Juliet Batten, Roses, 1980, watercolour on paper, (artist's collection). Page 96

Fig. 5 Di Ffrench, Diary, 1980, mixed media installation, (artist's collection). Page 97

Fig. 6 Di Ffrench, Diary, 1980, mixed media installation, (artist's collection). Page 98

Fig. 7 Robyn Kahukiwa, Hinetitama, 1980, oil on board (Palmerston North: Te Manawa).

Page 99

Fig. 8 Exhibition catalogue, Mothers, Women's Gallery, 1981 - 1982, showing Robyn Kahukiwa, Hinetitama, 1980, oil on board, (Victoria University Library).

Page 100

Fig. 9 Juliet Batten, Banner for the Bleeding from the Mending series, 1983, acrylic, fabrics and stitching on canvas, (artist's collection). Page 101

Fig. 10 Joanna Paul, Unwrapping the Body, 1977, self-produced-book, (Victoria University Library).

Page 102 
Fig. 11 Joanna Paul, Unwrapping the Body (detail), 1977, self-produced-book, (Victoria University Library).

Page 103

Fig. 12 Martha Rosler, The Bowery in Two Inadequate Descriptive Systems, 1975-75, Forty-five gelatin silver prints of text and image mounted on twenty-four backing boards. Multiple editions. (Edition 2/5 New York: Whitney Museum of American Art).

Page 104

Fig. 13 Martha Rosler, The Bowery in Two Inadequate Descriptive Systems (detail), 1975-75, Forty-five gelatin silver prints of text and image mounted on twenty-four backing boards. Multiple editions. (Edition 2/5 New York: Whitney Museum of American Art).

Page 105

Fig. 14 Joanna Paul, Felix Sleeping, 1980, Conte, (location unknown). Page 106

Fig. 15 Joanna Paul, Felix Sleeping, 1980, Conte, (location unknown). Page 107 


\section{Introduction}

Wellington, New Zealand's capital city and seat of Parliament since 1865, has long been a site of political and cultural activity. The central location and public accessibility of Parliament's buildings have resulted in them becoming:

... the natural focus for major political events and protests against government policies. In the 1920 s and early 1930s demonstrations of the unemployed took place in the grounds. Anti-Vietnam War protesters chanted outside Parliament in the 1960s and on one occasion invaded the Prime Minister's offices. Demonstrations became increasingly common from that time...

This history of governance and protest has played out in a city densely populated by museums and galleries. Wellington plays host to private dealer galleries led by pioneer Peter McLeavey, the non-collecting City Gallery Wellington, and Te Papa Tongarewa Museum of New Zealand, home to the country's national art collection, as well as major suburban galleries in Porirua and Hutt City. The proliferation of creative spaces existing in such close proximity to the seat of political power, has resulted in an inextricable relationship between the cultural and the political.

This distinctive combination of creativity and political engagement was showcased from October 2012 to February 2013 in an exhibition at Victoria University of Wellington's Adam Art Gallery: We Will Work With You! Wellington Media Collective $1978-1998$.

The Wellington Media Collective (WMC) was a politically motivated graphic design and communications operation that would stamp its mark on Wellington in the two decades from the late 1970s. ... Over this time they generated an impressive and distinctive body of work and, in doing so, produced a multifaceted history of political campaigns, social movements, graphic and print technology, performance and visual art, and activist organisations and networks. ${ }^{2}$

\footnotetext{
${ }^{1}$ John E Martin, "History of Parliament's Buildings and Grounds", http://www.parliament.nz/ennz/about-parliament/how-parliament-works/fact-sheets/00PlibJMPBG1/history-of-parliamentsbuildings-and-grounds, accessed October 2015.

2 Mary Ellen O'Connor, "We Will Work With You, Not For You", in Mark Derby, Jennifer Rouse and Ian Wedde (eds.), We will work with you: Wellington Media Collective 1978-1998, Wellington: Victoria University Press, 2013, p.85.
} 
Offering a comprehensive retrospective of their work, the exhibition provided a visual overview of the cultural and socio-political concerns which shaped Wellington, and New Zealand, during the last decades of the $20^{\text {th }}$ Century. What becomes apparent upon viewing these decades-old posters, is the fact that many of them convey political messages which retain contemporary relevance. New Zealand of 2013, and today, remains a society in which issues such as Māori land rights, unemployment and the privatisation of state owned assets are at the forefront of public debate. That the Wellington Media Collective worked with groups whose interest ranged across a wide spectrum of socio-political concerns, from conventional 'high' culture to various forms of oppositional or activist practice, served to position a retrospective survey of their work as particularly timely.

One aspect of their collective project aimed to 'spread the skills of printing and allied processes to those progressive groups of people in the community who traditionally have little or no access to these'. ${ }^{3}$ This opportunity to work with the Wellington Media Collective was taken up by the Women's Gallery, the focus of this thesis. Opening in January of 1980 it set out to exclusively display the work of women artists; its organisers firmly stated that 'our intention is a feminist gallery'. ${ }^{4}$ This clearly suggests that the gallery intentionally defined itself within a politicised discursive framework. This was symptomatic of the political unrest of the era:

The 1960s saw the emergence of protest movements which ran strong and successful campaigns against apartheid, the Vietnam War, nuclear weapons and destructive environmental projects.... In the 1970s and early 1980s Prime Minister Robert Muldoon, out of touch with the changing times provoked confrontations over Maori land occupations, sanctioned police raids on immigrants, shortcircuited environmental legislation, refused to intervene over French nuclear testing and split the country down the middle by insisting that the 1981 Springbok rugby tour went ahead. Muldoon's

\footnotetext{
${ }^{3}$ From the constitution of Wellington Media Collective Inc. 5 February 1979, quoted in O'Connor, "We will work with you, not for you", p.87.

${ }^{4}$ Anna Keir and Marian McKay, "Women's Gallery Planned for Wellington”, Broadsheet 76, 1980, p.44.
} 
authoritarian response bolstered demands from diverse groups for political, economic and cultural change. ${ }^{5}$

The Women's Gallery was one such group, campaigning not only for cultural change within the arts, but also wider political change through its feminist engagement with a range of socio-political issues. In this way the women associated with the gallery can be viewed as members of a politicised generation who saw social inequality not as an immutable reality, but as a series of constructed injustices which were ultimately worth challenging.

Published information relating to the Women's Gallery is sparse. Though mentioned occasionally in written histories of female artists in New Zealand, the majority of references to the gallery are oblique or tangential; none are particularly illuminating. ${ }^{6}$ This thesis will examine the Women's Gallery and the political and creative motives which shaped it. Further, it will establish the reasons for the gallery's relative invisibility in New Zealand's art history.

To produce a fact based chronology of the Women's Gallery will serve to make visible a feminist project which has slipped from view in New Zealand's art historical discourse. However, whilst there is a certain value in the attempt to challenge such erasure, the act of recovery is a limited one:

The historical recovery of data about women producers of art coexists with and is only critically possible through a concomitant deconstruction of the discourses and practices of art history itself. ... Historical recovery of women who were artists is a prime necessity because of the consistent obliteration of their activity in what passes for art history.... But alone historical recovery is insufficient. $^{7}$

\footnotetext{
${ }^{5}$ Jane Kelsey, The New Zealand Experiment: A World Model for Structural Adjustment?, Auckland: Auckland University Press, 1995, p.22.

${ }^{6}$ Anne Kirker's New Zealand Women Artists: A Survey of 150 Years, along with Elizabeth Eastmond and Merimeri Penfold's Women and the Arts in New Zealand: Forty Works 1936-86 both include acknowledgment of the Women's Gallery, in addition to listing some of the women most closely associated with it.

${ }^{7}$ Griselda Pollock, Vision and Difference: Feminism, Femininity and the Histories of Art, New York: Routledge Classics, 2003, p.77.
} 
Acknowledging the insufficiency of historical recovery, as argued here by Griselda Pollock, requires more than simply writing the Women's Gallery into visibility. An investigation into the culture of art display and criticism which rendered the gallery invisible is also required. In doing so, it will be possible to establish that the gallery's lack of presence in the historical record is not a justified exclusion. Rather, it rests upon a gendered hierarchy of opposition which enacts the relegation of women to secondary status.

This argument leads from an understanding that there are many potential factors influencing the exclusion of an artist - or group of artists - from the grand narrative of art history. Frequently such factors are dictated by the dominant ideology of those responsible for writing such narratives, rather than an intrinsic lack of value in the work of the excluded artists. An art history which saw fit to exclude the Women's Gallery was one written not from an objective standpoint of verifiable truth, but rather from a specific point of view. As Elizabeth Grosz has argued:

It is simply not possible to supplement knowledges by adding women to an otherwise neutral or objective knowledge: knowledges have not just "forgotten" women, their amnesia is strategic and serves to ensure the patriarchal foundations of knowledges. ${ }^{8}$

The most comprehensive published resource relating to the Women's Gallery is the 1988 book A Women's Picture Book: 25 Women Artists of Aotearoa (New Zealand). The book was compiled and edited by three women, including two - Marian Evans and Bridie Lonie - who played a key role in the Wellington Women's Gallery collective. Its compilation format allowed twenty five individual artists a space in which to present self-selected pieces of their work along with their thoughts on the creative, and often politicised, process behind them. ${ }^{9}$ Most - though not all - of the women included in the book also exhibited in the Women's Gallery, and additional information was provided in Afterwords and an Appendix relating specifically to the

\footnotetext{
${ }^{8}$ Elizabeth Grosz, "Bodies and Knowledge: Feminism and the Crisis of Reason", in Elizabeth Grosz (ed.), Space, Time and Perversion, New York: Routledge, 1995, p.40.

${ }^{9}$ Also see http://personal.victoria.ac.nz/marian_evans/women-pic-book/index.html where updated information regarding a number of the artists included has been added. Evans and Lonie write "We are sometimes asked if we are planning a sequel to "A Women's Picture Book". We are not, but here is an update on some of the artists. More information will be added from time to time."
} 
gallery. Whilst the material written by each artist gives valuable insight into the contexts within which their work was produced, the nature of the project ensured that the book came from a personal, rather than critical or objective viewpoint. The parameters for inclusion in A Women's Picture Book were outlined by Marian Evans, one of its three editors and a co-founder of the Women's Gallery, as follows:

Choosing potential contributors to this book had all the challenges of putting together an exhibition ... the artists in this book are part of our own, transitional, generation ... Affinity and connection felt by us were paramount in our consideration: personal affection towards many of the contributors was an element in the choices... ${ }^{10}$

This book does not attempt to serve as an accurate history of the Women's Gallery, nor as a critical appraisal of the artists who exhibited there. Thus this thesis sets out to fill a significant gap in the published record regarding the role played by the Women's Gallery in the art history of New Zealand. ${ }^{11}$

However, my thesis has been hindered by lack of access to crucial primary resources. Upon the gallery's closure in January of 1984, Marian Evans ‘inherited the Gallery's files when there was nowhere else for them to go and sold them to the Alexander Turnbull Library to help pay the costs of this book, a Women's Gallery/Spiral project'. ${ }^{12}$ Due to the personal nature of much of this material, and the archive's relative recentness, strict restrictions governing access remain in place. ${ }^{13}$ The vast majority of archived material remains as yet unarranged, and is subject to tightly restricted access. Specific viewing permission is required from the Curator of Manuscripts and Archives, or the Curator of Photographs at the Alexander Turnbull Library, in addition to the copyright holder for certain items. Further, much material

\footnotetext{
${ }^{10}$ Marian Evans and Bridie Lonie, "Afterwords", in Marian Evans, Bridie Lonie and Tilly Lloyd (eds.), $A$ Women's Picture Book: 25 Women Artists of Aotearoa (New Zealand), Wellington: Government Printing Office, 1988, p.229.

${ }^{11}$ Through consultation of the archived material held in the Alexander Turnbull Library, I have collated an exhibition history for the Women's Gallery. The list is as comprehensive as resources allow, and has been included as an Appendix to my thesis.

12 Marian Evans, "Appendix: The Women's Gallery, December 1979 - February 1984", in Evans, Lonie and Lloyd (eds.), A Women's Picture Book: 25 Women Artists of Aotearoa (New Zealand), p.252.

${ }^{13}$ Listings for this material can be found at http://tapuhi.natlib.govt.nz/ under the reference number 84 072. Specific restrictions can be viewed in each item's individual record.
} 
is currently under a total embargo, with viewing completely prohibited until the end of 2015 .

Limited access to these records has meant that a comprehensive history based on archival research has not been possible. Instead I have undertaken a wider examination of the cultural, political and theoretical context within which the Women's Gallery operated, and its critical relation to this landscape, to broaden the modest history I have compiled.

This thesis argues how the Women's Gallery, during its four years of operation, enriched the social, cultural and political landscape of New Zealand. In addition it examines the reasons for the gallery's current relative obscurity. Chapter one traces the political and artistic context which led to the creation of the Women's Gallery, and outlines a brief history of the project. This account is contextualised in relation to the growth of feminism as a grassroots political movement across New Zealand which led to the discussion of the status of women within the country's art world. This chapter traces the emergence of art criticism dealing specifically with female artists in New Zealand, alongside the development of woman only exhibitions in the 1970s as context in which the Women's Gallery was formed. It takes the gallery's Opening Show as an example of the way women re-thought exhibition making as a means to demonstrate the feminist and aesthetic aims of the gallery. A discussion of the collective operational structure of the gallery follows, along with an examination of its underpinning politics.

Chapter two locates the Women's Gallery at a time of transition in feminist artistic practice and criticism, whilst attempting to provide an alternative to the mainstream canon. It also draws attention to the difficulties inherent in discussing a group project whilst avoiding oversimplification in both creative and ideological terms. The changing nature of feminist criticism during the 1980s is highlighted through an investigation of Lita Barrie's attack in Antic of feminist art in New Zealand. In doing so I will locate the Women's Gallery within this period of transition, in order to account for its ultimate marginalisation. Through close analysis of a range of artworks displayed at the Women's Gallery, Barrie's assertion that a critical feminist art practice did not exist in New Zealand is refuted. This is achieved by highlighting 
the diversity of artworks exhibited at the Women's Gallery: from traditional perceptions of aesthetic quality and the professionalism of the artists who produced them, to the culturally and theoretically diverse viewpoints they represent. This analysis establishes the difficulty inherent in discussing the work of the Women's Gallery as a whole when it created a platform for such a disparate range of artists, unified through gender alone. The dangerous ease with which it is possible to reduce all difference along these clearly defined lines, allows a re-evaluation of the gallery by dismissing a falsely simplified version of the Women's Gallery that emerged in contemporary art criticism.

Chapter three proposes an alternative reading of the Women's Gallery, situating it as a temporary space, a type of expanded threshold which recognises non-oppositional difference amongst women. The chapter opens by outlining Victor Turner's theory of liminality, which is used as the basis for considering the Women's Gallery as such a liminal space. My argument is that the Women's Gallery is at once an inclusive and experimental space, and its gendered separation from society temporarily allowed for the rejection of oppressive patriarchal social structures which were viewed as dominant in the wider art world. By examining two artists whose relationships to the Women's Gallery were defined by varying levels of commitment, it is possible to trace not only the impact their involvement with the gallery had upon their practice, but also the diversity of the gallery's aesthetic output. Reframing of the Women's Gallery as a liminal space recognises and affirms the value of the project, rather than dismissing it as a failed experiment in feminist separatism with low standards of artistic quality.

In their desire to bring to the centre of women's working practices 'women's everyday realities and the expression of these in an art form' ${ }^{14}$ the Women's Gallery hoped to 'transform the meaning and function of a public gallery' ${ }^{15}$ The emphasis placed on transformative and exploratory creative processes indicates a desire for open-endedness: the Women's Gallery existed to explore new possibilities, both creative and socio-political. It sought to create a space in which that exploration was

\footnotetext{
${ }^{14}$ Marian Evans, "The Women's Gallery 1979-“, in Anne Else (ed.), Women Together: A History of Women's Organisations in New Zealand, Wellington: Daphne Brasell Associates Press, 1993, p.472. 15 Ibid., p.472.
} 
unrestricted by oppressive conventions of qualitative judgement or societal norms. As Phelan argues:

... art can be understood as a specific kind of action and feminism a specific form of language. The promise of feminist art is the performative creation of new realities. Successful feminist art beckons us towards possibilities in thought and in practice still to be created, still to be lived. ${ }^{16}$

My thesis concludes that the Woman's Gallery created a space in which the pursuit of these possibilities was allowed to take centre stage, and therefore deserves a respected place in a critical history of art in New Zealand.

${ }^{16}$ Peggy Phelan, "Survey", in Peggy Phelan and Helena Reckitt (eds.), Art and Feminism, London: Phaidon, 2001, p.20. 


\section{Chapter one}

\section{Locating the Women's Gallery}

In January of 1980, when the Women's Gallery opened in Wellington, its location on the ground floor of 26 Harris Street [fig. 1] placed it firmly within the vibrant and creative heart of New Zealand's capital city. Circa Theatre was 'just across the road', ${ }^{1}$ the city's public library (now City Gallery Wellington) a stone's throw away, and the floor above the gallery was occupied by PhotoForum/Wellington. In early 1981 the Wellington Media Collective moved to Marion Street, close enough that women from the gallery could 'walk over to make posters for the Women's Gallery exhibitions and - for a little while - to be artists and have fun'. ${ }^{2}$ The creative vitality of the area marked it out as an ideal location for an alternative gallery.

Marian Evans was instrumental in initiating the project and organising the practicalities of transforming a vacant office space into a politically engaged gallery. At the time of discovering the space in late 1979, Evans was working with Kidsarus 2, 'a feminist children's book-publishing collective' ${ }^{3}$ which aimed to publish children's stories centred upon female protagonists. Initially seeking an office for Kidsarus, Evans felt that the Harris Street property - attractive mainly due to the fact that it was 'cheap and large ${ }^{4}$ - would be the ideal venue for both an office and gallery. Evans then contacted Bridie Lonie, who thought that a gallery was a 'wonderful idea', along with Anna Keir whom the women had met during their involvement with $A$ Season's Diaries in Wellington in $1977 .^{6}$ This project, conceived by Joanna Paul, involved a "mixture of "professional" and "amateur" artists ... [who] got together ... to document their lives in drawings, words, paintings and collage throughout a chosen

\footnotetext{
${ }^{1}$ Marian Evans, "the bone people", http://wellywoodwoman.blogspot.co.nz/2010/11/bonepeople.html, 2010, accessed January 2015.

2 Marian Evans, "They might have completely forgotten us", http://wellywoodwoman.blogspot.co.nz/2013/01/they-might-have-completely-forgotten-us.html, 2013, accessed December 2013.

3 Judith Collard, "Spiral Women: Locating Lesbian Activism in New Zealand Feminist Art, 1975-1992" Journal of the History of Sexuality 15, no. 2, 2006, p.296.

${ }^{4}$ Evans, "Appendix: The Women's Gallery, December 1979 - February 1984", p.248.

${ }^{5}$ Ibid., p.248.

${ }^{6}$ The other women involved were Bridie Lonie, who was also closely involved with the Women's Gallery and a co-editor of A Women's Picture Book, Allie Eagle, Heather McPherson and Joanna Paul (all of whom exhibited at the Women's Gallery) and Gladys Gurney.
} 
month. ${ }^{97}$ The resulting diaries were displayed in the Victoria University Library, and subsequently in the Women's Studies Department at Waikato University. They were also exhibited during an exhibition of the work of Allie Eagle, Anna Keir and Jane Zusters in 1978 at the Canterbury Society of Arts Gallery in Christchurch. The format of this project was distinctive in a number of ways: in exploring alternative modes of artistic production, foregrounding personal experience as a legitimate creative subject matter, utilising a group format inclusive of women who were both accomplished artists and amateurs, and by displaying works in both a conventional gallery and alternative spaces. Meeting within this woman-only context of creative exploration arguably shaped the direction in which they chose to take the Women's Gallery, many of the elements highlighted above becoming central to its ideology. Together the women approached female artists from across the country who had demonstrated 'some sort of feminist analysis relating to their own work and the established arts system ${ }^{8}$ in order to create a group show for the gallery's opening.

In a pamphlet produced by the Women's Galley to coincide with its opening, the aims of the project were made explicit: 'The Women's Gallery ... a national gallery for women, has three aims: Educational, Supportive, Exploratory'. 9 The intention was to encompass all of these aims through the organisation of a programme of:

... exhibitions and performances built around themes relevant to the lives of all women, e.g Women and Violence, Women and Work, Mothers. To seek wide participation in these, with the aim of linking our experience to the wider reality and making the information we all have to share easily accessible to other women. ${ }^{10}$

Whilst these exhibitions lay at the heart of the Women's Gallery project, the themes which inspired them were frequently used as a way of raising questions and debate. Often educational workshops and additional activities were arranged to supplement the issues explored through the artworks themselves. For example the exhibition Women and Violence, which ran from 28 October to 6 December in 1980, was

\footnotetext{
${ }^{7}$ Juliet Batten, "Emerging from the Underground: the Women's Art Movement in New Zealand", in Women's Studies Conference Papers, Women's Studies Association of New Zealand, 1981, p.72.

${ }^{8}$ Evans, "Appendix: The Women's Gallery, December 1979 - February 1984", p. 248.

${ }^{9}$ The Women's Gallery, "Pamphlet", 1980, (Alexander Turnbull Archive), unpaginated.

10 Ibid., unpaginated.
} 
accompanied by an extensive associated programme of events. These ranged from film screenings and workshops on domestic violence to a Reclaim the Night celebration and a public day of discussion entitled "Women, Violence and Justice: what sort of deal do NZ women get from the law". ${ }^{11}$

In 1982 the gallery 'moved to the ground floor of 323 Willis Street, a building occupied only by women'. ${ }^{12}$ The first exhibition to be held in this new space entitled Silk and Pottery - opened on 2 March 1982. Despite the change of premises, the general format for thematic group exhibitions accompanied by supplementary activities was retained. The programme of workshops for the Women's Disarmament Exhibition (9 October - 20 November 1982) was as extensive as that held in conjunction with Women and Violence. Whilst this format dominated, physical constraints - the building at Willis Street was smaller than that at Harris Street - led to a tendency for smaller group shows, in addition to the occasional solo show.

Whilst the Women's Gallery was always run collectively, this collective was mutable rather than fixed, allowing numerous women a participatory and organisational role. Most women contributed their time on a voluntary basis, though the series of administrators were paid:

Many of those employed under Department of Labour schemes (the only source of money for employment) were artists, who had to learn the necessary administrative skills on the job and were prepared to come from Christchurch (Heather McPherson), Auckland (Sharon Alston) and elsewhere (Anna Keir, Barb McDonald) because they believed in what was happening. ${ }^{13}$

During the four years of the gallery's operation it exhibited the work of roughly 125 women over the course of 33 exhibitions. Events, activities and exhibitions were organised by 19 women in an administrative capacity, ${ }^{14}$ with the assistance of

\footnotetext{
${ }^{11}$ The lecture was held in the Public Library Lecture Theatre on 29 November 1980, and was jointly organised by the Women's Gallery and the Committee on Women. The poster advertising the event is held in the Alexander Turnbull Library. Archive no. Eph-C-WOMENS-GALLERY-1980.

12 Evans, "The Women's Gallery 1979-", p.472.

${ }^{13}$ Evans, "Appendix: The Women's Gallery, December 1979 - February 1984", p.250.

${ }^{14}$ These women, as listed in A Women's Picture Book: 25 Women Artists of Aotearoa were Anna Keir, Alison McLean, Sharon Alston, Lou Genet, Heather McPherson, Mary Bailey, Mar Leniston, Elspeth Collier, Linda Pearl, Barbara McDonald, Sue Turner, Linda Hardy, Errolyn Haines-Jones, Anaria Tangohau, Toni Nealie, Celia Elizabeth, Sarah Parkinson, Shirley Cameron and Melinda Hatherly.
} 
countless volunteers and participants. The intensity of the project, as well as a lack of consistent funding, took its toll on the energy of the women involved. 'At the A.G.M. in 1984 it was decided unanimously to close the Gallery. Financial difficulties, especially with the funding of workers, breakings in and thefts by neighbours ... were all reasons for stopping. ${ }^{, 15}$

Many of the women who were involved in the Women's Gallery prior to its closure have acknowledged the impact that their participation had upon their creative and personal lives. Juliet Batten, one of the eleven women who exhibited work in the Opening Show has written of the Women's Gallery that it:

... filled a gap that is like a desert for women to cross. It's like going across the Sahara without women - without water - to cross from your studio (which is probably your kitchen table) to a dealer gallery. Many women never make that journey. It's too arduous, too difficult. ${ }^{16}$

The space first created by Evans, Lonie and Keir on the ground floor of Harris Street represented more than just an office and gallery to many women. Batten makes clear the role played by the Women's Gallery in breaking down the structural barriers that prevented many women from becoming artists. Referencing both a desire for communality among women, and an acknowledgement of the limits placed upon them, she highlights issues central to the women's art movement in New Zealand. The material conditions of women's lives, and their increasing desire to address and change these conditions through collective political and artistic practice were core to the development of feminism in New Zealand in the 1970s.

In the 1970s the discourse of New Zealand art was concerned predominantly with a desire to characterise a distinctive national identity within art, and particularly painting which was considered the most elevated art form. The thread of this desire to delineate an art uniquely of and from New Zealand - and in particular 'New Zealand as an empty and unmetaphored land ${ }^{17}-$ can be traced back throughout $20^{\text {th }}$-century

\footnotetext{
${ }^{15}$ Evans, "Appendix: The Women's Gallery, December 1979 - February 1984", p.251.

${ }^{16}$ Juliet Batten, quoted in A Women's Picture Book: 25 Women Artists of Aotearoa (New Zealand), p.52.

${ }^{17}$ Ibid., p.187.
} 
art criticism. Francis Pound asserts that it 'was with Landfall that there came the first clear attempt to create a canon of New Zealand art'. ${ }^{18}$ This desire to canonise indicates a need within critical discourse to elevate exemplary artistic models to represent the identity of the nation. This process is therefore both cultural and political. As Priscilla Pitts asks: 'What better sign of a native New Zealandness than a landscape which had "always" been here, was in no way foreign or imported'? ${ }^{19}$ It is perhaps not coincidental that this portrayal of the country's landscape as favoured subject matter, fits ideally alongside the search for an appropriate style. Within New Zealand painting, the style which found great favour was the attempt by painters to capture the distinctive quality of New Zealand's unique natural light. As Arthur R.D. Fairburn wrote in 1934:

There is no golden mist in our air, no Merlin in our woods, no soft warm colours to breed a school of painters from the stock of Turner, Crome, Cotman and Wilson Steer. Hard, clear light reveals the bones, the sheer form, of hills, trees, stones and scrub. We must draw rather than paint, even if we are using a brush, or we shall not be perfectly truthful. ${ }^{20}$

This tendency to connect the quest for a national artistic identity to the depiction of New Zealand's unique light was compounded by Gordon H. Brown and Hamish Keith in their 1969 book An Introduction to New Zealand Painting. They state in their introduction that 'two main patterns emerge: a general orientation towards landscape . . . and a positive response on the part of a number of more important New Zealand painters to the distinctive qualities of New Zealand light'. ${ }^{21}$ In highlighting these patterns, Brown and Keith also insinuate the weight of their qualitative judgement into the debate, naturalising the 'importance' of those painters whose 'positive response' adhered to their specific definition of a distinctive New Zealandness.

\footnotetext{
${ }^{18}$ Francis Pound, "The Words and The Art: New Zealand Art Criticism c.1950 - c.1990", in Mary Barr (ed.), Headlands: Thinking through New Zealand Art, Sydney: Museum of Contemporary Art, 1992, p.187.

${ }^{19}$ Priscilla Pitts, "The Unquiet Earth: Reading Landscape and the Land in New Zealand Art", in Barr (ed.), Headlands: Thinking through New Zealand Art, p.89.

${ }^{20}$ Arthur R. D. Fairburn, quoted in "The Words and The Art: New Zealand art criticism c.1950 c.1990", p.188.

${ }^{21}$ Gordon H. Brown and Hamish Keith, An Introduction to New Zealand Painting 1839 - 1967, Auckland: William Collins (New Zealand) Ltd, 1969, p.9.
} 
Writing 20 years after Brown and Keith's prophetic statement - prophetic because it elevated and canonised the artists - Colin McCahon, Toss Woollaston and Rita Angus - who they believed to most clearly exemplify their thesis, Juliet Batten has highlighted the narrowness of their judgement: 'Much has been written about the quest for the "New Zealand" identity in art: in fact it has been written about as if it were the only identity search going on in the visual arts in this country'. ${ }^{22}$ National identity within the discourse of New Zealand art privileged positions most often occupied by white, heterosexual males concerned with depicting the landscape as subject matter. Recognition of this led women artists who were engaged with feminist politics to challenge and disrupt such assumptions.

Challenges to patriarchal perspectives within New Zealand art criticism were driven by a burgeoning groundswell of feminist awareness taking place across the country throughout the 1970s. Feminist positions were most vocally and democratically articulated through the feminist magazine Broadsheet, which published its first issue in July 1972. The magazine provided an easily accessible and public forum for women to explore the issues which impacted their day-to-day experience. Typical of much second-wave feminist literature, it was driven by a consciousness-raising methodology. Covering a broad range of issues including abortion law reform, domestic violence, body image and pay equity, the magazine's collective of women attempted to make clear the relevance of feminist politics to almost every aspect of women's lives. For women who were tentatively beginning to engage with feminist thought, Broadsheet provided both a means with which to feel connected to other like-minded women, and a resource through which to increase their awareness of feminist issues. There is also evidence that through the magazine, women in New Zealand were exposed to international feminist thought, both through content within the magazine - such as reviews of books by feminists such as Adrienne $\mathrm{Rich}^{23}$ - and because from 1977 'Broadsheet was bringing in from overseas and selling (mainly by mail order) feminist books that were hard to get from regular bookshops' ${ }^{24}$

\footnotetext{
22 Juliet Batten, "Art and Identity", in David Novitz, and Bill Willmott (eds.), Culture and Identity in New Zealand, Wellington: Government Printing Office, 1989, p.213.

${ }^{23}$ Pat Rosier, Been Around For Quite A While. Broadsheet: Twenty Years of Broadsheet Magazine, Auckland: New Women's Press Ltd., 1992, p.282.

${ }^{24}$ Ibid., p.12.
} 
Magazines such as Broadsheet, and the feminist art journal Spiral (first published in 1976) among others, were only one visible indication of the growing awareness of feminism spreading through the country. Throughout the 1970s several conferences were held which specifically addressed feminist politics within New Zealand: the United Women's Convention was held in Wellington in 1975, Christchurch in 1977, and finally in Hamilton in 1979. There was also a Radical Feminist Caucus which met in Wainuiomata in 1975, and Piha in $1978 .{ }^{25}$ Beginning the same year as the Women's Gallery opened, and still meeting annually now, was the conference of the Women's Studies Association of New Zealand, which has also published a biannual academic journal since 1984, along with proceedings of their annual conferences. ${ }^{26}$ The existence of such a widespread level of interest in feminist issues evinced by both the proliferation of published material, and the organisation of large-scale gatherings of politically engaged women, demonstrate the growing momentum behind the movement which contributed to the formation of the Women's Gallery at the close of this decade. The mood during this time was one of excitement at the growing awareness of women's potential to collectively enact positive change:

The seventies saw an upsurge of women working together, discovering each other and our ability to organise, influence and change. We discovered the strengths and stresses of belonging to a group, and the joys and dilemmas of collective action. We were intoxicated with the developing insights and understandings that enabled us to begin to name the world and our own experiences, instead of men always naming it for us.... ${ }^{27}$

Many women who were involved in this period of growing self-awareness and political engagement were also artists, a significant number of whom had trained under high-profile artist-teachers in New Zealand's art schools. However, receiving such training - and even excelling within this educational framework - did not often translate for women into a successful career as an artist. The art school environment itself, whilst officially welcoming of women (they were allowed admission) was

\footnotetext{
${ }^{25}$ Sandra Coney, "Why the Women's Movement Ran Out of Steam" in Sue Kedgley and Mary Varnham (eds.), Heading Nowhere in a Navy Blue Suit and other TALES from the FEMINIST REVOLUTION, Wellington: Daphne Brasell Associates Co Ltd., 1993, p.57. ${ }^{26}$ http://www.wsanz.org.nz/journal/index.html, accessed February 2014.

${ }^{27}$ Anne Else and Rosslyn Noonan, "Unfinished Business", in Kedgley and Varnham (eds.), Heading Nowhere in a Navy Blue Suit and other TALES from the FEMINIST REVOLUTION, p.190.
} 
structured in such a way that the proposition of achieving significant levels of success was presented as being inherently unlikely:

I remember that in my third year ... we had a group video project and it was clear to me that it was the males who directed and filmed and the females who assisted and cleaned up. No-one 'set it up' like this. They didn't need to. In 1973 in an art school where women comprised at least 50 per cent of the students but where only one woman was a teacher (who taught only stage I) and where women's work was rarely mentioned in Art History classes ... this was 'just the way it happened'. ${ }^{28}$

What is evident from Anna Keir's recollection of her experience is the naturalisation of the secondary status of women which she experienced in the art school environment. Female students in this environment had virtually no other women to relate to outside of their peer group - they were more often than not un-represented as teachers, artists worthy of learning about, or art historians. For these students there were no models of female success to which they could aspire. By placing the phrase 'just the way it happened' in scare quotes, Keir draws our attention to the artificiality of this statement - ideological environments of this sort do not 'just happen', they are socially created and perpetuated.

The pervasive negative attitudes met by women aspiring towards an artistic career were multitudinous and deeply entrenched, even in those who recognised the talent in such women. Claudia Pond Eyley, who trained under McCahon at Elam School of Fine Arts at The University of Auckland, gives an example of the repressive attitudes faced by women artists when she says: 'I announced I was having a baby and McCahon threw his hands up in the air and said, "Oh, what a waste, all that effort and energy, here goes another one, you'll never do any painting again"”. ${ }^{29}$ The assumption is clear: a mother belongs at home with her children, her 'effort and energy' to be transferred to, and fully consumed by, the requirements of meeting their needs. Though McCahon may have recognised the talent and potential in Pond Eyley,

\footnotetext{
${ }^{28}$ Anna Keir, quoted in Evans, Lonie and Lloyd (eds.), A Women's Picture Book: 25 Women Artists of Aotearoa (New Zealand), p.157.

${ }^{29}$ Claudia Pond Eyley, quoted in Evans, Lonie and Lloyd (eds.), A Women's Picture Book: 25 Women Artists of Aotearoa (New Zealand), p.102.
} 
he clearly believed that for a woman, being a mother and a successful practicing artist were in fact mutually exclusive.

It was not just in the classroom environment that female artists were underrepresented. The dominant critical mouthpiece for the New Zealand art world was also one in which the female remained, on the whole, silent. Established in 1976 Art New Zealand became 'the principal local art magazine, featuring writing from the populist to the scholarly'. ${ }^{30}$ In the years between its initial publication and the opening of the Women's Gallery, the country's mainstream art publication presented art in New Zealand as being an almost exclusively male domain, in terms of both critical voice and subject. An examination of the indexing of back issues on their official website shows a massive bias toward male writers and male artistic subjects. Juliet Batten, the year after the Women's Gallery opened, wrote of the magazine:

Art New Zealand, that mouthpiece of the art establishment, refuses to acknowledge the women's art movement because of its origin in feminist ideas. When I phoned the editor to enquire whether he would be interested in an article about the movement, I was told curtly, "we are not interested in propaganda, only art!"31

During the 1970s female artists gained an increased awareness of the disparity between the experience and representation of themselves and their male counterparts in the art world. This, in parallel with the growing visibility and accessibility of feminist politics throughout the country, resulted in a desire to tackle the sexism of the art world with newly acquired feminist strategies. Discussing the reasons behind the formation of the Women's Gallery, Marian Evans outlines the conditions that led to the popularity of consciousness-raising as a feminist strategy:

As happened elsewhere, local women discovered, or reminded one another, that women artists were disadvantaged by their ignorance of women artists of our past, within and outside New Zealand, by the lack of role models, particularly at art schools; by inadequate understanding of women's work by critics, dealers and public galleries, unless the work fitted male-defined expectations; and often, by employment discrimination in institutions. ${ }^{32}$

\footnotetext{
${ }^{30}$ Mary Barr, "Chronology", in Barr (ed.), Headlands: Thinking through New Zealand Art, p.209.

${ }^{31}$ Batten, "Emerging from the underground: the women's art movement in New Zealand", p.69.

${ }^{32}$ Evans, "Appendix: The Women's Gallery, December 1979 - February 1984", p.248.
} 
It was this lack of connection to a female art history that encouraged many feminists to attempt to reclaim the art of women of the past and rewrite these artists into the canon of art history. While it would be inaccurate to claim that women had been completely excluded from histories of art in New Zealand, it is important to note the lack of both frequency and seriousness with which women's artistic contributions had been presented. In many instances women are referred to as minor artists, and their presence in the discussion usually positioned in direct and qualitative relation to a male painter. For example, in Brown and Keith's An Introduction to New Zealand Painting, comments such as: 'In her best work, Ida Eise was strongly influenced by [John] Weeks' ideas ${ }^{33}$ clearly imply that for a woman to succeed artistically, she must do so in emulation of a male painter. In fact, it would seem that when writing about female artists, the tone almost verges upon sneering condescension:

Another woman painter, Olivia Spencer-Bower, was travelling the countryside ... painting with varied success ... However, rather than her portraits, which had a tendency towards sweetness, or her slightly self-conscious idea of working men in action, the subject that most clearly showed her talent were the simpler landscape paintings. ${ }^{34}$

The exceptions to this negatively loaded discourse are to be found in reviews of the work of Rita Angus and Francis Hodgkins, both of whom are treated as exceptions to the category of woman. Much writing relating to Hodgkins for example is framed within the debate surrounding New Zealand's geographical and artistic isolation more than as a woman, it is her role as expatriate that casts her as other: 'at the age of 37, she left once more for England to become New Zealand's best known expatriate painter'. ${ }^{35}$ Her success as the 'best-known' New Zealand painter in England, overshadows the fact that she is a woman. Angus, in contrast, is cast as a painter whose talent mysteriously exceeds the limitations of her sex, allowing her to gain success. While she may be a woman, she is not like a woman:

One traditionally feminine subject of which she grew particularly fond was her interest in painting flowers. These were not, however,

\footnotetext{
${ }^{33}$ Brown and Keith, An Introduction to New Zealand Painting 1839 - 1967, p.112.

34 Ibid., p.112.

35 Ibid., p.67.
} 
like the usual flower paintings that lined the walls of so many art society exhibitions. . . ${ }^{36}$

In order for her work to stand seriously beside that of the male artists in their book, Brown and Keith are compelled to highlight how unlike 'the usual' female painter Angus was. This discourse of exceptionality is interesting when viewed in light of the visibility of female artists in the canon of New Zealand's art history. Anna Keir writes of these "exceptional" women when discussing the lack of a female presence in the art landscape. She refers to the lack of 'models of women who were artists - not "exceptional" women such as Rita Angus and Frances Hodgkins who often seemed to me to have paid far too high a price, but of women around me who had children and other jobs and somehow integrated making art into that' ${ }^{37}$ It was in response to this perceived invisibility of women within art history that the strategy of reclamation and re-presentation of female artists was initiated.

Such projects were internationally widespread in the early 1970s, and the writings of international feminist critics such as Lucy Lippard and Judy Chicago were embraced and used as inspiration by feminists in New Zealand. In 1974 Lisa Vogel argued that the 'most pressing and fundamental work to be done by feminist art scholars is that of unearthing, documenting, and interpreting the art produced by women artists'. ${ }^{38}$ Whilst this project may have been taken on in New Zealand by the magazines, journals and conferences discussed previously, it was not until 1980 that the first art historical overview appeared in book format. Published in the same year that the Women's Gallery opened, Women in New Zealand Society is an example of consciousness-raising as is clearly indicated by the cover material: 'New Zealand women need to understand their history if they are to realise their potential to become a more powerful force within New Zealand society'. ${ }^{39}$ The book brings together eleven essays from contributors with backgrounds in various fields, examining the issues surrounding women in contemporary society from a New Zealand perspective.

\footnotetext{
${ }^{36}$ Ibid., p.136.

${ }^{37}$ Anna Keir, quoted in Evans, Lonie and Lloyd (eds.), A Women's Picture Book: 25 Women Artists of Aotearoa (New Zealand), pp.157-8.

${ }^{38}$ Lisa Vogel, "Fine Arts and Feminism: The Awakening Consciousness", in Arlene Raven, Cassandra L Langer and Joanna Frueh (eds.), Feminist Art Criticism: An Anthology, New York: Harper Collins, 1991, p.45.

${ }^{39}$ Phillida Bunkle and Beryl Hughes (eds.), Women in New Zealand Society, Auckland: George Allen \& Unwin Australia Pty Ltd, 1980, back cover synopsis.
} 
The subject matter of the essays ranges from "The Role and Status of Maori Women", to "Fertility, Sexuality and Social Control in New Zealand", alongside an essay labelled by the editors as 'the first serious study of New Zealand women artists' entitled "Women Artists in New Zealand", written by Janet Paul. This essay is divided into two sections, the first of which comprises a series of brief overviews of ten artists (or groups of artists in the case of "The Expatriates" and "Our Most Senior Modern Artists') and is conservative in critical approach. Each artist is given a brief biography, along with a summary of their most commonly depicted subject matter and style. This brief description of Mina Arndt is typical of the approach taken by Paul to her subjects:

She married in 1916, and went to live in Motueka. She had a stepdaughter and one son. She continued to work in her studio, until a severe illness sadly ended her life. Her paintings have a unique colour-sense and these, with her sensitive oil wash drawings and finely free etchings, make up a most considerable body of work. ${ }^{41}$

Although Paul's aim may be to introduce the reader to women artists who had been previously neglected by art history, by drawing her discussion of these artists along conventional lines she produces what in essence are female footnotes to the tradition of art historical writing typified by Keith and Brown. Through an emphasis on factual biographical detail, and brief yet value-laden descriptions of the work, Paul offers no real critical engagement with these artists or their art.

Clearly, this strategy is limited in its usefulness, as Linda Nochlin argues in her landmark essay of 1971 "Why Have There Been No Great Women Artists?” By attempting to discover and introduce neglected female artists into the art historical canon, critics such as Paul in no way question the fundamental values attached to the notion of what constitutes greatness itself. Her assumption is that there have in fact been women artists worthy of inclusion, who have been edited out of New Zealand's patriarchal art history by sexist critics. The way in which Paul presents her chosen female artists to the reader does not question whether the parameters of the discipline operate in order to allow only certain types of artistic creation to be granted

\footnotetext{
40 Ibid., back cover synopsis.

${ }^{41}$ Janet Paul, "Women Artists", in Bunkle and Hughes (eds.), Women in New Zealand Society, p.192.
} 
"greatness" status. By attempting to assimilate excluded women into the patriarchal discourse of art history writers such as Paul are forced to apply 'the traditional patriarchal standards of value to justify their selections, thus perpetuating the form of the initial oppression they wish to combat'. ${ }^{42}$

However, Paul follows this first section with a second entitled "The Questions", in which she attempts to analyse the conditions which have led to the exclusion of the women she has re-presented. In this portion of the essay she collates some important quantitative data regarding representation of women painters in exhibitions and gallery acquisitions, as well as in art schools and as recipients of Arts Council funding. Whilst the gathering of this information is important, what is more so is a critical examination of the societal factors which have resulted in the male bias that she reports. However, this portion of the essay also lacks a depth of critical analysis. Indeed, when directly discussing the influence of American feminist artists and critics such as Judy Chicago and Lucy Lippard - both of whom played a pivotal role in shaping the type of feminist strategies employed by the Women's Gallery - Paul is almost dismissive of the ambition of their politicised feminist project: 'The aim is admirable, the practice not effective unless there is a public wanting to know and prepared to include, say "narrative" art in its label-loving categories of acceptance'. ${ }^{43}$ Her conservatism is again reflected when she states somewhat flippantly and derogatorily that '[ $t$ ]raditional views of women painters get the feminists' goat' ${ }^{44}$

By describing along traditional lines the work and lives of the women painters that she introduces in the first section, and by dismissing the aim of feminist art as being essentially 'not effective', ${ }^{45} \mathrm{New}$ Zealand's first 'serious study' ${ }^{46}$ of women artists fails to challenge the structure and ideology of existing art history. However, there was a growing sense of challenge to conventional art histories being mounted within New Zealand, particularly through a number of exhibitions committed to displaying the work of female artists. The influence of international artists and critics such as

\footnotetext{
${ }^{42}$ Cassandra L Langer, "Against the Grain: A Working Gynergenic Art Criticism” in Raven, Langer and Frueh (eds.), Feminist Art Criticism: An Anthology, p.114.

${ }^{43}$ Paul, "Women Artists", p212.

${ }^{44}$ Ibid., p.212.

45 Ibid., p.212.

${ }^{46}$ Bunkle and Hughes, Women in New Zealand Society, back cover synopsis.
} 
Lippard and Chicago was demonstrated in New Zealand most notably by Alison Mitchell [Allie Eagle], who discussed Chicago at length in the catalogue essay for her 1975 exhibition Woman's Art: An Exhibition of Six Women Artists at the Robert McDougall Art Gallery in Christchurch.

This exhibition was one of several held throughout the country dedicated to displaying the work of women artists in the decade leading up to the opening of the Women's Gallery. These exhibitions were organised with differing levels of feminist engagement, although all purported to be addressing the historical male bias evident up to that point in New Zealand art and its history. It is worth closely examining Mitchell's essay for her exhibition catalogue to accompany the Christchurch exhibition, alongside that of another exhibition of women artists in New Zealand, in particular relation to their differing perspectives regarding female artists in the context of feminism. Both exhibitions were held in 1975 and were organised in order to mark International Women's Year, though, whilst they occurred in response to the same political stimulus, the curatorial practice informing each was noticeably different. Mitchell's Six Women Artists, was explicitly positioned as a feminist exhibition: 'It is my intention to briefly outline some of the motivating ideas and forces of the recent Woman's Art Movement and draw on resources from the feminist movement where it has radicalized the attitudes of women artists' ${ }^{47}$

In contrast, the catalogue produced to accompany Anne Kirker and Eric Young's New Zealand Women Painters at Auckland City Art Gallery in the same year succeeds in completely denying any mention of feminism or the woman's art movement. In fact the closest the writers get to an acknowledgement of the feminist art movement which was gaining traction across the country, was to refute the grounds upon which it stood: 'Femininity is not involved any more than masculinity is involved in the work of men painters. Art transcends sex' ${ }^{48}$ The curators go so far in order to deny sex as a factor in art, that they refer to the date when many of the artists held their first "oneman shows," despite the fact that the exhibition was organised to celebrate New

\footnotetext{
${ }^{47}$ Alison Mitchell, Woman's Art: An Exhibition of Six Women Artists, Christchurch: Robert McDougall Art Gallery, 1975, p.3.

${ }^{48}$ Anne Kirker and Eric Young, New Zealand's Women Painters, Auckland: Auckland City Art Gallery, 1975, p.4.
} 
Zealand's Women Painters. The format of the catalogue complies with traditional convention; a brief introductory essay is followed by the body of the catalogue which lists, explains, and indexes the work of each artist included in the exhibition. Each woman is introduced to the reader through a short biographical paragraph, with the emphasis on their formal art education and exhibiting history. The tone is dry and factual, even when value judgements are inferred, for example, in the case of Frances Hodgkins who the catalogue states 'gained increasing recognition in England, as an artist of considerable stature. Her work has been exhibited and collected widely in England and in New Zealand' ${ }^{49}$ Of note here is the emphasis again on Hodgkins as an expatriate - as a woman painter worthy of taking 'her place at the head of the catalogue ${ }^{50}$ because she has attained measurable and definitive success in the European art world. These women, like those written about by Janet Paul, are presented to us as women who have been overlooked, but who deserve inclusion within an otherwise unaltered canon of great art.

Through a comparison of format alone, striking differences become apparent between this catalogue and the one written by Mitchell to accompany the Christchurch exhibition. Where the Auckland essay was brief and conventional, Mitchell's reads like a manifesto for a feminist history of art, one which seeks to dismantle the existing art world in which women are "mostly unacknowledged in historical or current art dialogues, poorly or not represented at all in art gallery collections' ${ }^{51}$ Not only does the explicitly feminist stance taken by Mitchell in her catalogue essay set it apart from that written by Kirker and Young, the format which she uses to introduce the artists to the viewer represents an alternative way of thinking about issues of biography and identity. Rather than following traditional cataloguing conventions, Mitchell allows each artist with work displayed in the exhibition a more individual presence in the catalogue. Whilst the catalogue section for each artist includes the typical list of exhibited images alongside details of where they have previously exhibited, biographical detail is kept to a minimum. Compare the biographical information provided for Joanna Harris [Joanna Paul]: 'Born, December 1945; Hamilton.

\footnotetext{
49 lbid., p.5.

50 Ibid., p.4.

${ }^{51}$ Mitchell, Woman's Art: An Exhibition of Six Women Artists, p.3.
} 
Diploma Fine Arts, Elam B.A. Now living on Banks Peninsula' ${ }^{52}$ to this of Hermina Arndt in Kirker and Young's catalogue:

In early 1900's left for Europe where she studied in London under George Lambert at the London School of Art. . . . Worked in association with Laura and Harold Knight and Stanhope Forbes. About 1906 met the German engraver Hermann Struck and went to Berlin to study with him. Then studied under Lovis Corinth, an important member of the modern movement in Germany, who influenced much of her later work. ${ }^{53}$

The strong emphasis placed upon the listing of masters under whom the artist worked, reaffirms the notion that as a woman Arndt was able to achieve a degree of success due in major part to the (almost exclusively male) influence of others considered more important than herself. In striking contrast, Mitchell places almost no emphasis on formal training, and allows the artists their own voice, in two sections titled Statement and On Women as Artists. These statements strongly refute the mystical notion that 'art transcends sex ${ }^{54}$ purported by Kirker and Young. Consider this statement by Jane Arbuckle:

Our society does not encourage women to develop their abilities as artists. If we should choose to we must do it within the context of a male dominated art establishment and art education system.

Patriarchy discourages in a woman the single-mindedness and inner commitment to herself, that is necessary if she is to be an artist. ${ }^{55}$

Arbuckle's politicisation of her experience as an artist contributes to the creation of a discourse surrounding this exhibition which places it strongly within the current of politicised feminism that was emerging in the 1970s. The strategy of staging female group exhibitions, in order to refute the notion that art transcends sex, gained increasing currency within feminist art communities internationally throughout the 1970s. Exhibitions such as Womanpower: Women's Art (London, 1973), the touring exhibition $C a$. 7,500 organised by Lucy Lippard ${ }^{56}$ which showed in both the United

\footnotetext{
52 Ibid., p.12.

${ }^{53}$ Kirker and Young, New Zealand's Women Painters, p.5.

54 Ibid., p.4.

${ }^{55}$ Jane Arbuckle, "On Women as Artists" in Mitchell, Woman's Art: An Exhibition of Six Women Artists, p.8.

${ }^{56}$ Roszika Parker and Griselda Pollock (eds.), Framing Feminism: Art and the Women's Movement 1970 - 1985, London: Pandora Press (Routledge \& Kegan Paul Ltd), 1987, pp.187-194.
} 
States and Britain, and Womanhouse (1972) in which a house in Los Angeles was filled with a series of site specific installations created by women from Judy Chicago and Miriam Schapiro's Fresno feminist art programme ${ }^{57}$, all provide evidence of an emerging feminist tendency to exhibit in a group environment. In the words of one of the artists who exhibited in $\mathrm{Ca} .7,500$ :

Most exhibitions are single sexed ones (i.e. all male) and for as long as that holds true we have to promote ourselves and each other in a very conscious way. We chose, and feel it necessary to exhibit together ... to counter prejudice against women artists. Nobody else is going to do it for us. ${ }^{58}$

This desire to 'counter prejudice against women artists' clearly played a pivotal role in the motivation behind exhibitions such as Mitchell's Six Women Artists. With examples of an alternative framework for group exhibitions established in New Zealand and internationally, it is not surprising that the Women's Gallery adopted the group format for the majority of their shows. The establishment of the Women's Gallery five years after Mitchell's Six Women Artists can be seen as a continuation of this politicised feminist engagement with art making, which had become increasingly prevalent throughout the 1970s. By placing an interrogation of the formation of female subjectivity at the heart of their project, the Women's Gallery dismissed the assertion that female artists can simply be integrated into an existing art historical discourse.

In a piece published in Broadsheet the same month as the Women's Gallery held its opening show, ${ }^{59}$ Anna Keir and Marian McKay [Marian Evans] expressed in simple terms the philosophy behind their collaborative project. Central to their defining statement is a desire to cast the gallery in opposition to existing high art conventions in several ways: as a politically aligned feminist space, an area for creative experimentation and an accessible, supportive female environment.

\footnotetext{
${ }^{57}$ Whitney Chadwick, Women, Art and Society, New York: Thames and Hudson, 1990, p.357.

58 Parker and Pollock, Framing Feminism: Art and the Women's Movement 1970-1985, p.12.

${ }^{59}$ The Opening Show comprised the work of a group of 11 women artists, many of whom would go on to exhibit in numerous exhibitions at the Women's Gallery, and elsewhere. These women were: Juliet Batten, Allie Eagle, Claudia Pond Eyley, Keri Hulme, Bridie Lonie, Heather McPherson, Joanna Paul, Nancy Peterson, Helen Rockel, Carol Stewart and Tiffany Thornley.
} 
A women's art gallery is starting in Wellington. Hopefully this will provide an alternative to the existing gallery structures; a supportive environment for showing a wide range of women's work. Our intention is a feminist gallery; we want to show the work of women who are not only making art but also redefining its purpose for women. ${ }^{60}$

This commitment to working together as women was strongly reflected in the decision of the Women's Gallery to focus on presenting group rather than solo exhibitions, and to operate collectively. In line with other feminist projects of the time - such as Broadsheet itself - the gallery was run by a collective of women, rather than along more traditional hierarchical lines. Rather than a fixed and continuous collective, the gallery was operated on a fluid and changeable basis around a loose core of women. The Opening Show, co-ordinated by Evans and Keir set the organisational blueprint for the majority of exhibitions during the gallery's existence. Each exhibition was co-ordinated by a group of women who would organise the show around a specific theme. The curatorial approach encompassed a diverse range of methods:

... a co-ordinator would find out (from Wellington sources and national networks developed from those of the seventies groups) who was likely to have work available relating to the theme and invite them to contribute. On rare occasions a particular work would be requested; usually it was left to the individual to decide what she'd like to send. ${ }^{61}$

Not only were a wide diversity of women approached, but those women would generally retain individual control over which of their works were included within any given exhibition. This strategy clearly diverges from more conventional curatorial approaches in which a single dominant organisational point of view tends to control the entire content of an exhibition.

This multi-vocal approach to exhibition organisation becomes clear when we examine the process by which the Opening Show was produced. Funding from the Queen Elizabeth II Arts Council ensured that the exhibiting artists could travel to

\footnotetext{
${ }^{60}$ Keir and McKay, "Women's Gallery Planned for Wellington", p.44.

${ }^{61}$ Evans, "Appendix: The Women's Gallery, December 1979 - February 1984", p.248.
} 
Wellington. Evans says of the process that 'we stayed together for some of the time, in Jean Lonie's house and at my place; the whole process was photographed by Fiona Clark and videoed by Nancy Peterson and Carole Stewart'. ${ }^{62}$ During this period the women worked together in the gallery space to create the exhibition. Much of the time they worked in close contact, assisting each other, eating together and forming friendships. Rather than adhering to an overall plan for display, 'each woman negotiated her own space and put up her own work - with help from whomever was around' ${ }^{63}$ The layout of the gallery space appears to have facilitated this approach, comprising a large central space with a number of smaller rooms leading off from it. The only windows in the building appear to have been located on the street frontage, leaving large uninterrupted walls, ideal for the display of artworks.

The gallery's large central space was occupied by the work of seven women. 'Bridie [Lonie] made a nest/rope/alizarin crimson cloth and stocks piece about cycles of fertility', ${ }^{64}$ and Tiffany Carole Stewart contributed a number of 'lively, rich batiks' ${ }^{65}$ Upon one wall hung a sequence of six charcoal portraits of Muslim women by Helen Rockel. More images of women occupied the end wall, these were 'Claudia Eyley's vivid, joyful cutouts of women, children, babies, plants' ${ }^{66}$ The remaining wall in this central space was filled with a series of watercolours by Juliet Batten, entitled Roses [figs. 3 and 4]. Accompanying this series were two display cases, each containing pink objects associated with traditional representations of femininity - 'bra, rollers, sanitary belt... ${ }^{97}$ The central space in this main room contained a piece called Paua Shell Gods by Keri Hulme, and Heather McPherson's Goddess Figure [figs. 2 and 3], each mixed media installation created specifically for the exhibition. In the next room, a series of abstract watercolours by Allie Eagle [Alison Mitchell] and 'some fine figure drawings in pencil by Claudia Eyley' ${ }^{68}$ Finally, in the gallery's smallest room, Joanna Paul's conceptual piece Interior, based upon the sleeping rhythms of her son Felix. Whilst each women was initially asked to 'contribute something on the

\footnotetext{
62 Ibid., p.249.

63 Ibid., p.248.

${ }^{64}$ Ibid., p.249.

${ }^{65}$ Broadsheet, "Women's Gallery Opens in Wellington," Broadsheet 77, 1980, p.32.

66 Ibid., p.32.

67 Ibid., p.32.

68 Ibid., p.32.
} 
theme of the body, ${ }^{69}$ it is the diversity of approaches to this theme which is of interest.

This acceptance of a diverse range of approaches was reflected in the gallery's acceptance of a wide range of artistic skill and quality. Whilst Eagle, Paul, Eyley and Lonie were all art-school educated, the remaining women were largely self-taught. Analysis of Heather McPherson's Goddess Figure in this context works to reveal the prioritisation of process and participation over the notion of a finished artistic product. McPherson, a poet and the founder of Spiral, was invited by Evans and Keir to create a piece of work for the gallery's Opening Show. The fact that a writer was approached to display work in the inaugural exhibition is demonstrative of the ways in which the Women's Gallery diverged from conventional gallery practice. Whilst not a visual artist, the logic behind McPherson's involvement within an aesthetic environment becomes clear when viewed in reference to the gallery's aims. McPherson, discussing the beginnings of the Herstory Press in Wellington, demonstrates a close affinity with the gallery's collective and exploratory aim, explaining that: 'it was the idea of women working together for women's voices to be heard, positively, that was the aim, and the amalgam of arts - photographers as well as poets, writers, painters etc. Not so much the content as the fact of presence and capability' ${ }^{70}$

McPherson's contribution to the exhibition was a symbolic goddess figure [figs. 2 and $3]$, which the viewer was prompted to physically and creatively interact with. In the description of the piece in A Woman's Picture Book, McPherson explains that 'she had a hairdresser's head that was faceless and on the table beside her were cut out face shapes for women to fill in themselves, to put their own face on them. And they did'. ${ }^{71}$ In this example the individual and personal responses of the women who came to see the exhibition were as much a contribution to the artwork as the physical piece that was initially installed.

\footnotetext{
${ }^{69}$ Evans, "Appendix: The Women's Gallery, December 1979 - February 1984", p.248.

${ }^{70}$ Evans, Lonie, and Lloyd, A Women's Picture Book: 25 Women Artists of Aotearoa (New Zealand), p.40.

${ }^{71}$ Ibid., p.41.
} 
When viewing the photographic image of the figure as reproduced in $A$ Women's Picture Book, it seems highly unlikely that it would have been accepted on formal or aesthetic grounds for display in a conventional gallery environment. The piece consists of a cloth draped figure, with the blank head of a hairdresser's model. She is positioned in front of a handmade astrological chart (visually resembling a dartboard), the glyphs for each sign having evidently been drawn by hand. This amateurish collection of found and handmade items were assembled in order to instigate a participatory experience, rather than to create an aesthetically pleasing object or saleable commodity. An acknowledgement of this reprioritisation of functional over formal elements is provided by McPherson when she declares that: 'I'm not a visual artist and I haven't worked in those mediums, I felt in fact that mine was nowhere near visually successful, it looked home-made. That was okay'. ${ }^{72}$ That a piece the artist herself admitted was not 'visually successful' was displayed in the Opening Show is evidence of the seriousness with which the collective took their aims of being supportive and exploratory, as opposed to qualitatively judgemental.

McPherson's work was well received by feminists, Broadsheet discussing the work in their positive review of the Opening Show:

Mystifying at first, it comes alive as I read the "process book" describing its making and listen to the taped poem. Then the faceless/many-faced figure, in its odd assortment of draperies, with the doll-child below, takes on something of the significance of its foremothers, and becomes a fitting "Figurehead for a Creative Environment". I hope she stays. ${ }^{73}$

For feminist critics traditional markers of quality or aesthetic standards were set aside in favour of the exploratory nature of the work. Personal engagement with the piece was emphasized over the application of universal standards.

Art New Zealand, however, remained silent, the lack of critical engagement with the project acting as judgement in itself. In fact, it was not until 1983 that Art New Zealand published an issue dedicated to New Zealand women artists. However, the

\footnotetext{
72 Ibid., p.41.

${ }^{73}$ Broadsheet, "Women's Gallery Opens in Wellington", p.32.
} 
overwhelming majority of women artists foregrounded in this issue were not actually discussed in relation to feminism. A non-political formalist bias is emphasised through the selection of artists working predominantly as painters and sculptors, and on the whole in a figurative manner. These artists evidence the continuation of a conventional Fine Art tradition rooted in European history. Despite the fact that the Women's Gallery was exhibiting solely the work of women artists, at the same time as the publication of a magazine dedicated to New Zealand's women artists, the project bears almost no mention. Inherently political, feminist, interdisciplinary and inclusive in its approach to art-making, the Women's Gallery presents a more complex picture of woman's place in the art world than that which is played out in the pages of Art New Zealand. Their lack of response to Opening Show would set the tone for their response throughout the life of the Women's Gallery.

Wider critical response prompted by Opening Show was divided between positive and negative reviews, which were split along predictable lines. In contrast to the positive engagement demonstrated by Broadsheet, the level of vitriol and scorn directed at the gallery from the conventional arbiters of artistic judgement was at once viciously personal and stridently defensive. The primary notion being defended is that of aesthetic quality, based on the conventional ideals propagated by the high art gallery system of which the Women's Gallery was intentionally critical. According to the Director of the Suter Art Gallery, in a letter published in the Nelson Mail, the judgements for inclusion of works in mainstream galleries are purely formal. Whilst 'it may happen that all those participating in an exhibition are male ... The deciding factor is always aesthetic not sexual'. ${ }^{74}$ Clearly the implication is that women are incapable of producing art of a qualitative standard that would allow inclusion - there are no great women artists, if they existed, mainstream galleries would happily be displaying their work.

Neil Rowe also reflected this emphasis on high art formalism when reviewing the Opening Show, through personal criticism of the politicised nature of the gallery:

... [a gallery] that is so dogmatically based on an ideology that is determined to show art that serves its own polemical ends has less to

${ }^{74}$ Austin Davies, "Women's Art", Nelson Mail, Nelson, 1980. 
do with art than it has with politics and a form of therapy for disgruntled ladies. ${ }^{75}$

Both gallery director and critic were dismissive of the Women's Gallery's aims to explore personal and social politics. The level of vitriol could be read as being produced by the threat the gallery's interrogation of existing structures posed. An attempt to relegate the Women's Gallery to the position of '[a]rt gallery for the aesthetically disabled female ${ }^{76}$ did not prevent the gallery from functioning as both an interrogation of, and alternative to such structures.

One method by which the Women's Gallery aimed to create an alternative to conventional exhibition programming was through the extensive programme of participatory events which often accompanied their shows. The Opening Show itself was partnered by a week long programme. The motivation behind this strategy was to create a wider platform for consciousness-raising, and over the time that the gallery was open the 'associated programmes drew in many hundreds of women who were interested in a theme but who rarely or never went to art galleries' ${ }^{77}$ Of key importance here is the notion of inclusivity, the desire to eliminate the elitism which was believed to surround existing gallery structures. In utilising the gallery space as the physical and ideological hub for an accessible series of events, the collective invited into the gallery the broadest spectrum of women possible.

The programme of events held during opening week included an evening of screenings of films made by women and a "Grand All Women Concert", both of which were held off-premise and open to all: men, women and children. In addition, a storytelling event was held in the gallery which was also open to all. Two events were open only to women, both of which were held in the gallery itself. The first of these was a screening of a tape of the 1979 United Women's Convention, along with a slide show of work from the Women's Art Archive. The second, an evening of poetry and wine, for which attendees were invited to bring a poem to read. ${ }^{78}$ Common to all of these events was the participatory and social element, along with a broadening of

\footnotetext{
${ }^{75}$ Neil Rowe, Evening Post, Wellington, Feb 2, 1980.

${ }^{76}$ Davies, "Women's Art".

77 Evans, "Appendix: The Women's Gallery, December 1979 - February 1984", p.250.

78 The Women's Gallery, “Programme”, 1980, (Alexander Turnbull Archive), unpaginated.
} 
the function and purpose of the gallery environment. Writing two years after the closure of the Women's Gallery, Marian Evans references this attempt to redefine the rarified nature of the gallery space when she asks 'when did I last hear a child's voice at an art event? Or singing? See toys in an art gallery? ${ }^{79}$ That all of this was accepted - indeed encouraged - during the lifetime of the Women's Gallery demonstrates once again the drive to provide a creative space structured around communality and inclusivity.

This inclusivity, however, was pursued somewhat contradictorily from a foundation of male exclusion. Men were neither allowed to exhibit within the gallery, nor freely attend the exhibits and events that were held there. The two-stage method by which the collective chose to hold the opening of their first exhibition would set the precedence for many events and exhibitions to come. An 'informal all women opening on Monday, 21 January ${ }^{80}$ preceded an open attendance policy implemented the following day. The reasoning behind this gendered exclusion was addressed by the gallery from the outset. In a leaflet produced to accompany the Opening Show the collective outlined their justification for staging women only events:

When we undertake the task of breaking out of the images men have presented to us and exploring our exclusively female experience, then we become vulnerable. . . Hence at certain key moments men may be excluded from some events, not out of spite (as some would have it), but because we need to draw on the special advantages of being exclusively among women. An all women gathering makes the audience participants and includes everyone in our event. ${ }^{81}$

During the opening week, attempts to transform an all-woman audience into a group of participants were articulated in events such as the poetry reading, for which attendees were asked not only to engage as spectators, but also to bring a poem to read. That attendance at an event like this was marked with the desire - or at least the willingness - to participate, would have gone some way towards creating an atmosphere of camaraderie and acceptance.

\footnotetext{
${ }^{79}$ Evans, "Appendix: The Women's Gallery, December 1979 - February 1984", p.252.

${ }^{80}$ Keir and McKay, "Women's Gallery Planned for Wellington", p.44.

${ }^{81}$ The Women's Gallery, "Why a Women's Gallery?", 1980, (Alexander Turnbull Archive), unpaginated.
} 
The motivation to seek wide participation and inclusion, and to work collectively can be interpreted as a desire to eradicate the dogmatic sense of authority believed to be inherent in patriarchal society. In this respect, utilising collectivity becomes a politicised act. Roszika Parker and Griselda Pollock outline the opportunities created through a feminist application of working collectively, arguing that this method of organising intends to challenge:

... the myth of individual creativity which, in practical terms, results in isolation and exploitation for artists, and ... the particular experience of women, cut off from each other and from public acknowledgement as artists. Working collectively is both a reaction against an oppressive condition and a progressive critique of it. ${ }^{82}$

The demonstrative benefit of a collective way of working lies in the bringing together of women who would otherwise find themselves isolated as female artists, not only from a viewing public but also from each other.

Juliet Batten is quoted in an interview for the television programme Kaleidoscope in 1984, as saying that 'part of feminism is to work collectively and to break down hierarchies and power structures that are seen as male'. ${ }^{83}$ The expression of this belief by an artist whose work was displayed at the Women's Gallery reflects the choice of the gallery's founders to entrust the running of the project to a collective. These choices would indicate that there was a firm belief in the political potential of collectivity to create an alternative environment for art making that would both critique and disrupt the dominance of patriarchal high art standards.

Despite the intention to forge a unified whole from a disparate group of previously isolated women, the method of working collectively was not without difficulties. On one front these issues were logistical, the leaderless structure of a collective complicating notions of 'reaching consensus, the slow process of decision making, who takes responsibility' ${ }^{84}$ In addition to this there were ideological complications inherent in the simplified view that a unified group could be defined solely by their

\footnotetext{
82 Parker and Pollock, Framing Feminism: Art and the Women's Movement 1970-1985, p.3.

${ }^{83}$ Anne Kirker, New Zealand Women Artists: A Survey of 150 Years (2nd ed.), Craftsman House, 1993, p.178.

${ }^{84}$ Editorial, "Collectively Speaking", Broadsheet 110, 1983, p.28.
} 
feminist convictions. Laura Cottingham, discussing the proliferation in the 1970s of feminist groups choosing to organise themselves according to notions of solidarity and unity, argues that:

... the weight of the cultural and political forces positioned against seventies feminism put feminists in such a defensive position that unity between and among women was seen as necessary for feminism's, and women's, survival and success. Second-wave feminist ideology assumed that a unified sisterhood, especially among and between white, heterosexualized women, necessitated the appearance of a unified public front. ${ }^{85}$

Clearly this notion of a 'unified sisterhood' flattens the spectrum of identity contained within the category of woman. How do women whose identity does not sit comfortably within these markers of dual privilege negotiate their place within this restrictive definition of unity? Despite the problematic notion of any attempts to construct a 'unified public front', the overwhelming attitude of the women involved with the gallery was initially one of great hope. Hope that through the creation of a new method of working outside the limits of authoritarian decision making and qualitative judgement, the potential for personal and creative freedom would grow: 'the Gallery was a commitment that would set us free. We had to work together, with one another and with other women'.86

By actively seeking wide participation and making evident the connection of art making and display to a wider socio-political reality, the Women's Gallery sought to frame their group exhibitions within a strategy of dual consciousness-raising. On one level, the organisation of exhibitions around highly politicised sociological issues worked to draw the viewer's attention to the debate surrounding these issues. In addition, and of equal importance, was the opportunity provided within the framework of an issue-driven group exhibition to develop on a personal level the feminist and creative consciousness of the women whose work was exhibited. This double role can be seen to fit within the pattern recognised by Cottingham in her

\footnotetext{
${ }^{85}$ Laura Cottingham, "Shifting Ground: on the critical practice of Lucy R. Lippard", in Laura Cottingham (ed.), Seeing Through the Seventies: Essays on Feminism and Art, London and New York: The Gordon and Breach Publishing Group, 2000, p.29.

${ }^{86}$ Bridie Lonie, quoted in Evans, Lonie and Lloyd (eds.), A Women's Picture Book: 25 Women Artists of Aotearoa (New Zealand), p.248.
} 
discussion of feminist consciousness-raising groups of the early 1970s, when she argues that they were:

... committed to expanding women's active participation in the fine arts through a dual program that recognized the need to eliminate women's observable lack of confidence as well as the concrete institutional obstacles that prevented women from advancing as visual artists. ${ }^{87}$

By identifying this need to enact change at an institutional level, the collective chose to promote the Women's Gallery as an alternative to dominant patriarchal social structures. Drawing inspiration from the decade of feminist art-making and display which had come before, the Women's Gallery sought to create an accessible and transformative exhibiting space, free from institutional obstacles.

${ }^{87}$ Laura Cottingham, "L.A. Womyn: The Feminist Art Movement in Southern California, 1970-1979", in Cottingham (ed.), Seeing Through the Seventies: Essays on Feminism and Art, p.164. 


\section{Chapter two}

\section{Essentialism to Poststructuralism?}

The Women's Gallery opened at the end of a decade of growing feminist awareness and activism in New Zealand. The decade that was to follow - the 1980s - saw a profound shift in the examination of gender politics within the arts. Much theoretical debate taking place internationally in the fields of feminist art history, visual culture and film studies at this time was centred upon a critical re-evaluation of the issue of representation itself. In 1976 Laura Mulvey's seminal essay "Visual Pleasure in Narrative Cinema" was published, bringing to the fore an awareness of the gendered structuring of the very act of looking in which the male viewer fetishizes and objectifies the viewed female body:

In a world ordered by sexual imbalance, pleasure in looking has been split between active/male and passive/female. The determining male gaze projects its fantasy onto the female figure, which is styled accordingly. In their traditional exhibitionist role women are simultaneously looked at and displayed, with their appearance coded for strong visual and erotic impact... ${ }^{1}$

Whilst this understanding was to shape much feminist art and art criticism in the decades to follow, it did not play a visible role in feminist art theory in New Zealand until 1986 when Lita Barrie 'in two forceful essays, attacked much consciously feminist practice from the 1970s and 1980s as "a fundamentalist feminist art". 2 Barrie's critique of feminist art in New Zealand was utilised as a strategy to introduce poststructuralist thought to art historical debate in the country.

Developing from the foundations of Ferdinand de Saussure's linguistic model of arbitrary semiotic signification, the fields of structuralism and poststructuralism were to play a dramatic role in altering perceptions of the construction of meaning, not only in literary texts, but across all forms of representation. If language is based on a system of arbitrary signification, then it can only ever approximate meaning; there is no direct correlation between what we experience and how we represent this

\footnotetext{
${ }^{1}$ Laura Mulvey, "Visual Pleasure in Narrative Cinema”, in Peter Simon (ed.), The Norton Anthology of Theory and Criticism, New York: W.W. Norton \& Company Inc., 2001; p.2186.

2 Pound, "The Words and the Art: New Zealand Art Criticism c.1950 - c.1990", p.197.
} 
experience in language. In his essay "The New Cultural Politics of Difference" Cornel West discusses the shift from modernism to postmodernism in relation to the disruption of hierarchical understandings of cultural and social difference. Written in 1990, West's essay places the writings of Jacques Derrida at the centre of academic deconstruction:

Jacques Derrida's version of deconstruction is one of the most influential schools of thought among young academic critics. It is salutary in that it focuses on the political power of rhetorical operations - of tropes and metaphors in binary oppositions like white/black, good/bad, male/female, machine/nature, ruler/ruled, reality/appearance - showing how these operations sustain hierarchal world views by devaluing the second terms as something subsumed under the first. ${ }^{3}$

This deconstruction of binary structures of power was key to the changing approach to feminist art making and art criticism heralded by Barrie. The recognition that art, as a form of visual representation, is capable of constituting value-laden meaning, led to a desire to uncover the dominant social ideologies that such imagery reinforced. For feminist artists and critics, these new deconstructive methods were often utilised in order to provide evidence of the cultural subjugation of women in western culture. If woman had been cast throughout art history as the object always 'subsumed under the first' ${ }^{4}$ then theoreticians and artists set out to reveal the artifice of this opposition. In doing so, much of the feminist art which came before was attacked due to its lack of theoretical understanding:

...many feminist artists who were influenced by poststructuralism, psychoanalysis and subaltern theory distanced themselves from aspects of the early women's art movement. They criticized the celebration of innate femininity, and the retrieval of traditional female culture, for confining women to a separate biological and cultural sphere. ${ }^{5}$

As we have seen in chapter one, the formation of the Women's Gallery was influenced heavily by the grass-roots consciousness-raising feminism typical of the

\footnotetext{
${ }^{3}$ Cornel West, "The new cultural politics of difference", in Stephen Seidman (ed.), The postmodern turn: new perspectives on social theory, Cambridge: Cambridge University Press, 1994, p.75.

${ }^{4}$ Ibid., p.75.

${ }^{5}$ Helena Reckitt, "Preface", in Phelan and Reckitt (eds.), Art and Feminism, p.11.
} 
1970s. With an emphasis on collaboration and the creation of art about personal experience, the project can be seen to represent elements of the early women's art movement which became heavily criticised. The perception that the Women's Gallery exemplified essentialist ideals goes some way to explaining its subsequent exclusion from an art history which no longer valued these ideals. In order to investigate whether this charge of essentialism is justified, examination of both the writing of this poststructuralist critique, and the creative output of the Women's Gallery are required.

Through the creation of an exhibition space existing solely for the display of work by female artists, the Women's Gallery demonstrated a concerted move to exist independently of a patriarchal mainstream art system. However, this notion of female separatism has been heavily criticised by writers such as Judith Barry and Sandy Flitterman-Lewis, in their 1980 essay "Textual Strategies: The Politics of ArtMaking”. Their essay, like the work of Barrie in New Zealand, was deeply dismissive of many forms of self-declared feminist art which failed to demonstrate a critical understanding of the 'social construction of femininity' ${ }^{6}$ Flitterman-Lewis and Barry argue that:

...the separatist position seems to be an example of this selfvalidation gone awry: the very notion of positive... images of women relies on the already constituted meaning of "woman". Again; this unproblematic notion of "femaleness" does not take into account that meaning is a dialectical process... ${ }^{7}$

The very idea that a separate space can and should exist for women, rests firmly on the belief that woman herself can be defined through the recognition of a uniquely female identity, an identity which is not male. By creating a space which has at its foundation an admission of binary difference, there is a clear danger of reinforcing the negative implications of this difference; woman becomes defined by that which she is not - not-male, not-talented enough, not-deserving of inclusion. It is this danger that Austin Davies reinforces through his labelling of the Women's Gallery as an enclave

\footnotetext{
${ }^{6}$ Judith Barry and Sandy Flitterman-Lewis, "Textual Strategies: The Politics of Art-Making", in Raven, Langer and Frueh (eds.), Feminist Art Criticism: An Anthology, p.96.

${ }^{7}$ Ibid., p.93.
} 
'for the aesthetically disabled female'. ${ }^{8}$ In light of his views it is possible to argue that these women have enacted their own self-marginalisation, that they have unintentionally created for themselves a ghetto of aesthetic inferiority.

Structural parallels can in fact be drawn in this case between revisionist art histories such as that of Janet Paul discussed in chapter one - and the separatist positioning of the Women's Gallery in relation to institutionally conventional practices and systems of display. Both of these feminist strategies seek to create a space for woman within a discourse in which they are seen to be lacking due to discrimination rather than merit. However, the space thus created is often one which can be perceived to exist as a female addendum to the original - and therefore dominant - system. Just as the insertion of biographical information relating to previously neglected female artists does not alter the bias evident in the canon of New Zealand's art history, the creation of a Woman's Gallery does not fundamentally challenge the existence or dominance of a network for art display made up of publicly funded spaces frequently shaped by the values of a dominant 'high' culture, and privately owned dealer galleries motivated by profit. By 'adding on' their contributions and discoveries to such traditions, both art historian and gallery founder run the risk not only of accepting the dominance of these models, but also of reinforcing the inferiority of any work which exists outside of these sanctioned environments.

In this instance, however, such a critique would be an oversimplification of the terms of the debate. The above argument takes as its premise the accepted belief that the Women's Gallery was a separatist organisation. This position has been publicly stated by artists exhibiting in the gallery, such as Juliet Batten, who declared that the project 'challenged the existing art structures in every way. To begin with, it was separatist in that only women's work was exhibited'.

The strong commitment made by the founders of the Women's Gallery to the creation of a physical and ideological space for women can be read as an attempt to disconnect from normative societal standards. By defining the boundaries of this space along

\footnotetext{
${ }^{8}$ Davies, "Women's Art".

${ }^{9}$ Batten, "Art and Identity", p.223.
} 
gendered lines, the terms of difference between inside and out were clearly marked; in this instance a charge of separatism seems justified. However, can this apparent marking of an exclusively female territory be read as an unequivocal declaration of separatism? Whilst the Gallery's commitment to the display of work by female artists alone seems justification enough for a separatist label, the boundary of exclusion created was not impermeable. Yes, the work of men was excluded; men, however, were not. 'Exhibitions - except for a lesbian one - were open to all members of the public ... Some women found this policy reassuring, seeing it as "non-separatist"". ${ }^{10}$ It is at this point that the waters become muddied. By allowing male spectatorship to most - if not all - exhibitions, yet excluding male participation in many associated events and workshops,${ }^{11}$ the Women's Gallery sent a contradictory message regarding the relationship between men and the gallery space.

Attitudes towards this issue were complex and contradictory throughout the history of the gallery. Marian Evans, when reflecting on the disintegration of the Women's Gallery, acknowledged that the Gallery was 'often challenged by women who didn't see any value in a separatist institution'12 and also 'by women who believed the Gallery should never be open to men'. ${ }^{13}$ Simultaneously the gallery was criticised for going too far - and not nearly far enough - down the path towards female separatism.

Unpicking the lack of consensus regarding male admission to the Women's Gallery highlights a problem inherent in a critical project which takes as its subject a shifting collective of participants. It is all too easy to condense the issue into an oversimplification. If some women who claimed to speak for the gallery declared it a separatist project when the reality was considerably less definitive, how do we begin to speak to the complexity of individual points of view, be they creative or political? Ensuring that individual artists are not subsumed by an oversimplified conception of an essentialist group politic is of key importance, yet this task is fraught.

\footnotetext{
${ }^{10}$ Evans, "The Women's Gallery 1979-", p.473.

11 Ibid., p.472.

${ }^{12}$ Evans, "Appendix: The Women's Gallery, December 1979 - February 1984", p.251.

13 Ibid., p.251.
} 
It was not until 1986, in the inaugural volume of Antic, that published voices within New Zealand criticism directly addressed the theoretical terrain exposed by poststructuralist thought. Prompted by 'concern at the lack of a forum for critical discussion, especially in the visual arts ${ }^{14}$ the editorial team responsible for Antic hoped to provide an inter-disciplinary forum which would stimulate participation within a theoretical debate they saw as absent from New Zealand's critical landscape:

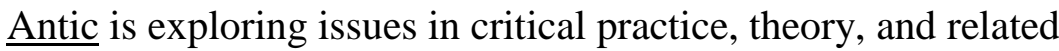
work in fiction; encouraging dialogue between disparate disciplines, approaches, and texts. Antic hopes to foreground aspects of a growing body of work dealing with recent directions in feminist and other theoretical practices often ignored by existing arts publications in New Zealand. ${ }^{15}$

By highlighting the importance of developments within feminist thought, alongside other theoretical practices, the space provided by Antic encouraged a direct engagement with complex theoretical debates occurring internationally. Examining this issue, it becomes clear that the emphasis fell heavily upon works which not only acknowledge, but engage with, poststructuralist thought and deconstruction. Several essays directly reference postmodernism, poststructuralism, or deconstruction in their titles, and many of those which do not take such a direct approach, nonetheless address such theoretical issues within the scope of their argument. Francis Pound, for example, in his piece "Nationalist Antitheses: A Compendium", draws attention to the ways in which New Zealand's history of nationalist art criticism was structured as a sequence of qualitative binary pairings, declaring that the 'hierarchical oppositions implicit in that N.Z. art criticism, from the thirties until today' ${ }^{16}$ can be divided into both 'good figures' and 'bad figures' ${ }^{17}$. The echoes of Derrida's 'tropes and metaphors in binary opposition... [which] sustain hierarchal world views ${ }^{, 18}$ are here made clear.

It is in response to the binary opposition between masculinity and femininity that Lita Barrie writes her critique of feminist art criticism and practice, "Remissions: Toward

\footnotetext{
${ }^{14}$ Susan Davis, Elizabeth Eastmond and Priscilla Pitts, "Editor's introduction", Antic 1, 1986, p.3.

15 Ibid., p.3.

${ }^{16}$ Francis Pound, "Nationalist Antitheses: A Compendium", Antic 1, 1986, p.73.

17 Ibid., p.73.

${ }^{18}$ West, "The new cultural politics of difference", p.75.
} 
a Deconstruction of Phallic Univocality". Adding her voice to those of international critics such as Mulvey, Barry and Flitterman-Lewis, Barrie writes from a geographically specific perspective in order to admonish both artists and critics in New Zealand for their lack of critical or theoretical engagement with the concept of femininity. Whilst Flitterman-Lewis and Barry conclude their essay with a discussion of artists they believe successfully navigate the intersection of theory and practice, Barrie's argument differs in that her conclusion rests upon her assertion that such work has not only failed to be produced in New Zealand, but would lack an understanding audience even if it did exist:

The power of deconstructivist feminist art in the hands of Barbara Kruger, Mary Kelly and Martha Rosler, for example, is due also to a highly sophisticated level of literacy which most New Zealand women artists do not possess - and which is not encouraged through this country's art school education curriculum. ${ }^{19}$

Two years previously, Barrie had been involved in a series of interviews with women artists entitled "Oral Histories: Women Artists". These oral histories were created in 1984 by the Women's Art Archive, in collaboration with the Queen Elizabeth the Second (QE II) Arts Council. ${ }^{20}$ During the course of the project, Barrie interviewed over 50 female artists, many of whom identified themselves as being feminist, and many of whom had exhibited work at the Women's Gallery. Her involvement in this project would initially appear to demonstrate a commitment to recording and preserving the working practices and political thoughts of these women. However, despite coming into contact with the work of so many feminist artists first hand, two years later she appeared to dismiss their work wholesale when she wrote:

What has not yet emerged in New Zealand is feminist work which plays upon the ambivalences inherent within the socio-historic determinants of 'femininity'. That is to say, CRITICAL feminist art, which challenges cultural codes which create women's repression. $^{21}$

\footnotetext{
${ }^{19}$ Lita Barrie, "Remissions: Toward a Deconstruction of Phallic Univocality", Antic 1, 1986, p.100.

${ }^{20}$ The interviews are held in Te Papa's library. Registration number CA000053.

${ }^{21}$ Barrie, "Remissions: Toward a Deconstruction of Phallic Univocality", p.99.
} 
Barrie structures her argument leading to this conclusion around loose categories of women's art which she believes are inadequate in their levels of critical engagement with the theoretical and representative conventions surrounding woman. The target in Barrie's crosshairs is not in fact these individual groupings of art, rather it is the entirety of feminist art and criticism being produced in New Zealand during the 1970s and early 1980s. All of those women interviewed by Barrie have thus been rendered as lacking. What we can extrapolate from this in relation to the Women's Gallery, is that Barrie saw no clear indications within their exhibition output of the type of work that did 'not just sit on the margin, but disrupt[ed] the phallocentric order'. ${ }^{22}$ Barrie has constructed her poststructuralist thesis upon the strategic dismissal of all feminist work which had come before. However, my task is to examine how thoroughly this charge stands up from the vantage point of historical distance, relatively short though it may be.

By investigating the categories by which Barrie delineates and dismisses New Zealand's feminist art, it will be possible to ascertain whether or not she presents an accurate picture. Barrie begins her essay by establishing herself as the voice of a theoretical, rather than merely descriptive, art criticism. She does this by introducing the reader to poststructuralist thought through the 'new French feminisms - echoes of which have not yet resounded in New Zealand'. ${ }^{23}$ She then goes on to attack art criticism in New Zealand, which she characterises as operating 'largely within a modernist tradition... [which] fails to acknowledge the complexities of authorship and of audience reception'. ${ }^{24}$ It is at this stage that she turns her critical attention to the producers of art, identifying four categories of art made by women in New Zealand. These categories are defined by Barrie as follows: 'shared imagery art', ${ }^{25}$ art which 'deals with a glorification of a matrilineal and sometimes mythical past', ${ }^{26}$ art made by women but 'based on masculine praxis', ${ }^{27}$ and finally art created by women who 'work intuitively (as distinct from critically) from their PHYSICAL experience'. ${ }^{28}$ By

\footnotetext{
${ }^{22}$ Lita Barrie and Stuart Morgan, "Altared Positions: A conversation between Stuart Morgan and Lita Barrie," Antic 1, 1986, p.105.

${ }^{23}$ Barrie, "Remissions: Toward a Deconstruction of Phallic Univocality", p.89.

${ }^{24}$ Ibid., p.91.

${ }^{25}$ Ibid., p.94.

${ }^{26}$ Ibid., p.97.

27 Ibid., p.98.

28 Ibid., p.99.
} 
focusing closely on two of these categories in relation to artworks exhibited at the Women's Gallery, I will refute Barrie's charge that critical engagement was absent from women's art in New Zealand at this time.

The first category under fire by Barrie is "the "Chicago-Lippard school of sharedimagery art", which emphasizes vaginal forms and menstruation and employs certain stylistic devices - pastel colours, soft materials and flowers' ${ }^{29}$ Evidence can in fact be found to support the claim that there existed a direct influence within New Zealand feminism of the work of Chicago and Lippard. Chicago's mixed media installation The Dinner Party (1979, Brooklyn Museum, New York) received a full page review in Broadsheet, where the work is praised not only for the 'extraordinary art and craft $^{30}$ it exhibits, but also the collective mode of its production and the way in which it celebrates 'women's art over the ages'. ${ }^{31}$ In her 1981 presentation to the Women's Studies Conference, Juliet Batten refers not only to Chicago specifically, but also to the notion that an exploration of female-specific artistic forms was a natural evolution which occurred in New Zealand without requiring international influence:

When news of Judy Chicago was carried back to Christchurch by a travelling woman, and the first copy of "Through the Flower" came with her, certain artists and writers had already begun to discover their own female images. News of the women's art movement in America came as confirmation of something that had already spontaneously been born... ${ }^{32}$

In fact, Batten herself was one such artist who was exploring the visual terrain of female-specific imagery, the results of which formed an exhibit for the Women's Gallery Opening Show. Her Roses series [figs. 3 and 4], comprising at least 9 watercolour paintings of roses on paper, ${ }^{33}$ is described by the artist as being 'all about connections between women', ${ }^{34}$ and visually and symbolically links the concept of

\footnotetext{
${ }^{29}$ Ibid., p.94.

30 Jocelyn Harris, "Vulvas on plates: Judy Chicago's Dinner Party", Broadsheet 72, 1979, p.35.

31 Ibid., p.35.

32 Batten, "Emerging from the underground: the women's art movement in New Zealand", p.72.

${ }^{33}$ I have not been able to find photographic documentation of the series in its entirety, but have pieced together the majority of the series from a sequence of slides held at the Alexander Turnbull Library.

${ }^{34}$ Evans, Lonie and Lloyd, A Women's Picture Book: 25 Women Artists of Aotearoa (New Zealand), p.52.
} 
woman with the image of the flowering rose. Created and hung in series, each painted image depicts a rose in various stages of transformation from bud to flower. Whilst the works vary slightly in size from panel to panel and are presented on cardboard mounts of irregular size and varying colours, these aesthetic discrepancies and interruptions are unified through the use of a colour palette heavily dominated by pink.

The works are a painted exploration of that conventional marker of femininity; the colour pink itself is as much the subject matter as the rose depicted, or the woman implied. From whites with the merest hint of a blush, through pale cherry blossoms and lavenders, to deep violets heavy with blue, Batten utilises the broadest spectrum of the colour's tonality. Immediately though, the words of Barrie come to mind, the viewer being presented with a sequence of works which are comprised almost entirely of 'pastel colours, soft materials and flowers'. ${ }^{35}$ Painted in watercolours, a medium often associated with amateurism or femininity, the works are soft and diffuse in their appearance, conforming to the notion of female-specific forms. The soft, loose manner in which these roses have been depicted may not be akin to traditional botanical studies intent upon the accuracy of categorisation, but the impulse nonetheless seems to be a reproduction of the subject matter based on mimesis rather than abstraction.

This certainly seems to be the case for the early panels in the series, though a stylistic shift gradually occurs as the sequence progresses towards a looseness that verges upon abstraction. However, what positions these images as something other than direct observations of flowers is not any aesthetic or stylistic element, but rather the way in which the viewer's interaction with the paintings was framed. The very fact of their presence in an exhibition and gallery intended exclusively for female artists immediately creates a heightened awareness of the artist's gender; being a woman is thus marked as being important and relevant. In Broadsheet's review of the Opening Show, the experience of viewing the work is described as follows: 'on the wall, a closed rose in pencil, then a flowing sequence of watercolours as the rose opens,

\footnotetext{
${ }^{35}$ Barrie, "Remissions: Toward a Deconstruction of Phallic Univocality", p.94.
} 
summed up in a poem/painting. "The pink of anger becomes the pink of passion"”. 36 This overt correlation between the symbolism of colour and emotion marks the personal symbolism of the emotive journey depicted by the artist. Set within the confines of a pink colour palette, and a traditionally feminine medium, Roses seems to be firmly positioned within the sphere of feminine forms and self-exploration - the parallel between the opening flower and the blossoming of the woman's awakened passion impossible to avoid. By aligning the pink image of the rose with an emotive and sexualised experience of womanhood, Batten can be criticised for falling into the trap highlighted by Barrie. It can be argued that through her emphasis on 'vaginal forms ${ }^{37}$ - the visual metaphor of an opening flower is not striking here in its originality - Batten, has 'simply reverse[d] the valuations attributed to each sex, to elevate an "essential female" and through this simple reversion attempt to encourage women's self-esteem through new prestige attached to women's biology'. ${ }^{38}$ Whilst Batten's Roses series does seem to affirm Barrie's assertion, this was not the only position on offer at the Women's Gallery. Was there no evidence here of truly 'CRITICAL feminist art, which challenges cultural codes which create women's repression'? ${ }^{39}$

Central to this notion of a critical feminist art was the debate surrounding the representation of the female body in a visual culture which privileged the male gaze. The problematic tension between the female body as image and object led many artists who were aware of postmodern theory to 'refuse to represent women at all, believing that no representation of the female body in our culture can be free from phallic prejudice' ${ }^{40}$ While this attitude may provide women with the least complex means of saving the female body from objectification, it is not wholly sufficient. As Diane Elam argues, 'feminism cannot dispose of the body any more than it can simply inhabit it. The difference of bodies remains a fact $-\mathrm{a}$ fact that menaces instead of

\footnotetext{
${ }^{36}$ Broadsheet, "Women's Gallery Opens in Wellington", p.32.

${ }^{37}$ Barrie, "Remissions: Toward a Deconstruction of Phallic Univocality", p.94.

${ }^{38}$ Ibid., p.95.

${ }^{39}$ Ibid., p.99.

${ }^{40}$ Craig Owens, "The Discourse of Others: Feminists and Postmodernism", in Scott Bryson, Barbara Kruger, Lynne Tillman and Jane Weinstock (eds.), Beyond Recognition, Representation, Power and Culture, Berkeley: University of California Press, 1994, p.180.
} 
legitimates our understanding of sexual difference'. ${ }^{41}$ The presence of the body is inescapable. Its materiality, along with the performative power it holds to enact gender, renders it a rich and accessible site of artistic exploration. Acknowledging the complexity of visually representing the gendered body need not necessarily lead to its rejection as a subject. However, the inherent dangers of objectification and reductivism cannot be ignored if a truly critical artistic practice is to occur.

One work exhibited at the Women's Gallery which occupies a representative position lying somewhere between disposing of and inhabiting the female body, is Di Ffrench's 1980 work, Diary [figs. 5 and 6]. In doing so, this mixed media installation provides evidence that female artists were capable of working from a critical point of view, in order to question the representation and formation of woman as subject. The piece was displayed in the exhibition Diaries, which ran from 22 July to 22 August, during the gallery's first year of operation.

The unifying theme, made explicit by the exhibition's title, has been a commonly utilised tool for feminist artists, the diary form privileging the exploration of personal experience. As Whitney Chadwick points out, 'women sought forms through which to valorize women's experience and the early 1970s saw an explosion of work that consciously reinserted women's personal experiences into art practice'. ${ }^{42}$ The diary, grounded in the day-to-day lived experience of individual women can be seen as a tool through which to reclaim and legitimise the importance of that very experience. Problematic parallels can easily be drawn between the diary as a form of personal artistic expression, and the addition of rediscovered women artists to the canon of art history. The diary can be dismissed as mundane, peripheral, everyday. It is none of those things which conventionally mark art as great: permanent, universal, transcendent. Neither does it necessarily act to interrogate the assumptions upon which those parameters of greatness are based. Bridie Lonie, writing of the diary form, speaks of its specific relevance to women's lives as follows:

\footnotetext{
${ }^{41}$ Diane Elam, Feminism and Deconstruction: Ms. en abyme, London and New York: Routledge, 1994 p.61.

${ }^{42}$ Whitney Chadwick, Women, Art and Society, p.356.
} 
Traditionally a woman's life has been measured in small acts such as those of the domestic routine, which involves minute organisational ability and concern for the nuances of feeling of those in her family. She could not devote time to making masterpieces. . . Time unfolded slowly, offering little room for grand schemes, or eccentric individuality - that province of the professional artist. So she cared for each day and all this was private: she could talk to her friends or she could talk to herself, and often she wrote a diary. ${ }^{43}$

By grounding her discussion of the diary so specifically within the everyday routine of women, she marks it in direct opposition to the 'grand scheme' of the 'professional artist' who produces 'masterpieces'. Rather than questioning this qualitatively based binary pairing, Lonie's discussion of the diary form serves to reinforce the separate position it occupies. The choice to organise an exhibition around an object of such a private and intimate nature, initially elevates that key tenet of early feminist thinking dismissed by Barrie: the personal is the political.

The brief issued to the artists who exhibited in Diaries was relatively open-ended, Lonie explaining that the 'women were asked simply to describe a month, and forms varied widely'. ${ }^{44}$ Many of the works on display bore a close relation to the traditional diary format, commonly exhibiting the inclusion of both the visual image and the written word. However, there was also space for artists to approach the brief from a more complex point of view. It is in the description of a month presented by $\mathrm{Di}$ Ffrench where we find evidence of an engagement with issues of representation, along with an interrogation of patriarchal structures of power. The inclusion of such a work points to the generalisation enacted by Barrie in her dismissal of all feminist art in New Zealand as failing to challenge the 'cultural codes which create women's repression'. 45

The installation, constructed using muslin, leather, hooks, newspaper and greasepaint, consisted of 15 pairs of muslin hangings, each of which bore the greasepaint smeared imprint of Ffrench's own body. The statement Ffrench wrote to accompany the piece reads as follows:

\footnotetext{
${ }^{43}$ Bridie Lonie, "Exhibitions Wellington: Diaries", Art New Zealand 18, 1981, p.14.

44 Ibid., p.14.

${ }^{45}$ Barrie, "Remissions: Toward a Deconstruction of Phallic Univocality", p.99.
} 
This is essentially a diary in that I imprinted my own body image (torso) onto the gauze rectangles, daily for the month of June 1980. Also newspaper clippings indicating dates were attached to the lower outside edge of each gauze. Conceptually the piece became a visual analogy for an aspect of education that has always been my deepest concern - corporal punishment. ${ }^{46}$

By making clear that the relationship between Diary as artwork, and the literal diary as source material is forged through the marking of time, Ffrench allows a reprioritisation to occur. Rather than situating the diary as a private confessional space for women to escape or observe their day to day lived experience, she instead positions it as a site of repeated action. The woman for whom this diary exists - in this instance Ffrench herself - is thus cast in the role of active agent, intent upon the production of meaning. This meaning though is never made explicit. The viewer is left to question whether Ffrench has cast herself as the victim of the corporal punishment that she references, the one enacting such punishment, or a range of positions in between. The ambivalence of her positionality forces the viewer to question the way in which visual systems construct meaning.

If the diary is here a site of action, it is important to note that the physical body is central to this activity. Not just any physical body, but that of the artist. In order to imprint her body's image onto the gauze, Ffrench had to apply greasepaint to her naked skin. It is an appropriation of Yves Klein's use of naked women as his substitute paintbrushes. However, whilst for Klein, the act of painting is made performative and visual, for Ffrench the invisibility of the process ensures that the viewer can only ever infer the trace of the body. This method of referencing, rather than directly presenting the image of a specific identifiable body, is central to the way in which this work navigates the complexity of female representation. Here the female body exists in a fragile state of representative limbo, a simultaneous presence and absence. Upon these grounds alone, Diary works to disrupt the dominance and authority of the male gaze. As Elizabeth Grosz writes of the human body's particular materiality:

\footnotetext{
${ }^{46}$ Di Ffrench, quoted in Evans, Lonie and Lloyd (eds.), A Women's Picture Book: 25 Women Artists of Aotearoa (New Zealand), p.111.
} 
The body can be regarded as a kind of hinge or threshold: it is placed between a psychic or lived interiority and a more sociopolitical exteriority that produces interiority through the inscription of the body's outer surface. ${ }^{47}$

By refusing a representationally accurate depiction of the female body, Ffrench explores this bodily threshold. The physical tangibility of Ffrench's installation also works to create another bodily agent in relation to the work - that of the spectator. Lonie's contemporary description of the piece asserts that 'Di Ffrench's hangings actually allowed one to enter between them' ${ }^{48}$ Suspended from the ceiling, the paintsmeared gauze hangings are unanchored by weight on their lower edges, their diaphanous semi-transparency susceptible to movement caused by passers-by. Ffrench herself discussed this interaction between spectator and object, writing of it:

...the strange beauty created by moving around and through the work - touch, smell of leather, fabric and body makeup; the draught created by one's own body which separated the gauzes, undulating with the intrusion. ${ }^{49}$

A heightened awareness of the viewer's own physical presence would be created through each movement of gauze. Ffrench's accompanying statement, which explicitly mentions corporal punishment, creates a context of meaning within which the viewer is encouraged to frame his or her interaction with the work. The materials chosen to hang the panels contribute to the sense of violent unease which serves to contradict the gentle first impression formed by the lightweight, delicate fabric. 'Leather straps, bamboo canes, fish-hooks (into skin forever trapped). In a strong metaphoric sense these were a sinister support system for thirty one gauze hangings, containing the body impressions (victims)' ${ }^{50}$ This sense of contradiction is enhanced by the juxtaposition of the intimately imprinted gauzes with mass-produced and widely disseminated newspaper clippings, Ffrench deeply enmeshing the private with the public.

\footnotetext{
${ }^{47}$ Elizabeth Grosz, "Bodies and knowledge: Feminism and the crisis of Reason", p.33.

${ }^{48}$ Lonie, "Exhibitions Wellington: Diaries", p.14.

${ }^{49}$ Di Ffrench, quoted in Evans, Lonie and Lloyd (eds.) A Women's Picture Book: 25 Women Artists of Aotearoa (New Zealand), p.111.

${ }^{50}$ Di Ffrench, quoted in ibid., p.111.
} 
By drawing the viewer's attention towards a form of punishment in which bodies do other bodies harm, Ffrench creates a palpable link between the viewer as active agent, and enactor of violence. Highlighting a social issue which is directly concerned with locating the body as a site of control works to visually articulate the social structures by which patriarchal dominance is enacted. The level of complexity with which Ffrench engages with the female body as subject indicates that - contrary to Barrie's argument - work was being produced which challenged the conventional markers of femininity. In doing so, Ffrench's Diary challenged the structures of power through which those representative conventions were prescribed and perpetuated, enacting a truly critical type of feminist art.

That an artist such as Ffrench, the complexity of whose work has led her to be described as 'one of the country's most dynamic and original artists', ${ }^{51}$ exhibited on a number of occasions at the Women's Gallery indicates a depth to the gallery's output that cannot be dismissed. Since her death in 1999, Ffrench's work has maintained a visible presence within the New Zealand art world. Her work 'is represented in many major public collections, including the Robert McDougall Art Gallery, Te Papa Tongarewa/Museum of New Zealand, Dunedin Public Art Gallery, Forrester Gallery, Oamaru, and Sarjeant Gallery, Wanganui'. ${ }^{52}$ This is not an artist who has been relegated to the margins of discourse, nor has her work been viewed through the lens of history as a dated relic typical of the early stages of an essentialist feminist art.

Barrie's second category of feminist art includes work which she believes deals with 'a glorification of a matrilineal and sometimes mythical female past' ${ }^{53}$ Interestingly, the exhibition that became the most successful of all of those mounted at the Women's Gallery initially appears to align with this category. Opening on 3 February, and running until 7 March of 1981 in the Harris Street premises, Mothers was accompanied by a Queen Elizabeth II Arts Council funded catalogue, and went on to tour throughout New Zealand in 1982, until it was shown again in the Willis

\footnotetext{
${ }^{51}$ Anne Kirker, "Di ffrench: Activating Ideas. A Survey of Selected Works 1977-1997", Dunedin: Dunedin Public Art Gallery, 2009, unpaginated.

52 Felicity Milburn, "Di ffrench: Light and Illusion", Christchurch: Robert McDougall Art Gallery \& Annex, 2001, p.6.

53 Barrie, "Remissions: Toward a Deconstruction of Phallic Univocality", p.97.
} 
Street premises from 14 June to 10 July. In October of 1982 it was also shown in the Antares Gallery, in Sydney. Evans says of the exhibition that:

\begin{abstract}
As Mothers was a touring show, to present an exhibition from a women's context in public galleries, we used it to give exposure to work from women who had a long-term commitment to their art work, particularly those women whose work was otherwise unlikely to be included in a public gallery exhibition. ${ }^{54}$
\end{abstract}

The exhibition included the work of many successful and highly regarded women artists, including Joanna Paul, Jacqueline Fahey, Di Ffrench, Robyn Kahukiwa, Robin White, and Keri Hulme. Hulme, who contributed both poetry and images to the exhibition, draws attention to the mythic female past of which Barrie is critical, when she states: "Why in an exhibition of "Mothers" deal only with mythical mothers? Because I feel motherhood isn't limited to the physical production of babies - there are creative mental and spiritual dimensions of mothering that are yet nearly totally unexplored'. ${ }^{55}$ If we look again to the writing of Flitterman-Lewis and Barry on this subject, it is striking how clearly Hulme's point of view aligns with their description of a type of feminist art which embraces matrilineal thinking.

This art seeks to reinforce satisfaction in being a woman in a culture that does the opposite... This type of artwork can also be seen to redefine motherhood as the seat of female creativity from which spring female deities, witchcraft, and matriarchal cultural heritage. Operating on the assumption that our society isolates women and inspires competition, this kind of art seeks to encourage the mutual glorification and bonding of women. ${ }^{56}$

Their critique of this type of art echoes that found in Barrie's writings for Antic, both arguments declaring that any work which situates the material female body as a unique site of physical and mythic experience offers no challenge to the "fixed and rigid category of "femininity". 57 Many of the artworks and poems included here are clearly the products of personal exploration into the emotional experience of motherhood. Often a multi-generational aspect is highlighted, whether in artworks

\footnotetext{
${ }^{54}$ Evans, "Appendix: The Women's Gallery, December 1979 - February 1984", p.249.

55 The Women's Gallery, Wellington, Mothers, 1981, p.9.

${ }^{56}$ Barry and Flitterman-Lewis, "Textual Strategies: The Politics of Art-Making", p.89.

57 Ibid., p.91.
} 
with titles such as Mothers and grandmothers by Claudia Pond Eyley (1981, collage) or in the text of the catalogue itself. Linda James for example, writes of her contributions to the exhibition: "Mothers" is about myself and my mother. The continuing and complex link from mother to mother, and everything it means to be part of this chain'. ${ }^{58}$ These links, chains and references to previous generations accumulate throughout the reading and viewing experience to convey a sense of the historical reach of motherhood. There is a cumulative recognition and strengthening of the presence of the many mothers who have come before; it appears to be making visible a matrilineal history. Whilst it is possible therefore to dismiss this exhibition according to the terms spelled out by Barrie, closer inspection of individual artworks again proves that such a conclusion is unjustified.

Chosen for reproduction on the catalogue's cover page, Robyn Kahukiwa's 1980 painting Hinetitama [figs. 7 and 8], can be read as a reclamation and celebration of a specifically Māori matrilineal history. However, the cultural complexity of the terrain explored by Kahukiwa places it within a more complex interrogation of the formation of woman within myth and contemporary representation.

Though it was displayed within the Mothers exhibitions, an awareness of the original context of its production serves to enrich our understanding of the work. Kahukiwa originally conceived of the idea for a series of paintings which 'redefine eight ancient myths of the Māori in visual terms'. ${ }^{59}$ The series acted as a redefinition in ideological terms as well as visual, due to Kahukiwa's placement of Māori women firmly in the centre of her retelling of cultural mythology. Taking as her starting point traditional Māori creation myths, she reimagined and re-presented them with women at their centre rather than at the periphery:

In the paintings which make up Wahine Toa (best translated as "women of strength"), I have chosen to portray eight important female elements in the earliest myths, women who have starring roles in the myth dramas in which they play out their scenes. ${ }^{60}$

\footnotetext{
${ }^{58}$ The Women's Gallery, Mothers, p.16.

${ }^{59}$ Robyn Kahukiwa and Patricia Grace, Wahine Toa: Women of Maori Myth, Auckland: Viking Pacific, 1984, p.10.

60 Ibid., p.10.
} 
Whilst this painting clearly references motherhood, it is the specificity of Māori mythology which lies at the work's heart. Hinetitama's creation myth describes her as the 'mother of mankind ... the first true human, being a fusion of the godly and earthly elements and born of woman'. ${ }^{61}$ As the first true human she can clearly be considered the first mother, the root at the beginning of the tree of human history. Kahukiwa has depicted the figure of Hinetitama centrally and frontally within a flat picture plane. She engages the viewer with a direct gaze, laying claim to her space within the heavily patterned square composition of the painting. Horizontally bisected by an illustrative depiction of green rolling hills, the background against which she stands is a fusion of symbolism and figurative representation. The sky, darkening upward from blue to star-flecked black, is broken into bands contained within concentric yellow circles, emanating from a central point above the head of Hinetitama. Kahukiwa refers to this graphic pattern as 'a spiral which represents the ten overworlds'. ${ }^{62}$ The lower half of the composition is also filled with graphic symbolism: linear bands of colour gradually darken from yellow through burnished autumnal shades of orange and brown, descending towards a deep dark brown verging on black at the bottom of the pictorial frame. According to Kahukiwa these darkening bands of colour are representative of 'the ten underworlds... beginning with the grass and trees and going through various layers into Meto, the extinct' ${ }^{63}$

Kahukiwas's symbolic depiction draws not only on Māori mythology, but also upon traditional Māori visual language. 'Much of the distinctive character of Maori carving is a result of the characteristic surface patterns used on the bodies of figures, on smaller objects and on architectural surfaces. In basic form, these surface patterns are either spiral or linear' ${ }^{64}$ This distinctive character is evident in Hinetitama, most obviously in the depiction of the figure of Tane which overlays that of Hinetitama. In addition, the use of a relatively flattened picture plane, along with the graphic patterning utilised to depict symbolic elements, creates a background which also bears an aesthetic affinity to traditional Māori carving. The hills, however, are depicted quite differently. In the narrow central horizontal band occupied by a mimetic rather

\footnotetext{
61 Ibid., p.70.

62 The Women's Gallery, Mothers, p.8.

63 Ibid., p.8.

${ }^{64}$ Roger Neich, "Wood Carving" in D. C. Starzecka (ed.), Maori Art and Culture, Auckland: David Bateman Ltd., 1996, p.89.
} 
than symbolic representation of the land, we see an aesthetic more in line with that of the painterly tradition of modernist landscape painting in New Zealand. Whilst the undulating hills are depicted in a simple manner, line and tonal variation are utilised to create depth and three-dimensionality. Here, paint has been used in a way that serves the purpose of illusionism rather than the formation of pattern. There is an elision evident within the pictorial space, between traditional Māori visual symbols and a western tradition of figurative realism.

This intentional integration of artistic traditions is also displayed in Kahukiwa's portrayal of Hinetitama herself. Anne Kirker writes that in Hinetitama, Kahukiwa has managed to 'successfully fuse both the Maori and Pakeha elements in a unified whole' ${ }^{65}$ This is perhaps nowhere so clearly displayed as in the simultaneous depiction of Hinetitama as a human figure, and a symbolic representation of mythology. Her upper body, face and hair are painted in a representational manner, the oils applied with care and blended to erase the appearance of brushstrokes. Her features are set strikingly within the smooth tonal graduations of her face, the enlarged eyes and mouth defined in a heavy linear manner. Whilst painted in a realistic manner, there is a stylised element to the simplification of the facial forms which we see frequently throughout depictions of women in the paintings of the selftaught Kahukiwa. Though present, this stylised element is subtle within the face. In the depiction of Hinetitama's body, however, the realistic human element has been subsumed by a stylised iconographic depiction of her mythology. This iconography is explained by Kahukiwa in Wahine Toa as follows:

The black, stylised figure which forms the bones of Hine-titama's arms, symbolised Tane, who is both her own father and the father of her children. The foetus represents mankind, the children of Hinetitama and Tane, and the lizard is a disguise Maui adopted when he tried to conquer death. ${ }^{6}$

The focus here is clearly upon the importance of whakapapa, the foetus representing all of Māori humankind, who can ultimately trace their genealogy back to Hinetitama and Tane. In many ways then, this painting is a pictorial depiction not only of Māori

\footnotetext{
${ }^{65}$ Anne Kirker, New Zealand Women Artists: A Survey of 150 Years, p.125.

${ }^{66}$ Kahukiwa and Grace, Wahine Toa: Women of Maori Myth, p.71.
} 
mythology, but also of the contemporary Māori experience. Tied strongly to her origins through a deep understanding of whakapapa, whilst also inescapably connected to European influence, Kahukiwa has fused these elements into something which is at once ancient and contemporary, both vibrant and strong.

Motherhood is indeed a dominant theme within the mythology of Hinetitama, she is present as both the origin of human life, and the maternal guardian of those children in death: 'I will welcome our children when their earthly life is ended. I will go in order to prepare an after life for them, where once again I can be a loving mother' ${ }^{67}$ This, however, does not necessarily lead to the conclusion that Kahukiwa is presenting a non-critical glorification of a matrilineal past. What such an assertion does not take into consideration is the specific cultural nature of the work. Kahukiwa is promoting a dismantling of the male/female binary here by elevating the matriarchal role of Hinetitama as equal to that of the male Tane. In 'pre-Christian Maori society... the high incidence of female representation in art, and the related narrative in chant poems and genealogy, indicate a complementary, not inferior, relationship to men'. ${ }^{68}$ This idea that there existed a complementarity of the sexes in pre-Christian Māori society is of vital importance when considering the efficacy of Barrie's critique in specific relation to a work such as Hinetitama, which is primarily informed by a non-Western worldview. As Hinemoa Awatere writes in "Toi Wāhine: The Worlds of Māori Women":

Another factor which has impacted on us as Māori women is the impact of a patriarchal religion, which in our case is Christianity. For instance almost all of the priests are men. ... Because of this, Māori women spiritual leaders have been relegated to the outer, 'abnormal' sphere of spirituality. ${ }^{69}$

The imposition of a patriarchal structure upon a colonised society makes it very difficult to then view that society through any lens other than that of the coloniser. It was not Māori culture which wrote Māori women out of their own mythology, rather it was the patriarchal voice of European influence. If we accept that premise, then we

\footnotetext{
${ }^{67}$ Ibid., p.34.

${ }^{68}$ Ngahuia Te Awekotuku, "Maori: People and Culture" in Starzecka (ed.) Maori Art and Culture, p.33.

${ }^{69}$ Hinemoa Awatere, "Mauri Oho, Mauri Ora", in Kathie Irwin and Irihapete Ramsden (eds.), Toi

Wahine: The Worlds of Maori Women, Auckland: Penguin Books Ltd, 1995, p.35.
} 
can gain an understanding of Hinetitama that is more subtly nuanced than reading it as a simple glorification of the mother or of woman. The positioning of the figure of Tane, for example, is not that of a being separate or inferior to that of Hinetitama; rather, he forms an integral part of her symbolic body - his arms 'form the bones of Hine-titama's arms' ${ }^{70}$ The umbilical cord nurturing the future of Māori humankind in the form of the foetus, is connected to the centre of both Tane and Hinetitama.

This early work visualised the epic Māori cosmological and genealogical narratives. In particular the series focused on the roles, relationships and mana of the main female characters. This act of reaffirming the whakapapa and mātauranga of these narratives highlighted the blood connections that flow from these wāhine toa down through the generations to the women of today. Kahukiwa's agenda for doing so is clear: '... as Māori women we need to reaffirm our place in Aotearoa and be accorded the same status that once was ours in traditional culture. ${ }^{71}$

The status that Kahukiwa is affording her Wahine Toa here is one sought through reclamation rather than redefinition. Hinetitama, along with the seven other women that she portrays, occupies a position defined by a complementary - rather than inferior - social relationship to man. Her insistence that this position of equality 'once was ours in traditional culture' 72 implies that it is the Christian, patriarchal world-view of the European colonist that has altered woman's position within New Zealand society. In Hinetitama though, Kahukiwa has refrained from producing a manifesto for a return to pre-Christian Māori society, rather she has unified Māori and European visual cultures in a re-imagined sympathetic co-existence. In the pursuit of this unification, Kahukiwa has also re-imagined the position of women by placing them at the centre of her mythological visual storytelling. Man, however, is not cast as other. Tane does not exist at the periphery of Hinetitama's narrative, rather he occupies a position at the core of both the visual and symbolic telling of her story. Their relation to each other is both symbiotic and cyclical.

\footnotetext{
${ }^{70}$ Kahukiwa and Grace, Wahine Toa: Women of Maori Myth, p.71.

${ }^{71}$ Hinemoa Hilliard, "Mana Maori: The Art of Robyn Kahukiwa", in Robyn Kahukiwa (ed.), The Art of Robyn Kahukiwa, Auckland: Reed Books, 2005, p.15.

72 Kahukiwa, quoted in ibid., p.15
} 
Kahukiwa's exploration of the way in which the relationship between man and woman is structured points to a critical awareness in her work. Barrie may assert that:

When women artists resurrect ancient goddesses and matriarchal symbols and position them in the place of patriarchal symbols, they leave the underlying structures of meaning unchanged. They merely annex an irrelevant past to present structures of meaning. ${ }^{73}$

Kahukiwa's perception of the past in this context is anything but irrelevant. Her exploration of the gendered nature of representation in both Māori mythology and European culture challenges the assumptions made by Barrie. Despite its location within an exhibition entitled Mothers, it becomes evident upon close inspection that Hinetitama fails to align with Barrie's categorisation. Kahukiwa has produced in this painting a visual expression of her engagement with 'the struggle to transform the cultural codes which produce women's repression' ${ }^{74}$

A work such as Hinetitama demonstrates the danger of generalisation when it comes to discussion of a project defined by its broad-ranging remit. Whilst Barrie initially seems to make a compelling argument for the lack of critical feminist art production within New Zealand at the time of the Women's Gallery, it is an argument not borne out by a close examination of individual artworks. Batten's Roses may by heavily indebted to early feminist art concerned more with exploration that a critical interrogation, but as has been demonstrated, this was not the only type of art exhibited within the Women's Gallery.

Close readings of both Ffrench's Diary, and Kahukiwa's Hinetitama allow us to refute Barrie's wholesale dismissal of feminist art in New Zealand in the 1970s and 80s. Rather than viewing her criticisms as based solely in empirical evidence, it becomes clear that her desire to promote a specific theoretical school of thought necessitates the rejection of that which has come before. Arlene Raven outlines the simplified narrative of feminist art history when she writes:

\footnotetext{
73 Lita Barrie, "Further Toward a Deconstruction of Phallic Univocality: Deferrals", Antic 2, 1987, p.32.

${ }^{74}$ Barrie, "Remissions: Toward a Deconstruction of Phallic Univocality", p.98.
} 
"Essentialists" are assumed to have made all the non-fashionable art of the body during the 1970s and to believe that femininity is innate... "Post-modern deconstructionists and appropriationists" are presumed to believe that femininity is a social construction and that nothing is innate. ${ }^{75}$

This oversimplification of the complex evolution of early feminist art - which has come to be defined as essentialist - into a critically aware poststructuralism is reflected in Barrie's project. Diary and Hinetitama exist as evidence that at the time of writing there was in fact evidence of 'CRITICAL feminist art, which challenges cultural codes which create women's repression'. ${ }^{76}$ That these works were displayed in the Women's Gallery, alongside work such as Roses points to the transitional nature of this period in the evolution of feminist art making. There was no clear dividing line demarcating the advent of critical feminist art in New Zealand. Rather, a site like the Women's Gallery existed as a space in which each point on this spectrum could be explored simultaneously.

Whilst it is possible to accede to the argument that the Women's Gallery does not reverberate throughout New Zealand's recent art history, it does not follow that we must conclude there is no reason to re-examine the project. The very fact that the creative work of women who chose to exhibit at the gallery continues to be displayed, re-evaluated and debated - Ffrench's oeuvre being but one example - promotes an alternative response. That a work such as Diary, so ideologically different to Batten's Roses series, was displayed in the same gallery should lead us to question how we can possibly propose a discussion of the Women's Gallery without collapsing all artistic and political difference. Rather than relegating the gallery to the realms of the qualitatively and ideologically unsound, perhaps it is better served by attempting to formulate a framework within which the Women's Gallery can be discussed, without resorting to reductivism. An attempt to forge a viable example of this type of discussion is the aim of the following chapter.

\footnotetext{
${ }^{75}$ Arlene Raven, "The Last Essay on Feminist Criticism," in Raven, Langer and Frueh (eds.), Feminist Art Criticism: An Anthology, p.227.

${ }^{76}$ Barrie, "Remissions: Toward a Deconstruction of Phallic Univocality", p.99.
} 


\section{Chapter three}

\section{Liminality and Difference}

In this chapter I use the work of Victor Turner, an anthropologist whose writing contributed significantly to the burgeoning field of Performance Studies, to situate the Women's Gallery as a space which existed simultaneously within and at a remove from the wider artistic and sociopolitical landscape.

Turner explores the concept of liminality, a process that is key to his theorisation of ritual which he adapts in relation to performance. There, the liminal is shorthand for a type of performance - often communal - which aims to enact a transformative experience, whether for performers, audience, or most frequently for both - the blurring of participatory lines often forming the structural heart of such performances. Liminal performance is associated with work that occupies a 'certain marginalized space which holds a possibility of potential forms, structures, conjectures and desires'. ${ }^{1}$ I argue that this description aligns with a view of the Women's Gallery itself. A more comprehensive understanding of Turner's investigation into liminality will elucidate a reading of the Women's Gallery as a liminal space.

Turner first addressed the liminal in 1967, in an anthropological study of the rituals of the Nbedu tribe in Zambia, ${ }^{2}$ this work acknowledged the foundations laid by Arnold van Gennep in his discussion of rites of passage. Van Gennep identifies ritual transformation as a tripartite process, involving 'separation, margin (or limen), and aggregation'. ${ }^{3}$ Primarily concerned with the participant's role or status within the tribal social structure, this process sees an individual or group separated from society in order for them to be reincorporated having transformed from one role to another. A typical example identified by Turner of such transformative rituals is the progression from boyhood to manhood. The threshold between one state and another is not one that is merely stepped over, but one that expands, folding outwards in order to be

\footnotetext{
${ }^{1}$ Susan Broadhurst, Liminal Acts: A Critical Overview of Contemporary Performance and Theory, London: Cassell, 1999, p.12.

${ }^{2}$ Victor Turner, The Forest of Symbols: Aspects of Nbemdu Ritual, Ithaca and London: Cornell University Press, 1967.

${ }^{3}$ Victor Turner, "Betwixt and Between: The Liminal Period in Rites de Passage", in Turner (ed.), The Forest of Symbols: Aspects of Ndembu Ritual, p.94.
} 
occupied both symbolically and physically. Within this temporary space, the participant becomes 'structurally, if not physically, "invisible"... A society's secular definitions do not allow for the existence of a not-boy-not-man, which is what a novice in a male puberty rite is (if he can be said to be anything) ${ }^{4}{ }^{4}$

It is not only the participant who becomes indefinable in the liminal phase; physical and calendrical space is also made strange.

Excavating and reapplying this rich resonant concept, Turner understood the limen to constitute a universally potent temporality, a "realm of pure possibility", a temporary breach of structure whereby the familiar may be stripped of certitude and the normative unhinged, an interlude wherein conventional social, economic, and political life may be transcended. ${ }^{5}$

Though existing within society, the limen occupies a marginal, amorphous position. The site of liminal transition is not defined through physical location alone, it is also demarcated by the finite passage of time - a threshold by definition must be passed over, and in doing so ceases to exist. This threshold stage serves a transitional purpose. Turner notes that for tribes such as the Ndembu it allowed necessary change to occur in a specific and ritualised manner. In order to free the concept of liminality from this socially scripted role, Turner developed the related concept of the liminoid. In doing so he hoped to 'describe symbolic actions or leisure activities in modern or postmodern societies that serve a function similar to rituals in pre-modern or traditional societies'. ${ }^{6}$ Whilst this attempt to shape a theory which is more readily applicable to the types of recreational and creative activities which occur in postindustrial society seems constructive, it is interesting to note that the liminal/liminoid distinction is one area of Turner's scholarship which has largely been dismissed by many who have built upon his work. ${ }^{7}$ In fact a gradual elision has occurred between

\footnotetext{
${ }^{4}$ Ibid., p.94.

${ }^{5}$ Graham St John, "Victor Turner and Contemporary Cultural Performance: An Introduction", in Graham St John (ed.), Victor Turner and Contemporary Cultural Performance, New York: Berghahn Books, 2008, p.5.

${ }^{6}$ Richard Schechner, Performance Studies: An Introduction, New York and London: Routledge, 2006, p.67.

${ }^{7}$ See, for example, the work of Jon McKenzie, Perform or Else: From Discipline to Performance (2001).
} 
these terms, the secular and unrestricted elements of the liminoid being absorbed into contemporary usage of the term liminal.

Richard Schechner's adaptation of Turner's theory of liminality, is in many ways an attempt to amalgamate the ritual process with the anarchic sense of openness implicated by the secular liminoid. Turner's distinction between the terms is of use here:

Liminal phenomena tend to be ultimately eufunctional even when seemingly "inversive" for the working of the social structure, ways of making it work without too much friction. Liminoid phenomena, on the other hand, are often parts of social critiques or even revolutionary manifestos - books, plays, paintings, films, etc., exposing the injustices, inefficiencies, and immoralities of the mainstream economic and political structures and organizations. ${ }^{8}$

It is perhaps this socially provocative element more than any other that has been worked into the fabric of liminality in relation to performance. The idea that societal norms are suspended is of course central to the pre-modern rituals discussed by Turner, but those norms are suspended only in order to be reiterated more forcefully upon aggregation. The participant is detached from society in order to realise the necessity of such social structures, and to learn how to perform a new role (for example that of man, rather than a boy) within those structures. This eufunctional element is notably absent in much contemporary usage of the term. As society becomes increasingly secular and individualised, the concept of liminality becomes separated from its pre-agrarian roots, and instead becomes more concerned with an identification with a marginalised position, and a suspension of conventional behaviour:

That somewhat circumscribed, restorative eufunctionality that Turner ascribes to the liminal yields, in the passage to liminoidity, an unqualified capacity to facilitate not only an enlightening critique, but, even more, the potential to effect social change, and to do so for the better. ${ }^{9}$ [my italics]

\footnotetext{
${ }^{8}$ Victor Turner, "Liminal to Liminoid, in Play, Flow, and Ritual: An Essay in Comparative Symbology", in Victor Turner, From Ritual to Theatre: The Human Seriousness of Play, New York: Performing Arts Journal Publications, 1982, p.54.

${ }^{9}$ Ian Maxwell, "The Ritualization of Performance (Studies)", in St John (ed.), Victor Turner and Contemporary Cultural Performance, p.61.
} 
It is the application of this understanding of liminal process, enriched through its inclusion of the liminoid, which may help shed critical light upon the short-lived project enacted by the Women's Gallery. In simplistic terms it is possible to argue that a gallery which mounted its opening show in January of 1980, and was closed by unanimous decision four years later ${ }^{10}$ could be dismissed as a failed project. However, the mapping of the Women's Gallery as a liminal space - one which is inherently finite - allows a reframing of the perception equating longevity and value. Rather, the Women's Gallery can best be understood as performing a liminal function within the history of feminist art in New Zealand.

The tripartite model for transformation drawn by van Gennep and Turner has clear parallels with the structural operation of the Women's Gallery. Whilst it is the second marginal period of liminality which is of immediate concern, both the initial period of separation and the final aggregational phase serve as useful tools in relation to this modelling. As has been discussed in detail in chapter two, the separation of the Women's Gallery from the dominant social fabric was a defining feature of the project. Although couched in the language of anthropology, Turner's description of this period of separation is relevant here. He states that 'separation clearly demarcates sacred space and time from profane or secular space and time'. ${ }^{11}$ The opposing qualifiers of sacred and profane can in this instance be jettisoned without impact upon the principal element - that such a space necessitates clear demarcation. In the case of the Women's Gallery this demarcation is both physical and ideological. The space occupied by the gallery, be it the Harris Street or Willis Street location, was one definitively marked by the architectural tangibility of its boundaries. As Gaston Bachelard proclaims, 'outside and inside form a dialectic division... it has the sharpness of the dialectics of yes and no' ${ }^{12}$ Entering the Women's Gallery, whether as artist or viewer, is to enter an interior physical space which exists at a remove from its surrounding environment. It is enclosed and defined by the walls of its exterior, whilst simultaneously being defined in relation to the outside in ideological terms. Adherence to the gendered isolation signified by the Women's Gallery enforces the

\footnotetext{
${ }^{10}$ Evans, "Appendix: The Women's Gallery, December 1979 - February 1984", p.251.

${ }^{11}$ Turner, "Liminal to Liminoid, in Play, Flow, and Ritual: An Essay in Comparative Symbology", p.24.

${ }^{12}$ Gaston Bachelard, The Poetics of Space, Massachusetts: Beacon Press Books, 1969, p.211.
} 
idea that 'separation comprises symbolic behaviour signifying the detachment of the individual or group either from an earlier fixed point in the social structure or a set of cultural conditions'. ${ }^{13}$ Women, as an unfixed and changeable group occupying the gallery space, are detached from the particular set of gendered cultural conditions to which the project seeks to propose an alternative.

That the creation of the Women's Gallery was based upon an act of at least partial separation is clear. However, from the outset this was never intended to be permanent or impermeable. As the gallery's founders stated: 'this separatism is not an end in itself, it is simply part of a process'. ${ }^{14}$ The gradual unfolding of this process occurred through the four year lifespan of the Women's Gallery. A transformative process can never be expected to continue indefinitely; transformation requires conclusion.

Marian Evans herself acknowledged this as a possibility when she wrote retrospectively of the gallery's closure that 'perhaps a transitional need had been met and times had changed. The needs of younger women were different; they had more resources and options than women had had in 1975 or 1980'. ${ }^{15}$ That closure ultimately resulted in the aggregation of the Women's Gallery into the wider society from which it had been temporarily separated. The crucial implication being that the transformative element which existed within the Women's Gallery remained as a trace in the reimagined artistic framework in which women no longer required a separate space. Those increased 'resources and options' which were identified by Evans as a contributing factor to the gallery's closure can also be viewed as part of a legacy facilitated by the creation of artworks and experiences within the context of the Women's Gallery.

Whilst it is evident that the creation and subsequent dissolution of the gallery allow for a reading of its short lifespan along lines drawn by Turner, it is the crucial central element which invites more extensive analysis. An artistic endeavour which enacted gendered separation in order to create change and opportunity for women cannot be rendered transformative, or indeed liminal, by virtue of this separation alone. However, this act of separation, which in effect insulated the inside against the

\footnotetext{
13 Turner, "Betwixt and Between: The Liminal Period in Rites de Passage", p.94.

14 The Women's Gallery, "Why a Women's Gallery?", unpaginated.

${ }^{15}$ Evans, "Appendix: The Women's Gallery, December 1979 - February 1984", p.251.
} 
outside, can be seen to echo the structure of liminal processes in which 'former rights and obligations are suspended, the social order may seem to have been turned upside down'. ${ }^{16}$ This destabilisation of the existing social order is central to the foundation upon which the Women's Gallery was based. The prioritisation of the experiences of women within this specifically created space was a direct response to the assertion that 'men have defined the human experience through their art and women have often felt excluded'. ${ }^{17}$ By forging an arena in which women's attempts to define their experience of the human condition were seen not only as viable, but valuable, the Women's Gallery allows for a suspension of these gendered social obligations. That this disruption to the social order is one that occurs within an isolated and clearly defined space is further indication of the liminal aspect of the space.

Liminality can perhaps be described as a fructile chaos, a fertile nothingness, a storehouse of possibilities, not by any means a random assemblage but a striving after new forms and structure, a gestation process, a fetation of modes appropriate to and anticipating postliminal existence. ${ }^{18}$

It is this sense of experimental creativity which resonates particularly well in reference to the Women's Gallery. The interruption of dominant patriarchal artistic discourse which occurred within the gallery was not dictated by a preconceived or singular sense of conclusion. There was no coherent unified voice which claimed a right to usurp the creative authority of the dominant male nationalist painter. Rather, the intention was to create a space in which multiple artistic voices could coexist without recourse to oppositional difference. This space allowed those features which have come to define liminal creativity to occupy a position of centrality 'heterogeneity, the experimental and the marginalized'. ${ }^{19}$ In many ways the consistent focus on group rather than solo shows is key to this foregrounding of multiplicity as a platform for experimentation, the spectrum of issues engaged with only enhancing this sense of 'striving after new forms and structure.' By exploring issues as diverse as the environment, nuclear disarmament and self-image, the group

\footnotetext{
${ }^{16}$ Turner, "Liminal to Liminoid, in Play, Flow, and Ritual: An Essay in Comparative Symbology", p.27.

17 The Women's Gallery, "Why a Women's Gallery?", unpaginated

${ }^{18}$ Victor Turner, "Are there universals of performance in myth, ritual, and drama?", in Richard

Schechner and Willa Appel (eds.), By means of performance: Intercultural studies of theatre and ritual, Cambridge: Cambridge University Press, 1990, p.12.

${ }^{19}$ Broadhurst, Liminal Acts: A Critical Overview of Contemporary Performance and Theory, p.12.
} 
shows staged by the Women's Gallery indicated that the role of women needed to be drastically reimagined in all strata of social engagement, not just those specifically relating to the politics of gender, sexuality and identity.

By identifying the Women's Gallery as a liminal space, we can reframe its temporality as an inherent feature of its status as threshold. In what specific ways though can the gallery be seen to have acted as a threshold, either for individual artists, or in wider terms? Examining the way in which a number of female artists have written of their involvement with the Women's Gallery, it is interesting to note the common thread which seems to emerge, serving to link their diverse experiences:

Bridie Lonie: It was a space where I felt able to make art about things that bothered me: to use it as a place for art to fulfil its cleansing, developing function: the achievement of new understanding and growth, marked by the rite de passage. This function is at odds with any intention to make a living from art by making saleable objects. ${ }^{20}$

Barbara McDonald: I believe the Women's Gallery was tremendously influential in changing the public attitude to women, art, roles, everything. Especially the Mothers exhibition in touring N.Z. and having organised activities associated with the exhibition organised by local women. That's revolutionary. ${ }^{21}$

Sharon Alston: We certainly made some changes in people's thinking, and positively influenced other galleries in terms of how you can make art works more accessible, friendlier, less intimidating, more fun, more surprising, more experimental, more risky. We forced people, women, to look at women's art, to produce it, and to feel good about it. ${ }^{22}$

What becomes evident as we read these recollections is the emphasis each woman places upon the notion of change, and the role played by the gallery in the implementation of that change. Whether discussing personal, creative or societal development, the impact of each woman's encounter with the Women's Gallery was one in which a transformative or developmental experience was highlighted. Speaking to personal experience is of course a subjective and private process, but

\footnotetext{
${ }^{20}$ Bridie Lonie, quoted in Evans, Lonie, and Lloyd, A Women's Picture Book: 25 Women Artists of Aotearoa (New Zealand), pp.168-9.

${ }^{21}$ Barbara McDonald, quoted in ibid., p.146.

22 Sharon Alston, quoted in ibid., p.132.
} 
when we consider that each of these women foreground the transformative nature of their experience within the gallery, it becomes increasingly viable to argue that the gallery provided women with a unique space which in which they could enact the necessary experimentation which would allow them to experience - to some degree at least - positive change. The change highlighted by each of the women is articulated in various ways, for some the primary benefit seems to be a recognition of personal development and an increased confidence in her abilities. Juliet Batten, for instance, writes after the closure of the Women's Gallery that 'I'm feeling so good about my art. I've given up my main university teaching jobs in order to be a full-time artist and that feels great'. ${ }^{23}$ Allie Eagle [Alison Mitchell], in a similar vein, discusses the way in which the lessons learned during her time at the gallery, and with the other women involved carried with her. 'The early women's art movement ... and later the Women's Gallery in Wellington are still very special to me. ... Marian's encouragement (and Juliet Batten's) to have the freedom to make statements about myself ourselves/our ideas/ambitions - will always be a very valuable keystone in my life as an artist'. ${ }^{24}$ The emphasis in both of these instances is not on the Women's Gallery as a closed and final creative destination, but rather as a free and experimental space - "a fructile chaos" 25 - through which women could pass, with the possibility of remaining marked by the experience.

Although an examination of this type of personal response is valuable to the extent that it appears to reinforce the assertion that the Women's Gallery existed as a transformative or liminal space, it can be criticised as being largely anecdotal. By examining in greater detail the types of relationships forged between individual artists and the Women's Gallery, a more comprehensive outline of the gallery as a space which allowed for the 'striving after new forms' ${ }^{26}$ can be drawn. As has been demonstrated, one particularly distinctive aspect of liminal spaces and processes is their existence at a partial remove from wider society. Whilst such a space clearly exists within a wider social context, it is simultaneously isolated from it by virtue of boundaries which are both physical and imagined. In the case of the Women's

\footnotetext{
${ }^{23}$ Ibid., p.56.

${ }^{24}$ Ibid., p.85.

${ }^{25}$ Turner, "Are there universals of performance in myth, ritual, and drama?" p.12.

${ }^{26}$ Ibid., p.21.
} 
Gallery though, these boundaries did not mark a binary division between inside and outside. The gap between allowed traverse, there existed no hermetic seal to prevent slippage between inside and out. Artists who chose to display work there were not bound by any obligations to exclusivity, nor were they expected to make a commitment to exhibit work at more than one exhibition. The scope did exist however, for women to form a close and enduring connection to the Women's Gallery project. By examining the work of two artists, each of whom pursued fundamentally different levels of engagement with the gallery, we can gain a more accurate sense of the way in which this particular developmental and exhibiting space functioned.

Juliet Batten, whose work has been touched upon in previous chapters, is an artist whose involvement with the Women's Gallery was deep and relatively continuous. Her work was exhibited in five of the gallery's exhibitions: Opening Show, Diaries, Self Image, Sexxuality and Mothers. In addition to her presence as an exhibiting artist within the gallery, she was also a vocal advocate for the women's art movement in New Zealand, speaking and writing about its development whilst striving to encourage wider participation. Due to her visibility in the published record during this period it is possible to track the evolution of her creative development. By viewing this development through the specific lens of her relationship with the Women's Gallery, a picture can be built which demonstrates the liminal power of the gallery project as a transformative space within her career. This transformation was in fact made overt by Batten herself within her section of $A$ Women's Picture Book. As we have already noted, her discussion of the gallery throughout this interview is one in which its transformative nature was placed squarely at the centre of the reader's understanding. From the Women's Gallery acting as a welcoming oasis within an art environment that was 'like a desert for women to cross', ${ }^{27}$ to her assertion that after its closure her self-belief allowed her to give up 'university teaching jobs in order to be a full-time artist' ${ }^{28}$ the sense of personal progression is palpable.

\footnotetext{
27 Juliet Batten, quoted in Evans, Lonie, and Lloyd, A Women's Picture Book: 25 Women Artists of Aotearoa (New Zealand), p.52.

${ }^{28}$ Ibid., p.56.
} 
Her painted work created in the earliest days of the galley, such as the Roses series exhibited in the Opening Show and discussed in chapter two, demonstrated a quality of execution, level of finish, and overall aesthetic appearance not necessarily in line with conventional qualitative standards. When comparing Roses to the 1983 work Banner for the Bleeding [fig. 9], a marked sense of progression is revealed, both stylistically and thematically. Where her earlier series was executed in watercolours alone, this work utilises mixed media, involving the application of acrylic paint alongside the use of fabric and stitching. Rather than applying these stereotypically defined craft materials in a traditional manner, Batten exhibits a more considered and integrated exploration of the stitching process. She layers fabrics - including that of the canvas - and manipulates stitched threads in a manner which elevates their purpose from the utility of stitching, to that of a distinctive creative material used to formulate pattern and line.

In contrast to the figurative representation of subject matter in the Roses series, these banners appear abstract in their handling of imagery. There are no mimetic reproductions of identifiable objects here, no illusionistic use of perspective to achieve depth of field. Rather, the picture plane is one that has been manually altered by the three-dimensionality of stitched thread and overlaid fabric, resulting in a shallow non-perspectival depth of field. Batten has built the ground of this picture depth upon a base layer of acrylic paint applied in localised areas across the canvas. The texture of this application has created a blotched, running, ink-dyed effect. Echoing the banner's title, the pigment bleeds through the capillary-like fissures in the canvas's surface, spreading outward from the areas of densest application. Upon this surface, Batten has layered and stitched fabric to create shapes both geometric and organic. This sense of depth, minimal though it may be, is perhaps most evident in the square of overlaid fabric placed on the long vertical shape stretching down the left side of the canvas, as well as the misshapen oval to its right. Each of these intrusions into the structural integrity of the canvas has been achieved through multiple layers of material and process. The geometric square shape is most immediately evident, its angularity and near uniformity jarring with the amorphous softness created by the painted areas, and the majority of the fabric forms. When examined closely, the square appears to be made up of vertical bands of fabric, their zigzag edges pointing to the use of pinking shears. What initially appeared uniform becomes imperfect 
through prolonged attention, the bands of dark and light fabric are warped and stretched at their edges from the variable act of hand stitching. Like the distinctive zigzag edging, these small pulls in the fabric at the point of the thread's penetration refer the viewer indexically back to the signified human hand, the hand which chose and operated the pinking shears, the hand which threaded the needle in order to stitch fabric onto canvas.

This handmade element is more obviously evident in the rough oval shape which occupies the right hand side of the canvas, in line horizontally with the square. Where the geometry of the square presents an initial sense of uniformity - albeit one that is soon disrupted by close observation - this asymmetric curvilinear shape is instantly recognisable as having been created by hand. Reminiscent of a spore or cell under the enlarging lens of a microscope, there is something indefinably biological about the combination of stitched markings, fabric and paint which make up this self-contained image. Its boundaries are encircled by two distinctive hand stitched borders, one heavy and rough applied in a dark thick thread, and the other more delicate and light, stitched more closely and accurately. Inside this border is a dark mass, presumably made of fabric, upon which a central white core has been created with paint. This paint appears to have been daubed inconsistently onto the fabric surface, and as a result it varies in thickness. Where the paint has been directly applied it remains thick and opaque, but in the areas between these spots it has been stretched and dragged across the fabric, thinning to near transparency. Into this painted central area, a band of vertically aligned stitches of varying heights have been sewn, spanning the width of this section. The multitude of textures, lines, shapes and patterns created by this extensive layering process are indicative of the experimental possibilities of stitching as a medium.

The conventional connotations of stitching are limited: the utilitarian process of making or mending clothing, or the type of educational sewing demonstrated through the needlework sampler. Each of these disciplines is inherently connected to constructed ideals of female domesticity, and rather than being outlets for creative expression they could be viewed as relatively predetermined processes. Through her exploration of a medium that is relegated to the gendered sphere of the domestic, Batten attempts to open out its possibilities as a tool for creative expression. 
I damaged cloth and paper in as many ways as I could, and then mended it. It was healing and satisfying. It was also making a political statement about the materials of art. I think of a stitched mark as the equivalent to a painted mark. ... Stitching is about bringing things together, making connections. It feels very life affirming. ${ }^{29}$

This elevation of the stitched mark to the level of the painted mark is indeed a political assertion within this context. The densely layered interplay of paint and stitch as creative marks works in a way that exceeds purely aesthetic considerations. Rather, the equality with which each medium has been treated can be read as a refusal to accept the binary division which qualitatively separates art and craft. In Roses, the thematic allusions drawn by the artist's choice of imagery were those of a personal exploration of femininity, the floral subject matter rendered clichéd by its metaphorical treatment. In contrast, the abstraction and preoccupation with medium conveyed in Banner for the Bleeding disallows such a simplistic reading. Whilst the shapes created may be suggestive of some form of organic life, the lack of a clearly defined representational image emphasises instead the process of the work's creation. The mental unpicking of these processes enacted by the viewer is an attempt to understand the way in which the work was materially created. The act of creation, politicised as it has been, becomes the work's subject matter.

Considering these two quite different works by Batten, both of which were exhibited within the Women's Gallery, it is possible to trace a transformative development in her visual work over this time. Whilst the Roses series could perhaps be fairly criticised as displaying an amateur level of finish and execution, in addition to a simplistic - and some would argue, essentialist - metaphorical usage of imagery, the same charge does not apply to Banner for the Bleeding. Batten has said of the work that 'the stitched and painted banners came out of a kind of political anger - about the burning of women, and the battering of women'. ${ }^{30}$ So whilst on one hand these works can be viewed as a continuation of her desire to explore imagery that finds its source in women's experience, the considered use of materials from the spheres of high art

\footnotetext{
${ }^{29}$ Juliet Batten, quoted in ibid., pp.55-6.

30 Juliet Batten, quoted in ibid., p.54.
} 
and domestic craft elevates the work from that of purely personal expression. It exists, in part, as an exploration of the artificially constructed gendered terms of artistic production. Recognition of this increased sophistication in Batten's visual work can viewed through the frame of the liminal space provided by the Women's Gallery. Writing in defence of female centred imagery in Antic, Batten emphasises the transitional nature of this type of work:

The image was a gateway. Even Judy Chicago, who did the vulva to death, has written of it as a passageway - 'through the flower'. In New Zealand, I know of no artist who has continued to work with overt vaginal iconography. And even here, when it has appeared, it has often been associated with the gateway as an image (Menstrual Maze, Lifescape), suggesting that it is an image of process... ${ }^{31}$

This transitional process can be seen echoed in the work of Batten herself - whilst the Roses series may not have displayed 'overt vaginal iconography' there can be little doubt that the unfurling of the tightly closed bud, and eventual blossoming of the open flower can be viewed within the context of this type of imagery. As has already been established, there were very few environments for the display of art which would have exhibited such work so readily. What the Women's Gallery allowed, through its desire 'to support working women artists by providing space for exhibitions', ${ }^{32}$ was the opportunity to display work such as Roses without the application of stringent artistic standards. Through the provision of a space that displayed such work, the Women's Gallery foregrounded the notion of creative exploration, allowing artists such as Batten the opportunity to move through this visual process and develop a more sophisticated creative iteration of their ideas. Women could enter a space that promoted 'experimentation and sharing of knowledge ${ }^{33}$ in order to assist them in 'developing the confidence, skills and training, ${ }^{34}$ required to 'explore new ways of expressing their ideas'. ${ }^{35}$

Tracing the artistic difference apparent between Batten's work displayed in Opening Show, and the work produced after a three year period of involvement with the

\footnotetext{
${ }^{31}$ Batten, "The Edmonds Cookbook and the Ivory Tower", in Antic 2, 1987, p.10.

32 The Women's Gallery, "Pamphlet", unpaginated.

${ }^{33}$ Ibid., unpaginated.

34 Ibid., unpaginated.

35 Ibid., unpaginated.
} 
Women's Gallery, a marked sense of development is clear. The liminal space of the gallery, existing at a remove from the 'universal values of a history of heroic art produced by men which had so systematically excluded women's production from its mainstream', ${ }^{36}$ allowed artists such as Batten a rare opportunity to cross the threshold from 'unskilled as an artist when I began', ${ }^{37}$ to being in a position to pursue artmaking as a full time career.

Perhaps the strongest residual trace of Batten's involvement with the women's art movement was an ideological, rather than aesthetic one. As Anne Kirker argues, her 'particular achievement has been as a teacher and facilitator. Her belief in collaborative art has encouraged many women to make contact with their often unexplored creativity'. ${ }^{38}$ As Batten's own self-confidence grew, so did her belief that collaborative work could facilitate this personal and creative development in other women. She 'initiated a number of collaborative art projects, co-ordinated the cooperative 100 Women project and devised several ritual pieces, all of which drew a number of women into the making of the work' ${ }^{39}$ Of particular interest here is the emphasis which Batten lays on the collaborative process of creation, over and above that of the production of an artwork as an end product. Although exhibiting a collaborative working process similar to that used by Judy Chicago to create Dinner Party, her practice diverges from that of Chicago, as she explained in 1983: 'For Judy Chicago, aesthetic excellence comes first and working relationships operate within that limitation; for me, the work process is most important, and I strive for the highest aesthetic quality possible within that limitation'. ${ }^{40}$ For Batten then, conventional standards of quality in relation to the artwork as end product, are secondary to the benefits that could be derived from the process 'as a means for the disruption of the accepted relations between artist, artwork and audience, and for the active constitution

\footnotetext{
${ }^{36}$ Whitney Chadwick, "Women Artists and the Politics of Representation", in Raven, Langer and Frueh (eds.), Feminist Art Criticism: An Anthology, p.169.

37 Juliet Batten, quoted in Evans, Lonie, and Lloyd, A Women's Picture Book: 25 Women Artists of Aotearoa (New Zealand), p.50.

${ }^{38}$ Kirker, New Zealand Women Artists: A Survey of 150 Years, pp.177-8.

${ }^{39}$ Priscilla Pitts, "Not just a pretty face: Feminine wiles in New Zealand women's art practice", in Christina Barton and Deborah Lawler-Dormer (eds.), alter/image: feminism and Representation in New Zealand art 1973-1993, Wellington: City Gallery Wellington and Auckland City Art Gallery, 1993, p.21.

40 Juliet Batten, quoted in Kirker, New Zealand Women Artists: A Survey of 150 Years, p.178.
} 
of a female audience'. ${ }^{41}$ This commitment to collaboration and process as tools to engage a politically aware female audience seems to exist, for Batten, in an antagonistic relationship with the concept of 'aesthetic excellence'. Perhaps it is for this reason that the impact of her contribution has been viewed as one concerned with her role as facilitator, rather than artist.

It would be remiss to assume that a dismissal of aesthetic quality as the primary aim of certain collaborative projects implies a complete rejection of such notions on the part of either Batten or the Women's Gallery. As we have seen, some of the work exhibited at the Women's Gallery may not have adhered to conventional standards of aesthetic quality. However, as has been demonstrated in previous discussion of the work of Ffrench and Kahukiwa, this was clearly not the case for all work displayed there. Accessibility and support may have been the keystones of the Women's Gallery project, creating a fundamental shift in perceived standards of quality, but even within this environment certain qualitative standards remained. '.. as far as I know only one work was rejected, partly because some members of the collective at the time felt it was oppressive to women, partly because of its technical quality. ${ }^{42}$ That this demonstrates a re-evaluation of the terms of artistic quality rather than a wholesale disregard for the concept is reinforced when we examine the work of another artist who exhibited several times at the Women's Gallery.

Joanna Paul's working relationship with the Women's Gallery differed from the relatively close connection between artist and gallery exhibited by Batten. Paul recalls her contribution to exhibitions at the Women's Gallery as follows:

I took part without making a directly 'feminist' statement in the inaugurating show of ' 80 ... I placed rectangles of colour round a small white room (transposition teased out by the location of Felix' sleeping waking rhythms.) It was an unusually comfortable place to work with a child. ... I enjoyed contributing to 2 more diary exhibitions but did not see them. ${ }^{43}$

\footnotetext{
${ }^{41}$ Pitts, "Not just a pretty face: Feminine wiles in New Zealand women's art practice", p.21.

42 Evans, "Appendix: The Women's Gallery, December 1979 - February 1984", p.249.

43 Joanna Paul, quoted in Evans, Lonie, and Lloyd, A Women's Picture Book: 25 Women Artists of Aotearoa (New Zealand), p.82.
} 
This recollection offers a contrast to the level of personal investment we see in Batten's descriptions of her involvement in the gallery. The varying degrees to which women were able to build a working relationship with the Women's Gallery is indicative of the way in which it operated in relation to the wider art world. As a liminal space, the Women's Gallery existed at a remove from the patriarchal societal conventions of the mainstream art world, but as we have already seen the boundaries which enacted this separation were permeable. An acknowledgement of Paul as an artist successfully exhibiting on either side of this boundary works to counteract negative charges which paint the gallery as an enclave 'for the aesthetically disabled female'. ${ }^{44}$ In Evans' introduction to Paul in A Women's Picture Book, she writes that she was 'part of the women's art movement in the 1970s while maintaining a fairly close but unaligned involvement with the established art world' ${ }^{45}$

The very fact that this dual participation was noted by Evans is of interest. Paul's relatively continuous inclusion in both group and solo exhibitions throughout New Zealand indicates a level of acceptance on the part of the 'established art world' of her work. The resurgence of interest in both her written and visual work after her death in 2003 only serves to reinforce this. By drawing the reader's attention to this participation in both the women's art movement, and the 'established art world', Evans situates Paul as an artist whose work can be accessed across a broad spectrum of visibility. Whilst refusing to label herself a feminist, Paul's work is typified by a sense of personal observation and experience which is rooted in a sense of female subjectivity. As she put it: 'my experience is meshed in myself in my own observations from where I stand and I'm not going to let anybody else's picture of the world get in the way'. ${ }^{46}$ Whilst conveyed in language that speaks of personal experience, it is difficult not to read this opinion along gendered lines. As a woman practising a form of representation heavily dominated by the expression of a naturalised male visual narrative, Paul's assertion of personal subjectivity over socially ingrained ways of seeing is powerful. It can in fact be seen to align with a

\footnotetext{
${ }^{44}$ Davies, "Women's Art".

${ }^{45}$ Evans, Lonie, and Lloyd, A Women's Picture Book: 25 Women Artists of Aotearoa (New Zealand), p.80.

${ }^{46}$ Jill Trevelyan, "'To see the moment is to farewell it.' The drawings of Joanna Margaret Paul", in Jill Trevelyan and Sarah Treadwell (eds.), Joanna Margaret Paul: Drawing, Auckland: Auckland University Press, 2006, p.20.
} 
feminist desire to 'understand the question of representation as a political question, to have an analysis of women's subordination within patriarchal forms of representation'. ${ }^{47}$

Paul's early career coincided with the development of the women's art movement in New Zealand, her involvement in key exhibitions relating to the development of a feminist art linking her work directly with the movement:

In 1975 Paul's work was included in a landmark exhibition organised by her friend Alison Mitchell (later known as Allie Eagle), entitled Woman's Art at the Robert McDougall Art Gallery in Christchurch. In 1977 - a year after the death of her daughter Imogen - she exhibited 'Unpacking [Unwrapping] the Body', an interrogation of medical terminology, at the United Women's Convention at the Christchurch CSA Gallery. In the same year ... Paul instigated an influential exhibition project 'A Season's Diaries' by asking a group of women friends to document their lives during the month of October. When the Women's Gallery was established in Wellington in 1980, she participated in a number of its projects and exhibitions. ${ }^{48}$

What this chronologically structured narrative infers is that the development of Paul's career occurred in parallel with that of the women's art movement within New Zealand; that one can perhaps be defined in part as a product of the other. Whilst it may in fact be the case that Paul's career benefited from her inclusion in these exhibitions, it is important to note that her work was concurrently being exhibited outside of this context. During the period between exhibiting in Women's Art and the closure of the Women's Gallery, Paul's work was also shown in the Bosshard Galleries in Dunedin; the Brooke Gifford Gallery, Christchurch; the Suter Art Gallery, Nelson; the Brooker Gallery, Wellington; the Wellington City Art Gallery and the Dunedin Public Art Gallery. ${ }^{49}$ During this time she also 'received formal recognition for her art when she was awarded the Frances Hodgkins Fellowship' ${ }^{50}$ What this proliferation of display would suggest is that, unlike Batten, who has identified the Women's Gallery and the wider women's art movement which

\footnotetext{
${ }^{47}$ Barry and Flitterman-Lewis, "Textual Strategies: The Politics of Art-Making", p.87.

${ }^{48}$ Trevelyan, "'To see the moment is to farewell it.' The drawings of Joanna Margaret Paul", p.20.

${ }^{49}$ City Gallery Wellington, "beauty, even: Joanna Margaret Paul 1945 - 2003", Wellington: City Gallery Wellington, 2004, p.

50 Trevelyan, "'To see the moment is to farewell it.' The drawings of Joanna Margaret Paul", p.12.
} 
surrounded it as being vital for her development, the same cannot necessarily be said for Paul.

Paul's consistent inclusion within both the public and private gallery system indicates a level of conventional success within this mainstream context. Where the arc of progress traced within Batten's development fits cleanly with the transformative liminal model of the Women's Gallery, it seems unlikely that a discussion of Paul's oeuvre will contribute significantly to building this case. However, there is value to be added through an exploration of Paul's work to the development of the liminal model, in specific relation to the foregrounding of multi-vocality within such a space. The clear discrepancy that can be identified between the positions occupied by Batten and Paul in the mainstream art world is at the heart of this development.

It was declared in Paul's obituary in Art New Zealand that she 'worked for love - not for money, neither for status nor fame. And so, during her public life as an artist just on 34 years - Paul existed on the margins of the art world: where she lived, how she practised, and what she believed in' ${ }^{51}$ This declaration of marginality seems to be at odds with her continuous exhibiting history. However, these two elements need not necessarily be mutually exclusive. Paul chose to spend most of her adult life outside of New Zealand's main centres, she consciously rooted her artistic practice within 'the particular circumstances of [her] domestic life, ${ }^{52}$ and chose to work across a diverse range of artistic fields: 'painting and drawing, photography, film-making, poetry, publishing, architectural history and critical writing' ${ }^{53}$ It was these choices that marked Paul as marginal, but what her success appears to demonstrate is that even from a position of marginality, creative credibility and mainstream acceptance can be attained. Her decision to exhibit in the Women's Gallery - a space heavily marked by its marginal position, despite its physical location in an urban centre - can perhaps be seen as an extension of such positional choices.

\footnotetext{
${ }^{51}$ Peter Ireland, "A Shape to Part the Space: Joanna Margaret Paul 194 -2003", Art New Zealand, no. 108,2003, p.59.

52 Joanna Harris [Joanna Paul], in Mitchell, Woman's Art: An Exhibition of Six Women Artists, p.12.

53 Ireland, "A Shape to Part the Space: Joanna Margaret Paul 1945 - 2003", p.59.
} 
The complexity of Paul's 1977 work Unpacking the Body (and its 1996 reworking) is indicative of much of her working practice. First realised as an installation, and subsequently as a self-produced book entitled Unwrapping the Body [figs. 10 and 11], the physical manifestation of the work is at once an object, an artwork, a poem, a private lamentation, and an investigation of the relationship between visual and written language. Produced after the death of her ten-month-old daughter - about whom she wrote the poetry series Imogen - the work forces its viewer to enact a tangible kind of unwrapping. The slim book is encircled by a corrugated cardboard sleeve which must first be removed, allowing access to a brown paper envelope. Slipping the triangular fold of paper from the incision which holds it in place, we unwrap this outer envelope to find another inner cover.

The pages it encloses are comprised of a series of photographic images and words both typed and handwritten in a variety of fonts. The layout of the written pages alters continuously, aligning vertically on one page, and horizontally on the next. Sometimes the bound edge of the page represents the top, and at other times the bottom, of the written page. At times, multiple alignments coexist in the open pairs of pages, forcing the viewer to gently handle the work, turning it in their hands and passing it through various phases of orientation. The words, an etymological exploration of the anatomical, unravel and evolve like lists or poems across the page, meanings slipping and transforming as they accumulate. Paul explains her creative process as follows:

I found seven or eight basic symbols - cup-sword-tree-wheel-housering ... which I made manifest by hanging in frames (STROMA) corresponding objects ... above these items in their flesh coloured frames hung the list of terms and etymologies. ... I thought the piece ... was about science: anatomy, physiology, a bridge between the languages of science and imagination. I think I was also building a shrine/temple/body for my dead child. ${ }^{54}$

Exhibiting a tenuous synthesis of word and image, it is reminiscent in many ways of Martha Rosler's 1974-5 work The Bowery in Two Inadequate Descriptive Systems [figs. 12 and 13]. Rosler's pairing of photographic image and typed word 'not only

\footnotetext{
54 Joanna Paul, quoted in Bridie Lonie, "The subject of motherhood as treated in New Zealand painting," in Mothers, p.7.
} 
exposes the "myths" of photographic objectivity and transparency: it also upsets the (modern) belief in vision as a privileged means of access to certainty and truth ('seeing is believing')' 55

Paul's work, whilst highlighting the inability of either visual or linguistic representation to wholly express meaning, points to an exploration of both which is an act of reclamation rather than deconstruction. In both works the relationship between word and photograph opposes the conventional practice of using words as captions to illuminate the meaning of an image. Instead Rosler's words and images riff associatively upon a theme, her usage of both 'calculated (as the title suggests) to "undermine" rather than "underline" the truth value of each'. ${ }^{56}$ Whilst Paul uses a similar list-like format, there is a sense that she is striving instead for cohesion, to create a language that is enriched through use of word, image and body. As she remarked of writing poetry, 'I often use poetry to say something I can't talk about in paint - to look at an event, a movement, a tone of voice, something not entirely understood' ${ }^{57}$ Whilst this particular work may not have been exhibited at the Women's Gallery, the very fact that it was created 'points to the fact that, even in 1977 , women artists were negotiating the meanings of femininity in relation to both nature and culture, a fact that problematizes any essentialist reading of their work' ${ }^{58}$

That an artist such as Paul, whose work demonstrates an exploration of such thematically, formally and theoretically complex ideas, would embrace the Women's Gallery as a viable space in which to exhibit contributes further to the assertion that the gallery project should not - and cannot - be dismissed as being inhabited by 'the aesthetically disabled female'. 59

What then of the work Paul chose to display at the Women's Gallery? Her contribution to Opening Show was conceptual in its execution, physically marking

\footnotetext{
${ }^{55}$ Owens, "The Discourse of Others: Feminists and Postmodernism", p.179.

56 Ibid., p.178.

57 Joanna Paul, quoted in Trevelyan, "'To see the moment is to farewell it.' The drawings of Joanna Margaret Paul", p.16.

${ }^{58}$ Christina Barton and Deborah Lawler-Dormer, "'Unrly practices' An introduction to A different view: 20 New Zealand women artists 1973-1993", in Alter/Image: Feminism and Representation in New Zealand, p.13.

59 Davies, "Women's Art".
} 
with coloured cardboard the transient traces of her son's sleeping and waking rhythms in the gallery space. Much of the other work she chose to display under the Women's Gallery banner was also concerned directly with her children:
Although Paul faced enormous practical difficulties in the conflicting roles of mother, wife and artist ... characteristically she turned the adversity to advantage, because the paintings and drawings of her children (to say nothing of the poems) remain among the most memorable of her works. ${ }^{60}$

Perhaps then, an exhibition specifically examining the concept of motherhood endures as a particularly relevant forum for Paul's work. Included in the catalogue for Mothers are listings for 11 visual works by Paul: five under the title Magdalena and six under the heading Felix. In addition to these visual works, three poems are also included in the catalogue, all of which relate to her children. Two of the three images of Paul's work displayed in the catalogue are entitled Felix Sleeping [figs. 14 and 15], both of which are executed in conte, and are of relatively small size, each measuring $380 \times 457 \mathrm{~mm}$. The apparent simplicity with which she has treated her subject belies the complexity of thought the images exhibit in relation to visual representation.

The fragmentary, multi-layered forging of meaning that we find in Unwrapping the Body is again evident in these sketches of the artist's infant son. The title - Felix Sleeping - suggests a closed and easily defined subject matter, the sleeping child immobile and simple to transcribe to paper. However, rather than a traditionally complete portrait each image here presents a fragment, a snatched and partial glimpse. Paul creates individual images, each of which focus on a slightly different aspect of her sleeping child, calling into question our ability to perceive the human subject in its entirety. Trevelyan writes that 'Paul was fascinated by the processes of perception', 61 this fascination being deeply evident within these delicate and quiet line drawings.

More so than any other formal feature, it is the negative white space of the paper which dominates here. Though the space is unfilled, it is certainly not unused, the expanse of empty space threatening compositionally to "consume the image

\footnotetext{
${ }^{60}$ Ireland, "A Shape to Part the Space: Joanna Margaret Paul 1945 - 2003", p.59.

${ }^{61}$ Trevelyan, "'To see the moment is to farewell it.' The drawings of Joanna Margaret Paul", p.8.
} 
entirely'. ${ }^{62}$ What this white space does, other than throwing the drawn lines into sharp relief, is to suggest a multiplicity of possibilities. The expanse of negative space could be filled over and over with these minimal lines of representation, each the physical manifestation of infinitesimal shifts in perception. There is a sense of abstraction produced here, which is particularly evident in Felix Sleeping III [fig. 15]. It takes more than a momentary glance for the sequence of sketched lines and marks to settle into the discernible form of a child's hands, the visual stimulus requiring cognitive assistance in order to partially fulfil its representational promise. The suggestion here is of infinite possibility, negating the assertion that visual representation will ever have the ability to produce a definitively truthful image.

This suggestion of vision and perception being fragmentary and cumulative is reiterated through the continuation of Paul's legacy after her death. Exhibitions such as 2004's beauty, even: a tribute to Joanna Margaret Paul 1945 - 2003 held by the City Gallery Wellington, and 2006's Joanna Margaret Paul: Drawing at the Mahara Gallery, which was accompanied by a substantial book, both point to the prolific nature of Paul's creative output. 'At the time of her death at fifty-seven in 2003, Paul left an extensive archive of writing, self published books, hundreds of drawings and paintings, and over one hundred and fifty sketchbooks. ${ }^{63}$ Like the fragmentary images Paul created of Felix sleeping, the fragments of her creative life, when layered upon one another work cumulatively in support of her assertion that "when my work is all laid out together the jigsaw puzzle of my life will show itself, I think ... It's oblique, but it's all there'. ${ }^{64}$ This suggested mode of viewing is made possible by her repetition of familiar subject matter such as family, interior spaces, windows, the objects of everyday life, and also the repeated emphasis on formal elements - in particular a considered use of negative space in both her visual art and poetry. The search for meaning and value in her work occurs through a process of accumulation and repetition; it occurs in the spaces where dialogue takes place between individual visual or written fragments. This fragmentary and diverse method of working can be

\footnotetext{
62 Ibid., p.15.

${ }^{63}$ Emma Bugden and Greg Donson, "Introduction", in City Gallery Wellington, beauty, even: a tribute to Joanna Margaret Paul 1945-2003, p.7.

${ }^{64}$ Joanna Paul in Trevelyan, "'To see the moment is to farewell it.' The drawings of Joanna Margaret Paul", p.12.
} 
considered a politicised one: her working practice rendering the imposition of a linear narrative arc of career progression extremely difficult.

For Paul, the Women's Gallery was but one of the many fragments which comprised her creative life, perhaps no more or less important than any other. That she chose to exhibit within the gallery's specific forum is indicative not only of her prolific output and varied career. Her presence within the history of the Women's Gallery, alongside women such as Heather McPherson, who by her own definition was 'not a visual artist', ${ }^{65}$ points to the unconventionally disparate range of artists whose work was displayed there. McPherson, Batten and Paul occupy quite different positions upon the spectrum of mainstream critical acceptance within the art world in New Zealand. That each artist was welcomed and celebrated within the context of the Women's Gallery strengthens the assertion that the space provided there was one which broke down society's hierarchical conventions. The transient boundaries marking this space allowing instead for the creation of a 'fructile chaos' ${ }^{96}$ in which normal rules and divisions were jettisoned to create 'an interlude wherein conventional social, economic, and political life may be transcended'. ${ }^{67}$

That the Women's Gallery operated as a platform for artists whose work ranged across the broadest spectrum of perceived aesthetic quality demonstrates one way in which it operated as a non-reductive forum for the expression of difference. Sexual difference is of course foregrounded in this instance through the act of naming. Some would argue that by definitively entitling this space a Women's Gallery, an acceptance of patriarchal binary division is implied. However, this is in fact a false division which can be all too easily applied by those on the outside if they are unwilling to look in. Toril Moi speaks of this danger when she writes that the 'binary model of difference as enclosed or captured between the two opposite poles of masculinity and femininity blinds us to that which escapes this rigid structuration' ${ }^{68}$ It is those subtleties of difference which an external viewer will fail to see if they fall

\footnotetext{
${ }^{65}$ Heather McPherson, quoted in Evans, Lonie, and Lloyd, A Women's Picture Book: 25 Women Artists of Aotearoa (New Zealand), p.41.

66 Turner, "Are there Universals of Performance in Myth, Ritual, and Drama?", p.12.

${ }^{67}$ St John, "Victor Turner and Contemporary Cultural Performance: An Introduction", p.5.

68 Toril Moi, Sexual/Textual Politics, London: Methuen \& Co. Ltd., 1985, p.154.
} 
into the trap of reading the Women's Gallery along the essentialist lines drawn by an assumption of binary difference.

I think that the apparent coherence which the term 'woman' assumes in contemporary ideology ... essentially has the negative effect of effacing the differences among the diverse functions or structures which operate beneath this word. Indeed, the time has perhaps come to emphasize the multiplicity of female expressions and preoccupations... ${ }^{69}$

First published the year before the opening of the Women's Gallery, Julia Kristeva's thoughts on the restrictive use of 'woman' as a label representing coherence rather than multiplicity are particularly valid here. Looking back at the short history of the Women's Gallery the refusal of coherence - despite an affirmation of common ground - is evident in a variety of forms. The diverse range of issues and themes around which group shows and workshops coalesced can be seen as directly emphasising the multiplicity of 'female preoccupations'.

Exhibitions such as Lesbiana (October 1980) and Maori Women's Show (March and April 1981) are perhaps the most conspicuous indicators of a desire to present an image of woman which was not constricted by those markers of privilege: being white, heterosexual and middle-class. The presence of work by artists such as Kahukiwa, to which an exploration of contemporary cultural identity was central, alongside more traditional Māori weaving and Cook Island Tivaevae, indicates a desire to represent a meaningful exploration of cultural diversity. ${ }^{70}$ When Evans and Lonie state that they 'were enormously privileged at the Women's Gallery by the Maori artists, writers and musicians who shared their perceptions of the world with us', ${ }^{71}$ they highlight a recognition not only of cultural multiplicity, but also an expansion of the parameters of what formally constitutes the art to be found in a gallery. The work of musicians and writers was as valid as that of visual artists, women who worked in 'sculpture, video, film, watercolours, oils, prints, poetry ${ }^{\text {'72 }}$ all allowed an equal voice. By bringing the marginal - in terms of gender, sexuality,

\footnotetext{
69 Julia Kristeva, "Women's Time", in Toril Moi (ed.), The Kristeva Reader, Oxford: Basil Blackwell Ltd., 1986, p.193.

${ }^{70}$ Evans and Lonie, "Afterword 1", p.230.

71 Ibid., p.230.

72 Evans, "Appendix: The Women's Gallery, December 1979 - February 1984", p.248.
} 
cultural heritage, professionalism, creative form and medium - into the centre at the Women's Gallery, an alternative to existing on the fringes was provided for these women.

Moi asserts that 'In a sense, then, Kristeva does not have a theory of "femininity", and even less of "femaleness". What she does have is a theory of marginality, subversion and dissidence. In so far as women are defined as marginal by patriarchy'. ${ }^{73}$ Key to this acknowledgment of woman's marginal position in patriarchal society is that it 'allows us to view this repression of the feminine in terms of positionality rather than of essences. What is perceived as marginal at any given time depends of the position one occupies' ${ }^{74}$ Essences are intrinsic, immutable. Positions, however, are subject to change. The definitions which once rendered an individual or group as other, are always open to deconstruction.

That the Women's Gallery existed as a liminal space in which conventional barriers to the creation and display of art were removed, allowed for the creation of a space in which women were not relegated to the margins. If 'the ways in which space has been historically conceived have always functioned to either contain women or to obliterate them' ${ }^{75}$ then the Women's Gallery provided an alternative to this. A space with mutable boundaries cannot contain, and a space which exists to allow experimentation and the acceptance of difference cannot obliterate. Existing as a threshold, a space through which women could pass, the Women's Gallery provided, in the words of Victor Turner a 'system of potential alternatives" ${ }^{76}$ to those limited and rigid definitions of femininity and artistry.

\footnotetext{
${ }^{73}$ Moi, Sexual/Textual Politics, p.167

${ }^{74}$ Kristeva, "Women's Time", p.166.

75 Grosz, "Women, Chora, Dwelling", p.120.

${ }^{76}$ Victor Turner, quoted in Maxwell, "The Ritualization of Performance (Studies)", p.61.
} 


\section{Conclusion}

The year in which the brief existence of the Women's Gallery came to an end was marked by seismic change in New Zealand's political and social landscape. The snap election of 1984, called by Prime Minister Robert Muldoon - along with his subsequent landslide loss - opened the door for a Labour government which was to drastically alter the economic ideology of the country. Under the leadership of David Lange and the economic vision of Roger Douglas, the government pursued a 'model of pure neo-liberal economic theory'. ${ }^{1}$ Initially, Labour's victory appeared full of promise to those involved with the women's movement in New Zealand:

...the Lange government had come to power in 1984 with an extensive and detailed women's policy, the first in New Zealand's history. The policy supported the establishment of a Ministry of Women's Affairs, dramatic increases in child care funding, equal pay for work of equal value, and a raft of other traditional feminist demands such as more representation for women on government bodies. $^{2}$

From a societal point of view, the Lange government appeared to be presenting policies which largely squared with the foundation of social equality upon which the Labour party had been built. It was, however, the economic direction in which the government would lead the country which would dramatically impact upon women's lived experience. As Jane Kelsey argues, 'women's economic role had traditionally been marginalised ${ }^{3}$ through the gendered expectations of unpaid domestic work and childrearing. From this starting point of economic marginalisation, Labour's economic policy 'deepened the feminisation of poverty'. ${ }^{4}$ The unrolling of this economic policy sought to gradually dismantle the welfare state, and replace it with market liberalisation and free trade in which 'wage restraint and structural unemployment became key elements'. 5 The increased visibility of women's issues

\footnotetext{
${ }^{1}$ Jane Kelsey, The New Zealand Experiment: A world model for structural adjustment?, Auckland: Auckland University Press, 1995, p.1.

2 Phillida Bunkle, "How the Level Playing Field Levelled Women," in Bunkle and Hughes (eds.), Heading Nowhere in a Navy Blue Suit and other TALES from the FEMINIST REVOLUTION, p.92.

${ }^{3}$ Kelsey, The New Zealand Experiment: A world model for structural adjustment?, p.286.

${ }^{4}$ Ibid., p.286.

5 Ibid., p.2.
} 
represented by Labour's women's policy can be seen to have acted as a smokescreen under which these economic changes could be made.

Our focus as feminists had been mainly on the social realities - we had no significant response to the economic realities. Others did. In the second half of the eighties, with remarkable speed, new right philosophy swept New Zealand. Both Labour (from 1984 to 1990) and National (from 1990) governments pursued policies designed to promote private interests and success for the few, rather than the public interest and excellence for all. ${ }^{6}$

This emphasis on private interests and the elevation of the individual is of central importance here. The foregrounding of the individual within a free-market economy acts to reduce state responsibility, the need to depend upon the state for financial assistance accompanied increasingly by connotations of personal failure or wrongdoing. Poverty was wrapped in the rhetoric of laziness and poor decision making, with 'hard work' naturalised as the only route out. Rather than being acknowledged as a structural problem aggravated by a decline in job stability and the increasing temporisation of employment opportunities, 'responsibility for social wellbeing was individualised, privatised, neutralised' ${ }^{7}$

The dismantling of the welfare state, and its replacement with a market driven economy in which individual agency takes front and centre, signalled a growing ideological shift which was echoed in the discourse surrounding feminism, particularly within the popular media. The communal consciousness-raising of the second wave feminism of the 1970s gradually gave way to multiple versions of postfeminism, in which it is again the individual who assumes centrality. Whilst the problematic label 'postfeminism' is widely disputed, the term broadly encompasses: 'a set of assumptions, widely disseminated within popular media forms, having to do with the "pastness" of feminism, whether that supposed pastness is merely noted, mourned, or celebrated'. ${ }^{8}$

\footnotetext{
${ }^{6}$ Anne Else and Rosslyn Noonan, "Unfinished Business", in Bunkle and Hughes (eds.), Heading Nowhere in a Navy Blue Suit and other TALES from the FEMINIST REVOLUTION, p.198.

${ }^{7}$ Kelsey, The New Zealand Experiment: A world model for structural adjustment?, p.294.

${ }^{8}$ Yvonne Tasker and Diane Negra, "Introduction: Feminist Politics and Postfeminist Culture", in Yvonne Tasker and Diane Negra (eds.), Interrogating Postfeminism: Gender and the Politics of Popular Culture, Durham and London: Duke University Press, 2007, p.1.
} 
Within contemporary popular culture, the iteration of feminism which is most frequently celebrated is that of woman as an agent of choice. Postfeminism:

...works to commodify feminism via the figure of the woman as empowered consumer. ... Assuming full economic freedom for women... Postfeminist fictions frequently set aside both evident economic disparities and the fact that the majority of women approach paid labor as an economic necessity rather than a "choice." As this suggests, postfeminism is white and middle class by default, anchored in consumption as a strategy (and leisure as a site) for the production of the self. ${ }^{9}$

The echoes between this portrayal of the feminist woman as an 'empowered consumer', and an increasingly individualised responsibility for social well-being are immediately apparent. This cultural shift away from the state or collective, and towards the individual, is a factor which has helped to shape the retrospective exclusion of the Women's Gallery from the writing of New Zealand's art history.

As has been made evident throughout this examination of the Women's Gallery, the political and creative have been intrinsically linked throughout the project. The sociopolitical environment in New Zealand at the time of the gallery's creation played a significant role in determining the ideology behind its collective operational structure. The emergence of grassroots feminist activism in New Zealand was frequently organised along communal lines, evident in the proliferation of publications such as Broadsheet and Spiral, the conferences held throughout the 1970, and the emergence of the Women's Gallery itself. This tendency towards collectivity appears to have waned during the gradual societal shift towards individual centrality; the likelihood of this being a coincidence is slim. As Sandra Coney wrote in 1993:

In 1992 when the National government redesigned the accident compensation scheme, entirely disenfranchising women in the home in the process, there was barely a peep from the women's movement. ... The movement was silent because there is no movement - only isolated groups working on specific issues. The

\footnotetext{
${ }^{9}$ Ibid., p.2.
} 
local women's liberation groups with a broad platform of aims have all but vanished. ${ }^{10}$

In a society organised along individual lines, the appeal of engaging with a project which placed communality and collectivity so firmly at the core of its value system appears minimal. If domination of a masculine and painterly pursuit of a national aesthetic identity helped to shape the exclusion of the Women's Gallery from critical attention at the time of its creation, then perhaps the anomalous nature of a collective within an individualised society can be seen to have impacted upon the lack of critical interest it has received since its dissolution. Despite the Women's Gallery's lack of overt presence within the published art historical record, subtle traces can in fact be found if we allow our search to focus on individuals, rather than the gallery as a whole.

It is evident that since the mid-1970s 'women have been resolutely written into New Zealand history, a project which has gathered strength as more women entered graduate programmes in history and related disciplines'. ${ }^{11}$ Whilst the methods and successes of this project have been evaluated throughout this thesis, there is value in examining whether any of the women who exhibited at the Women's Gallery have been effectively written into New Zealand's art history. It is through these women that the Women's Gallery marks its silent presence - silent, because in many instances no significant mention of the gallery is made in relation to these individual artists.

Artists whose work at the Women's Gallery has been examined in detail within this thesis include Robyn Kahukiwa, Di Ffrench and Joanna Paul. As we have seen, each of these artists has maintained a presence in the art world, both in terms of published criticism, and the continued visibility of their work in galleries and museums. Multiple works by each of these women are included within New Zealand's national collection at Te Papa Tongarewa, which is further indication that their work has gained a level of recognition and status within the mainstream. These artists are not

\footnotetext{
${ }^{10}$ Sandra Coney, "Why the Women's Movement Ran Out of Steam", p.54.

${ }^{11}$ Caroline Daley and Deborah Montgomerie, The Gendered Kiwi, Auckland: Auckland University Press, 1999, p.11.
} 
the only women who have displayed at the Women's Gallery who can be considered successful when viewed along conventional lines of marked visibility.

Consulting the list of Women's Gallery exhibitors included in A Women's Picture Book results in the discovery of many successful individual female artists. Examples include Ans Westra, heralded by Art New Zealand as 'one of the premier photographers in Aotearoa', ${ }^{12}$ and Christine Hellyar who has exhibited widely both within New Zealand and internationally, ${ }^{13}$ along with artists such as Fiona Clark, Jacqueline Fahey, Rhondda Bosworth and Robin White. This strengthens the argument that the relative invisibility of the Women's Gallery is not predicated upon a poor quality of aesthetic output by the artists who exhibited there. In actual practice, many artworks and artists associated with the gallery throughout its four year history have maintained a presence within the context of the mainstream art world. When viewed through the achievements of individual artists, the Women's Gallery attains a significant presence within the artistic landscape of New Zealand in the late 20th Century. Perhaps though, there is a lack of desire within a highly individualised society to embark upon an engagement with a collective working model. As we have previously seen, the collective mode of working, along with the wide diversity of work displayed at the Women's Gallery made reductive oversimplification of the political and aesthetic nature of the project a very real danger. The combination of these problematic factors regarding collectivism goes some way towards offering an explanation for the lack of an overt presence of the Women's Gallery within the published record. For those willing to follow the threads of individual contributions however, a rich presence begins to emerge.

This presence, which insinuates itself into New Zealand's art history through the cumulative recognition of individual artists, is not the only one marked by the Women's Gallery. Inclusivity played a pivotal role in shaping the parameters for considerations of aesthetic quality within the gallery's exhibiting history, leading to the criticism from some quarters that the Women's Gallery 'should come out into the

\footnotetext{
${ }^{12}$ Damian Skinner, "The Eye of an Outsider: A Conversation with Ans Westra", Art New Zealand, no. 100, 2001, p.94.

${ }^{13}$ See http://christinehellyar.com/exhibitions.html for a comprehensive exhibition history.
} 
open and call their gallery the "Art Gallery for the aesthetically disabled female". ${ }^{14}$ Whilst this damning attack invites criticism on a number of levels, the key issue here is to address the reasons behind the decision on the part of the Women's Gallery to actively display work which would not be deemed worthy of inclusion in more mainstream gallery spaces. Heather McPherson's Goddess Figure along with Juliet Batten's Roses series, both of which have been examined in some detail previously, can be deemed to lack conventional levels of aesthetic quality associated with traditional 'high art' standards. Each of these pieces reflects a quite different level of aesthetic development - Batten's series is indicative of a tentative and unpolished painterly technique in the process of exploration. She has written of her experience when first beginning to paint that she found the process:

...terribly painful... because I'd never been to art school and I felt that very keenly. I was in my thirties, I had no skills and I had so much in me that wanted to come out... All my questions were at the most basic level - like how do you stretch watercolour paper, or what is the difference between students' and artists' watercolours. ${ }^{15}$

By creating a space in which women in this position could come together and learn from one another, in addition to exhibiting their work, the Women's Gallery sought to remove some of the 'institutional obstacles ${ }^{16}$ which ordinarily would have thwarted the progression of an artist such as Batten. McPherson's Goddess Figure occupies a position at the furthest end of the conventional qualitative spectrum, the artist herself declaring that 'I'm not a visual artist... mine was nowhere near visually successful... That was okay'. ${ }^{17}$ Perhaps Allie Eagle best explains the importance of this environment of acceptance when she writes:

I'm very grateful for all those times $\&$ processes/relaxing in noncommercial situations where the focus on artistic production was on the quality of our lives and communication not marked by boundaries of isms and excellence - things that seem to thwart open

\footnotetext{
14 Austin Davies, "Women's Art".

15 Juliet Batten, quoted in Evans, Lonie, and Lloyd, A Women's Picture Book: 25 Women Artists of Aotearoa (New Zealand), p.52.

${ }^{16}$ Laura Cottingham, "L.A. Womyn: The Feminist Art Movement in Southern California, 1970-1979", p.164.

${ }^{17}$ Heather McPherson, quoted in Evans, Lonie, and Lloyd, A Women's Picture Book: 25 Women Artists of Aotearoa (New Zealand), p.40.
} 
dialogue $\&$ taking risks $\&$ inevitably prevent less 'professional' women entering into the dialogue..$^{18}$

This demonstrative rejection of aesthetic mastery as a requirement for display acts to prioritise the exploratory process of creation over the production of a commodifiable end product. The foregrounding of the liminal model as a method for framing a critical discussion of the Women's Gallery seeks to recognise value in elements other than the purely formal or aesthetic.

The utilisation of a discussion of liminality adapted from Turner's scholarship has been employed primarily as an attempt to shape a recognition of the Women's Gallery that is centred upon its existence as a collective space. In order to address the very particular place the gallery occupied in the socio-political and artistic landscape of New Zealand in the early half of the 1980s, it is necessary to view the project in its entirety. The challenges inherent in attempting to do so are numerous. The risk of reductivism which presents itself when such a disparate range of working practices and aesthetic outcomes are displayed within the same space is perhaps the foremost of these dangers. No individual artist's work can be taken as representative of the diverse output of the gallery; nor can those individual contributions simply be divorced from the Women's Gallery project. The emphasis placed upon the transformative and transitional nature of the gallery as liminal space allows for an engagement with the Women's Gallery that values not only those artists - such as Joanna Paul and Di Ffrench - whose work remains visible within a mainstream context.

The liminal model also allows value to be found in the processes of aesthetic and personal development undergone by many other women who have remained absent from the written version of New Zealand's art history, Juliet Batten perhaps being the most prolific example. Recognising that the remit advanced by the Women's Gallery was not one built purely upon the pursuit of artistic excellence, it becomes ineffective to dismiss the project due to the fact that it failed to meet standards which it never in fact set for itself. This awareness does not necessarily imply that the Women's Gallery jettisoned all standards of aesthetic quality, neither does it imply that no work

\footnotetext{
${ }^{18}$ Allie Eagle, quoted in ibid., p.86.
} 
of a high aesthetic standard was produced there. This, as has been demonstrated for example through the work of Kahukiwa and Paul amongst others, was certainly not the case. The multiplicity of these individual contributions reflect Turner's final phase in ritual theory. Re-aggregation represents 'the return of the subjects to their new... position in the total society'. ${ }^{19}$ Numerous women who passed through the gallery's liminal space subsequently went on to mark their presence in the wider art world, carrying a trace of the experience with them.

Through the act of defining the Women's Gallery as a liminal space, it has also been possible to re-examine the transitory nature of its existence. Rather than locate the gallery's short life span within a discourse of failure, it is instead possible to acknowledge that it in fact functioned as a site of threshold. The passage of time which has elapsed since the gallery's closure has similarly been one of transition, in this case marked by socio-political change. As we have seen, the widespread economic changes which have reshaped New Zealand's social structure have played a role in the continued absence of the Women's Gallery from critical artistic discussion. What is evident, though, is the continued relevance of many of the issues - both socio-political and artistic - tackled by the Women's Gallery throughout its lifetime. Clearing a space for women to explore and express these issues, whilst enabling them to produce and display art ensured that the political and creative were constantly linked: that through art women could endeavour to explore new possibilities and create social and personal change. 'The Women's Gallery gave a freedom to make statements about myself/ourselves, our ideas/ambitions - a challenge to realise visions for change. ${ }^{20}$ Reiterating the words of Peggy Phelan, the Women's Gallery as a project, was demonstrative of a type of:

Successful feminist art [which] beckons us towards possibilities in thought and in practice still to be created, still to be lived. ${ }^{21}$

\footnotetext{
${ }^{19}$ Turner, "Liminal to Liminoid, in Play, Flow, and Ritual: An Essay in Comparative Symbology", p.24.

${ }^{20}$ Allie Eagle, quoted in Evans, Lonie, and Lloyd, A Women's Picture Book: 25 Women Artists of Aotearoa (New Zealand), p.86.

${ }^{21}$ Phelan, "Survey", in Phelan and Reckitt (eds.) Art and Feminism, p.20.
} 


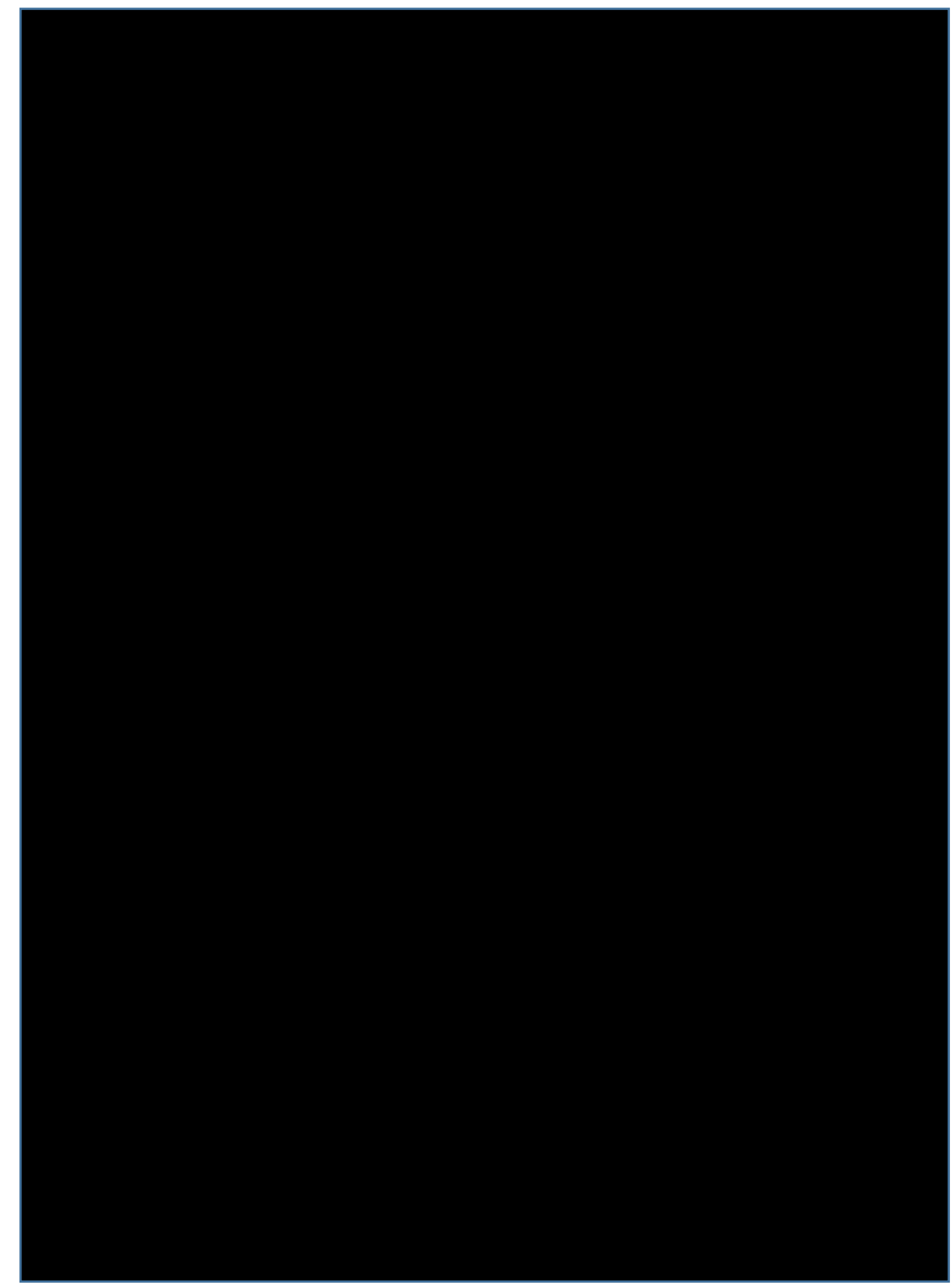

Fig. 1: Opening Show artists outside the Women's Gallery, 1980, photograph taken by Fiona Clark.

Outside 26 Harris Street, Wellington, January 1980

1-r: Marian Evans, Allie Eagle, Nancy Peterson, Juliet Batten, Anna Keir, Heather McPherson, Bridie Lonie, Keri Hulme. In front: Brigid Eyley, Claudia Pond Eyley.

Absent: Joanna Margaret Paul, Carole Stewart and Tiffany Thornley.

(Photograph courtesy of Marian Evans.) 


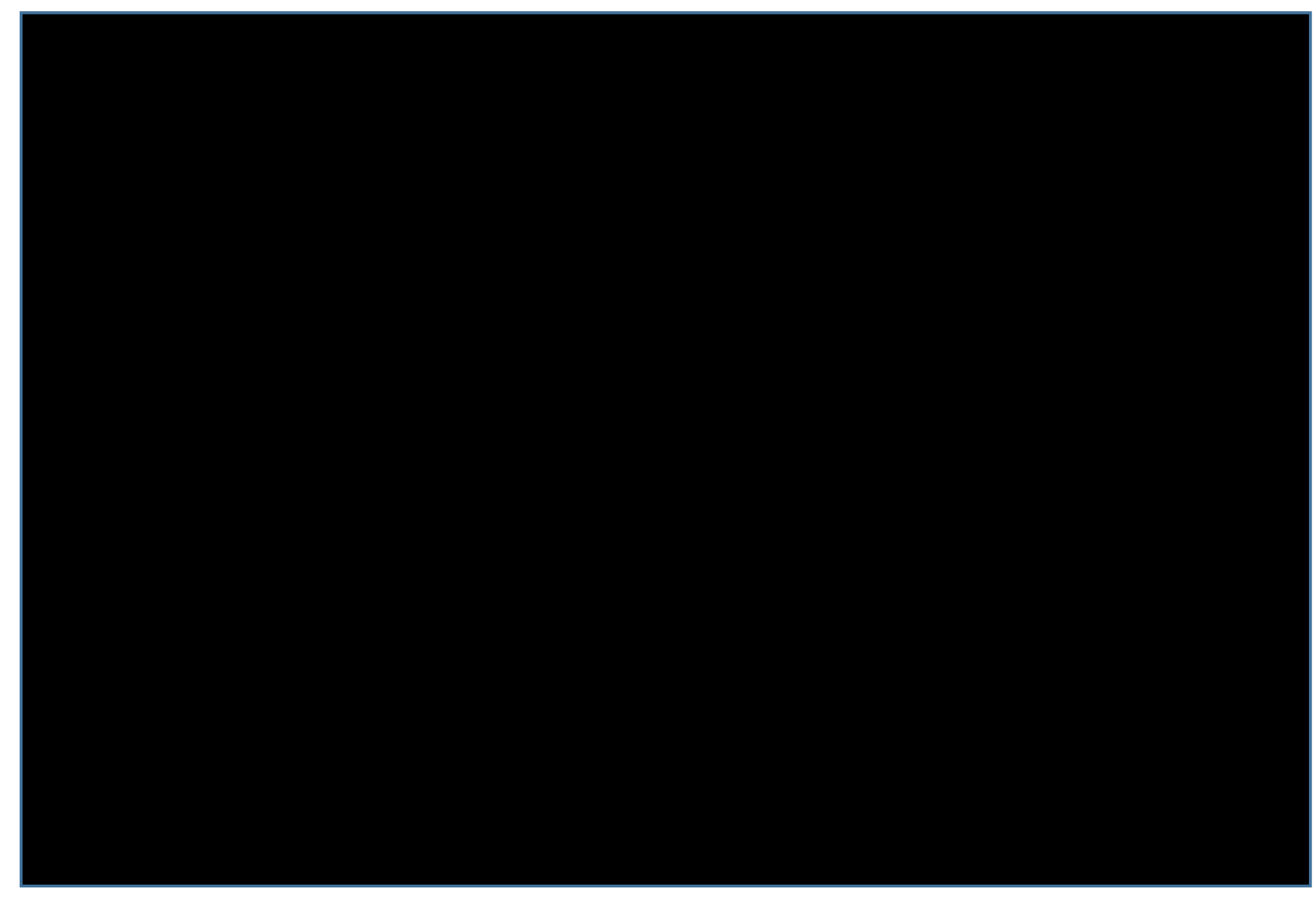

Fig. 2: Heather McPherson, Goddess Figure, 1980, mixed media.

Photograph of the artist with mixed media installation at the Women's Gallery Opening Show. Also see fig. 3 for a full-length view of Goddess Figure.

(Temporary installation) 
Fig. 3: Juliet Batten, Roses, 1980, watercolour on paper, (artist's collection).

This photograph was taken during the installation of the Opening Show at the Women's Gallery. Also visible: Goddess Figure, Heather McPherson, 1980, mixed media installation.

(Photograph courtesy of Alexander Turnbull Library, Wellington.) 


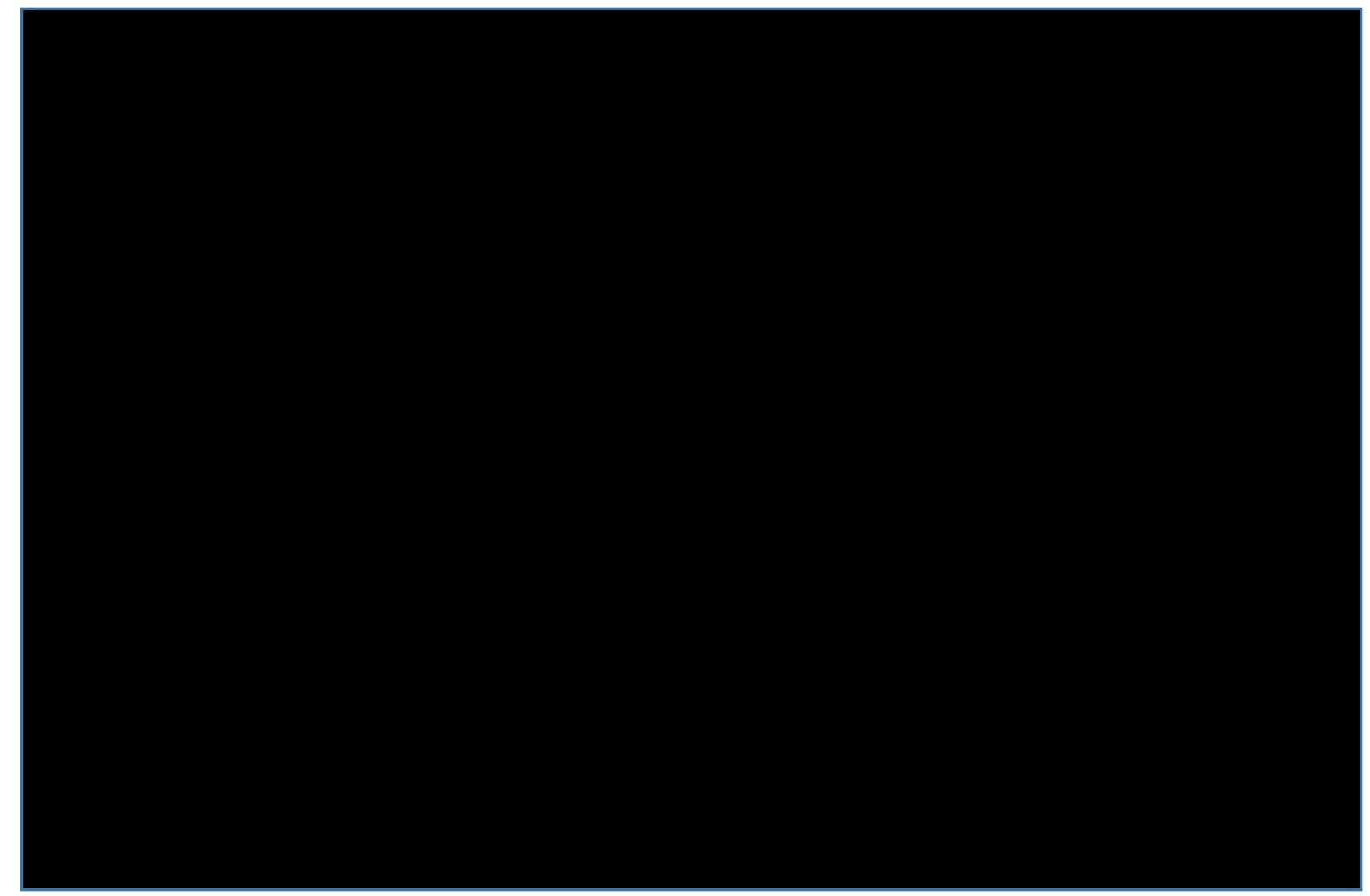

Fig. 4: Juliet Batten, Roses, 1980, watercolour on paper.

(Artist's collection, photograph courtesy of the artist.) 


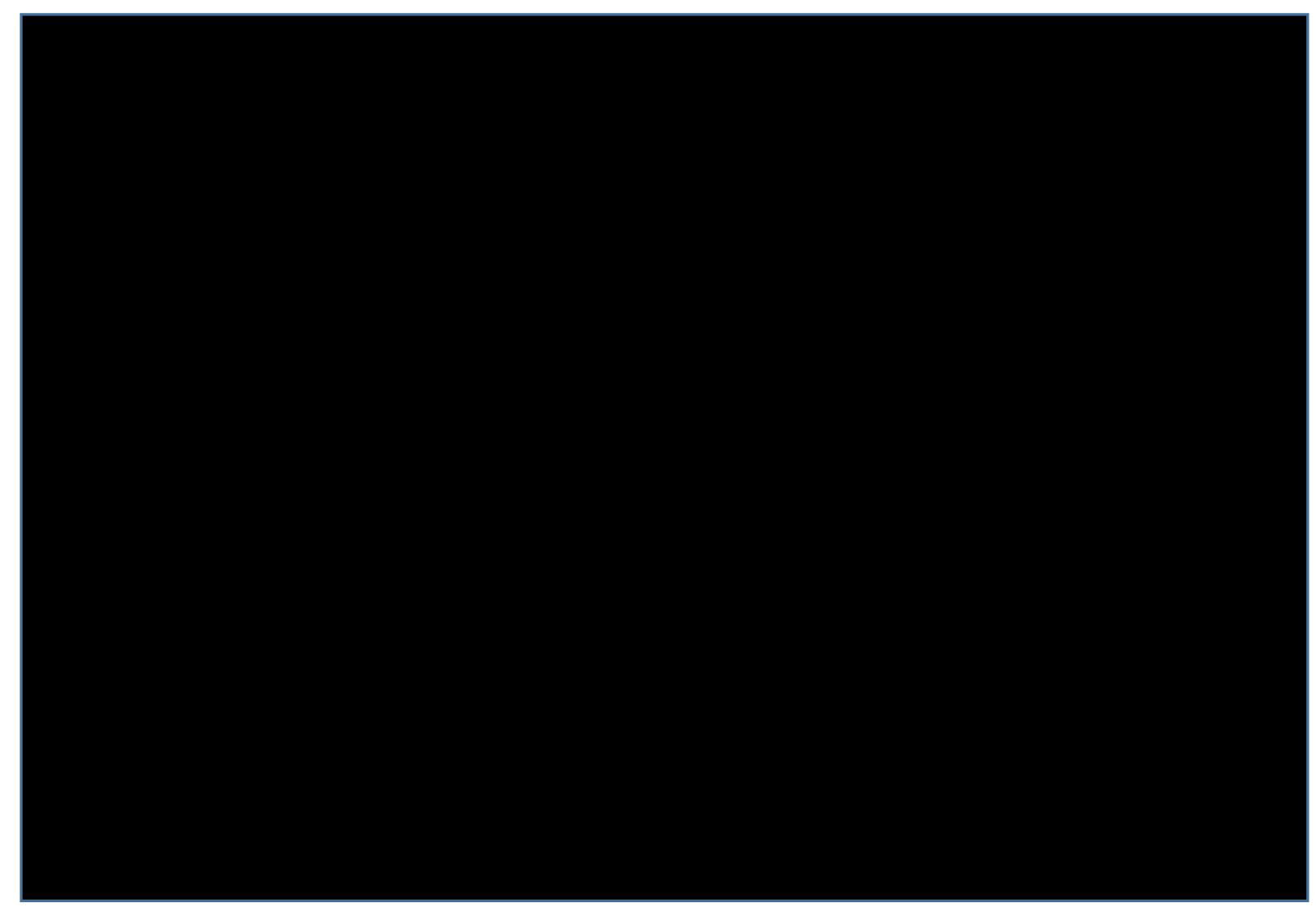

Fig. 5: Di Ffrench, Diary, 1980, mixed media installation.

(Artist's collection, photograph courtesy of the artist's husband.) 


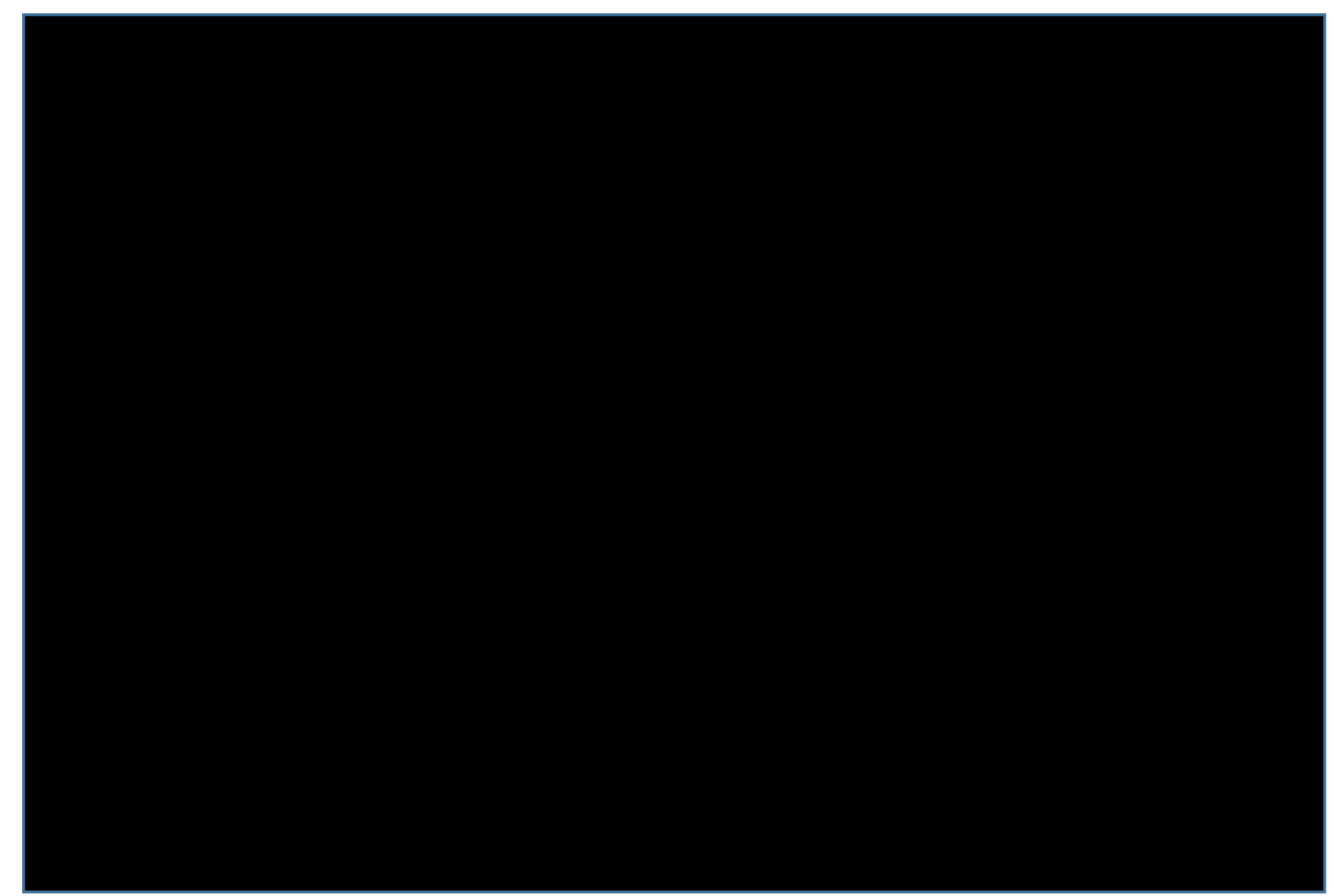

Fig. 6: Di Ffrench, Diary, 1980, mixed media installation.

(Artist's collection, photograph courtesy of the artist's husband.) 


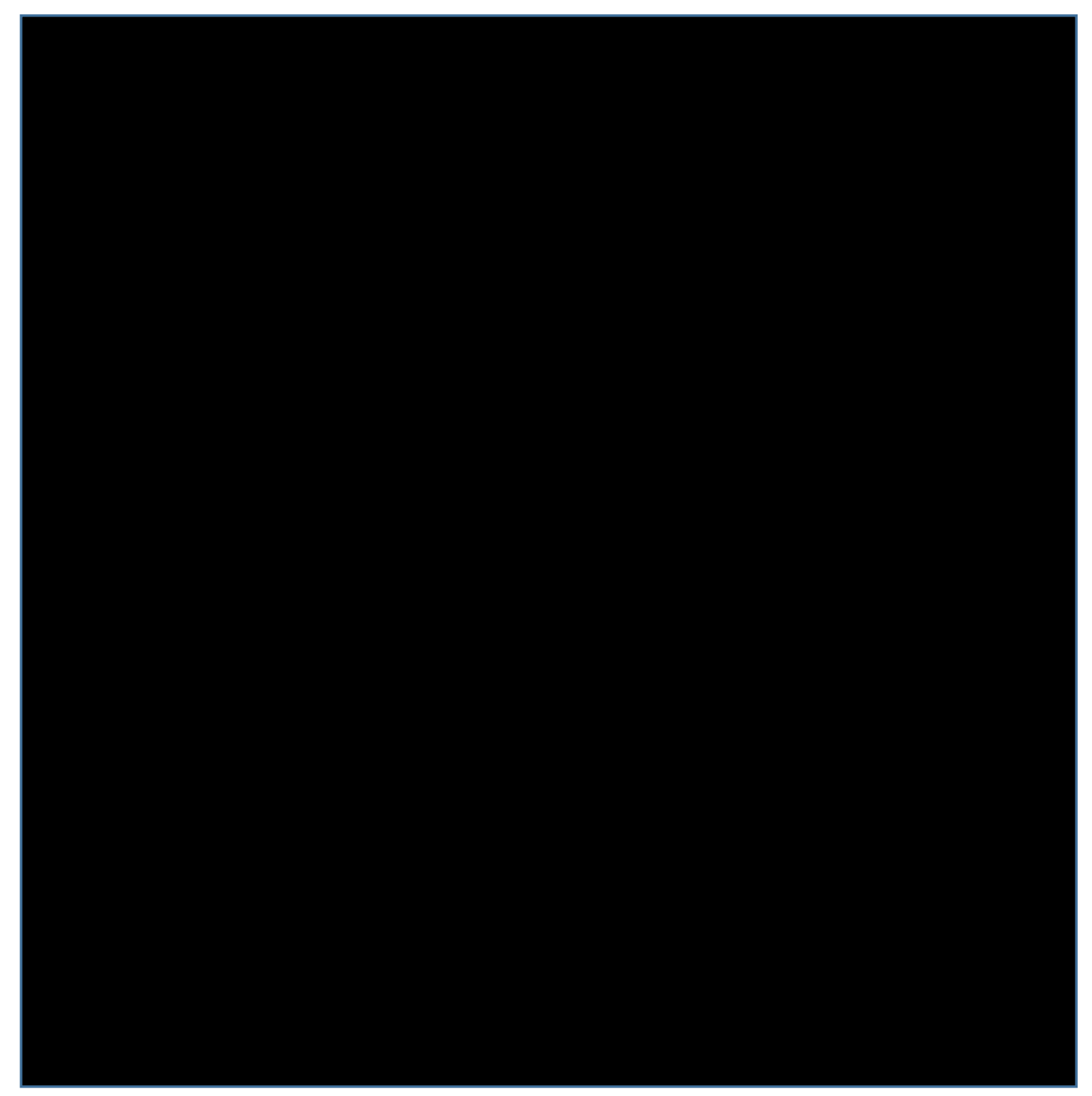

Fig. 7: Robyn Kahukiwa, Hinetitama, 1980, oil on board.

(Palmerston North: Te Manawa) 


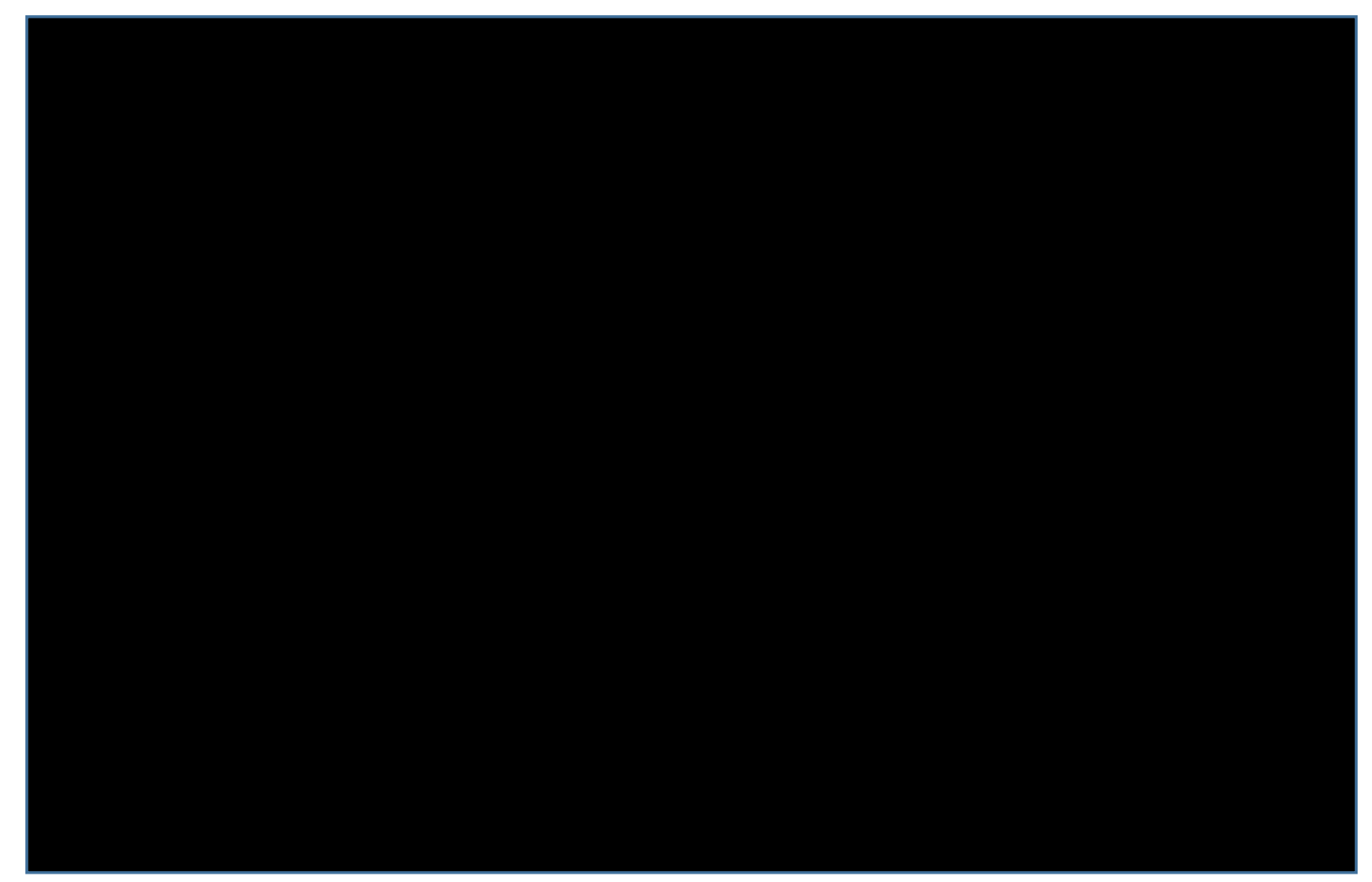

Fig. 8. Exhibition catalogue, Mothers, Women's Gallery, 1981 - 1982, showing Robyn Kahukiwa, Hinetitama, 1980, oil on board.

(Victoria University Library) 


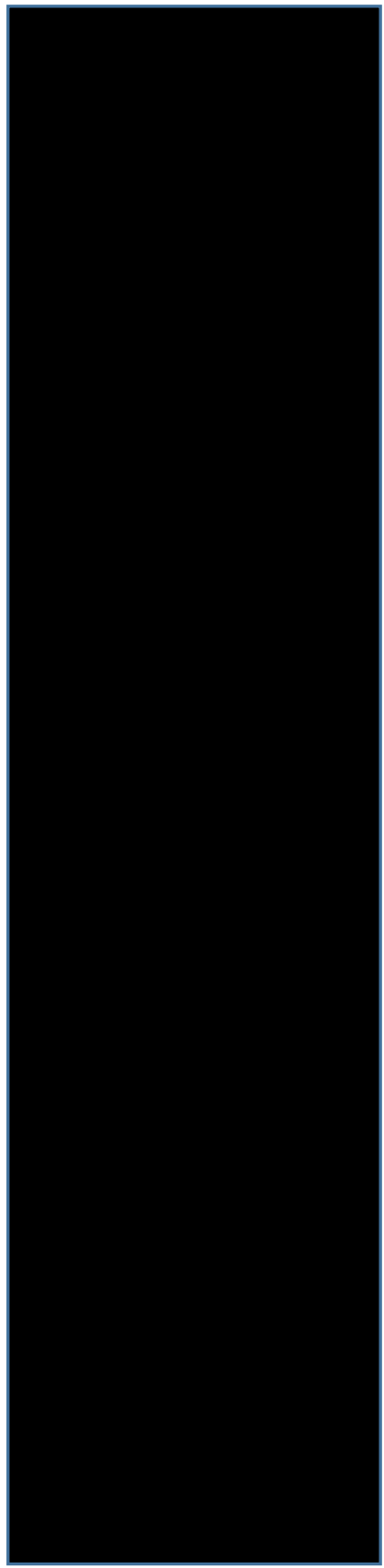

Fig. 9: Juliet Batten, Banner for the Bleeding from the Mending series, 1983, acrylic, fabrics and stitching on canvas.

(Artist's collection) 


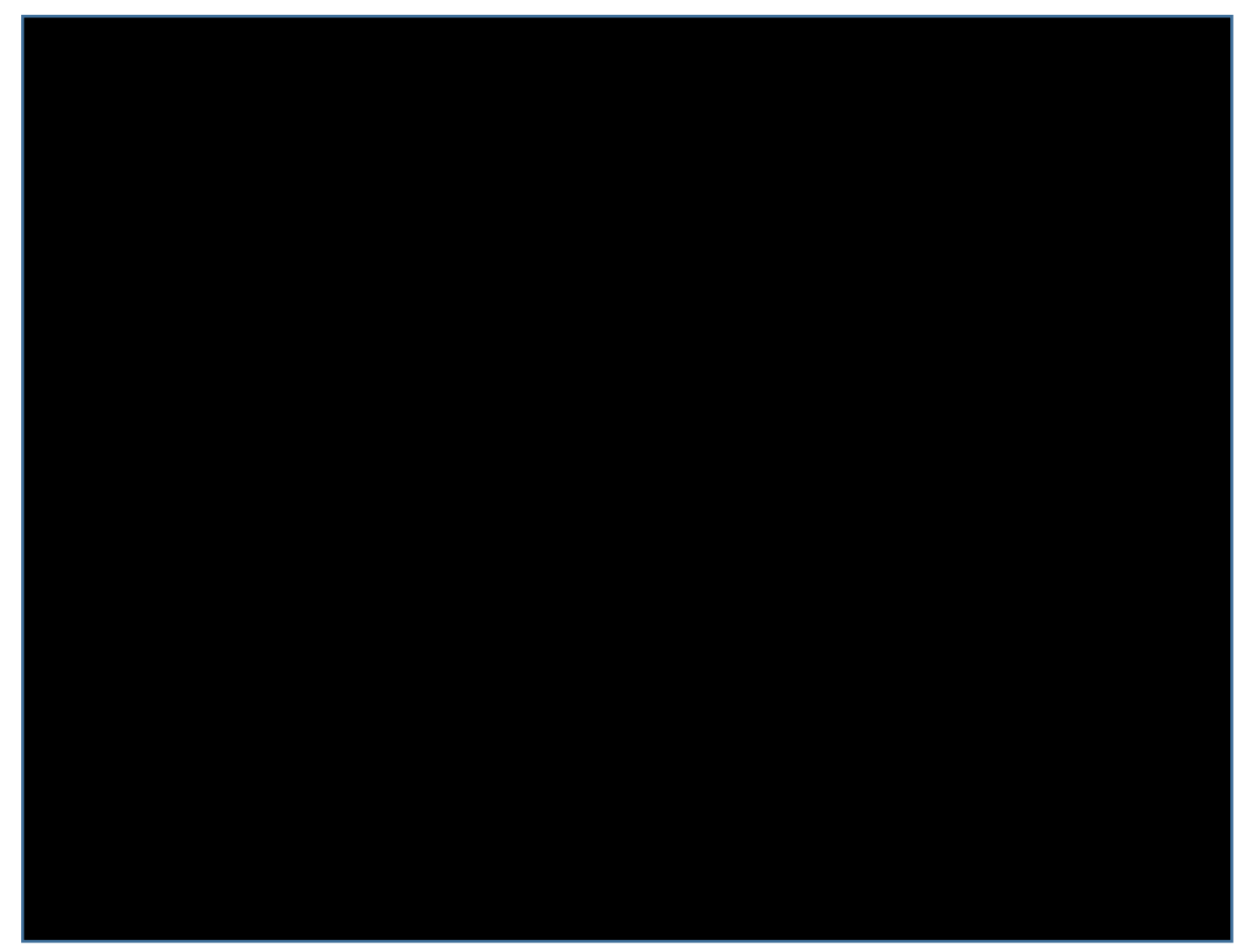

Fig. 10: Joanna Paul, Unwrapping the Body, 1977, self-produced book.

(Victoria University Library) 


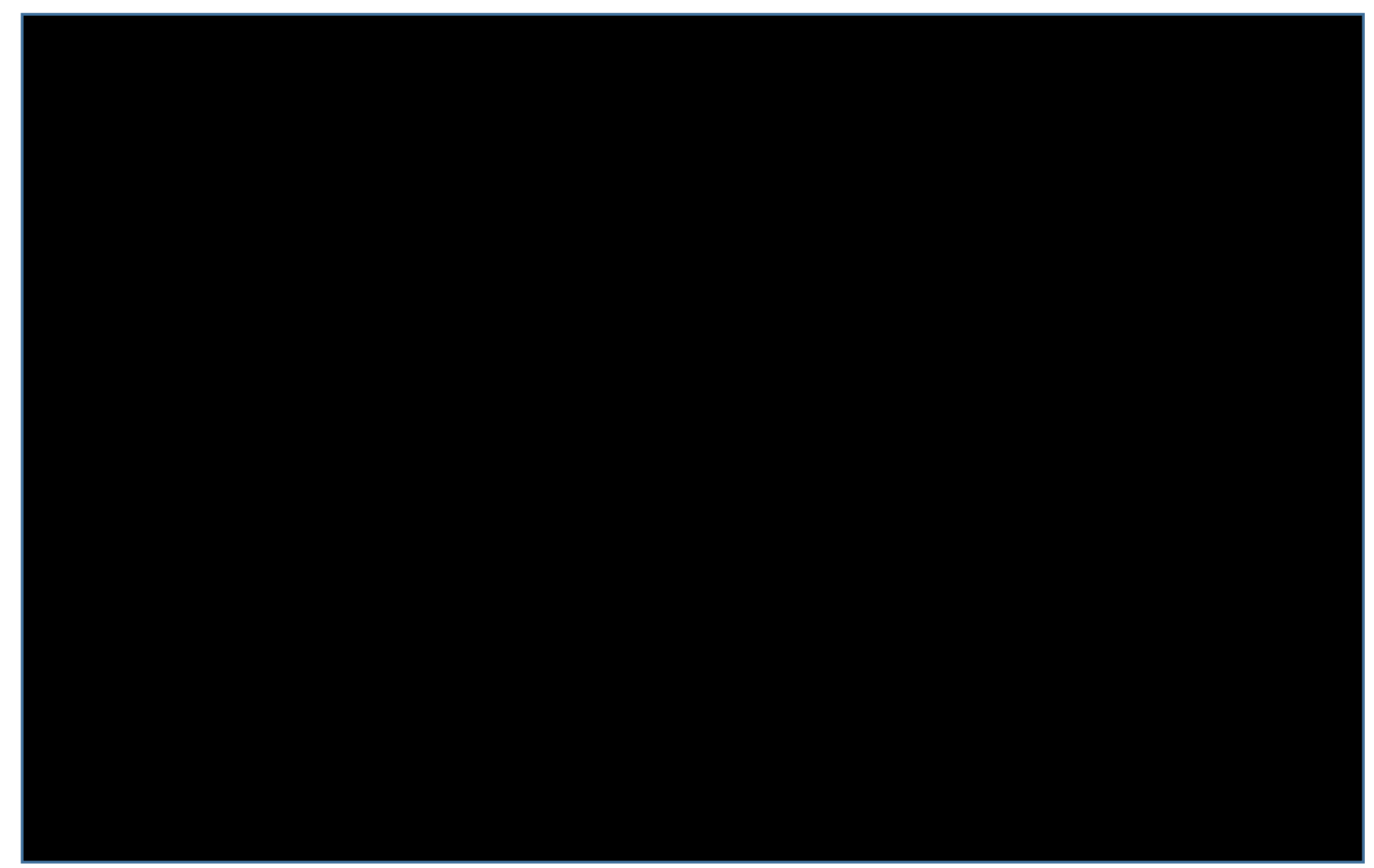

Fig. 11: Joanna Paul, Unwrapping the Body (detail), 1977, self-produced book. (Victoria University Library) 
Fig. 12: Martha Rosler, The Bowery in Two Inadequate Descriptive Systems, 1975-75, Fortyfive gelatin silver prints of text and image mounted on twenty-four backing boards.

Multiple editions. (Edition 2/5 New York: Whitney Museum of American Art). 


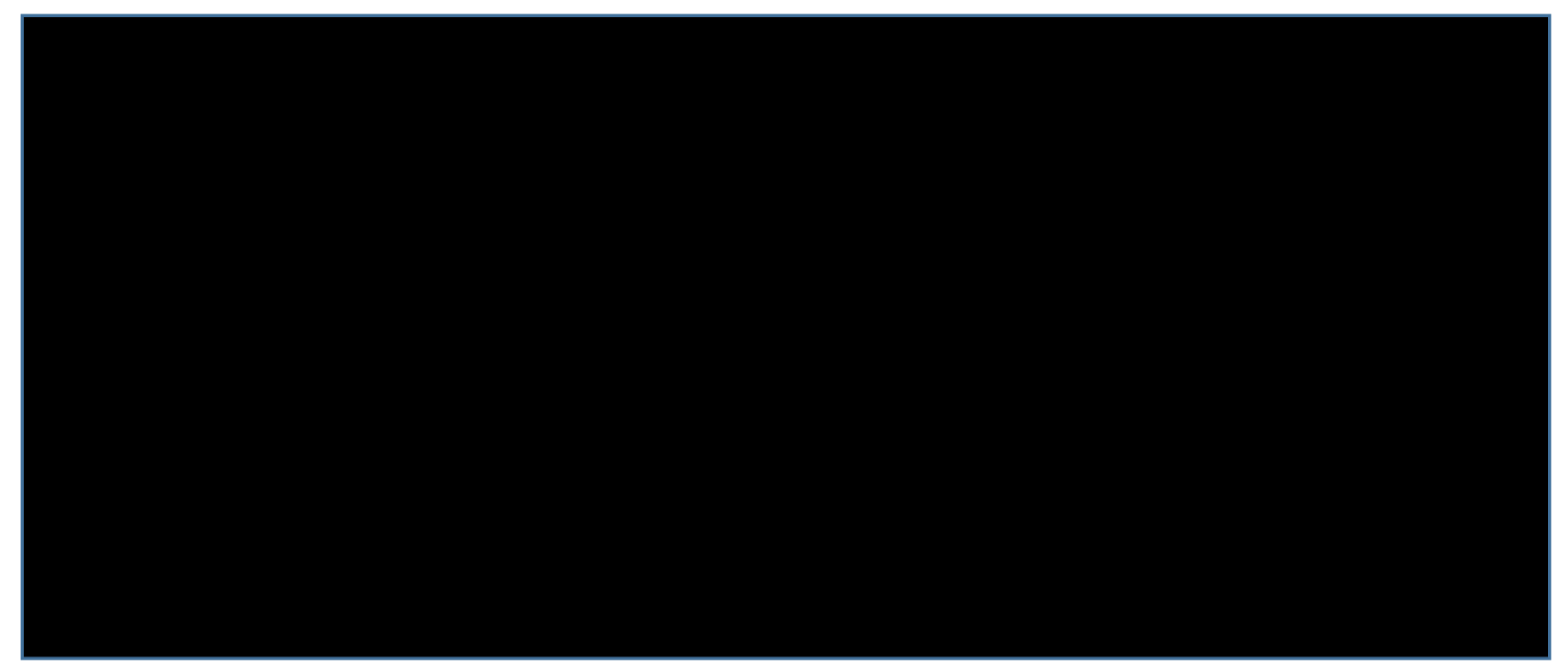

Fig. 13: Martha Rosler, The Bowery in Two Inadequate Descriptive Systems (detail), 1974-75, Forty-five gelatin silver prints of text and image mounted on twenty-four backing boards.

Multiple editions. (Edition 2/5 New York: Whitney Museum of American Art). 


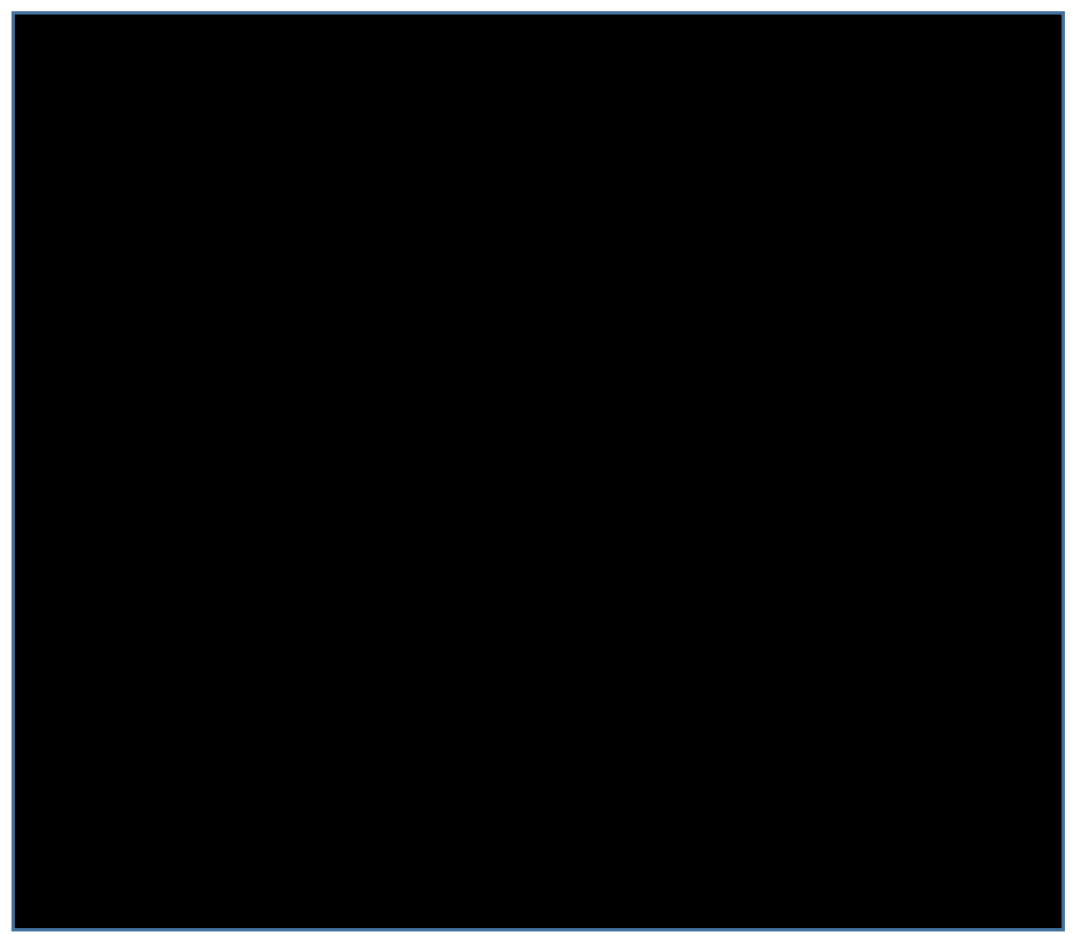

Fig. 14: Joanna Margaret Paul, Felix Sleeping, 1980, conte.

(location unknown) 


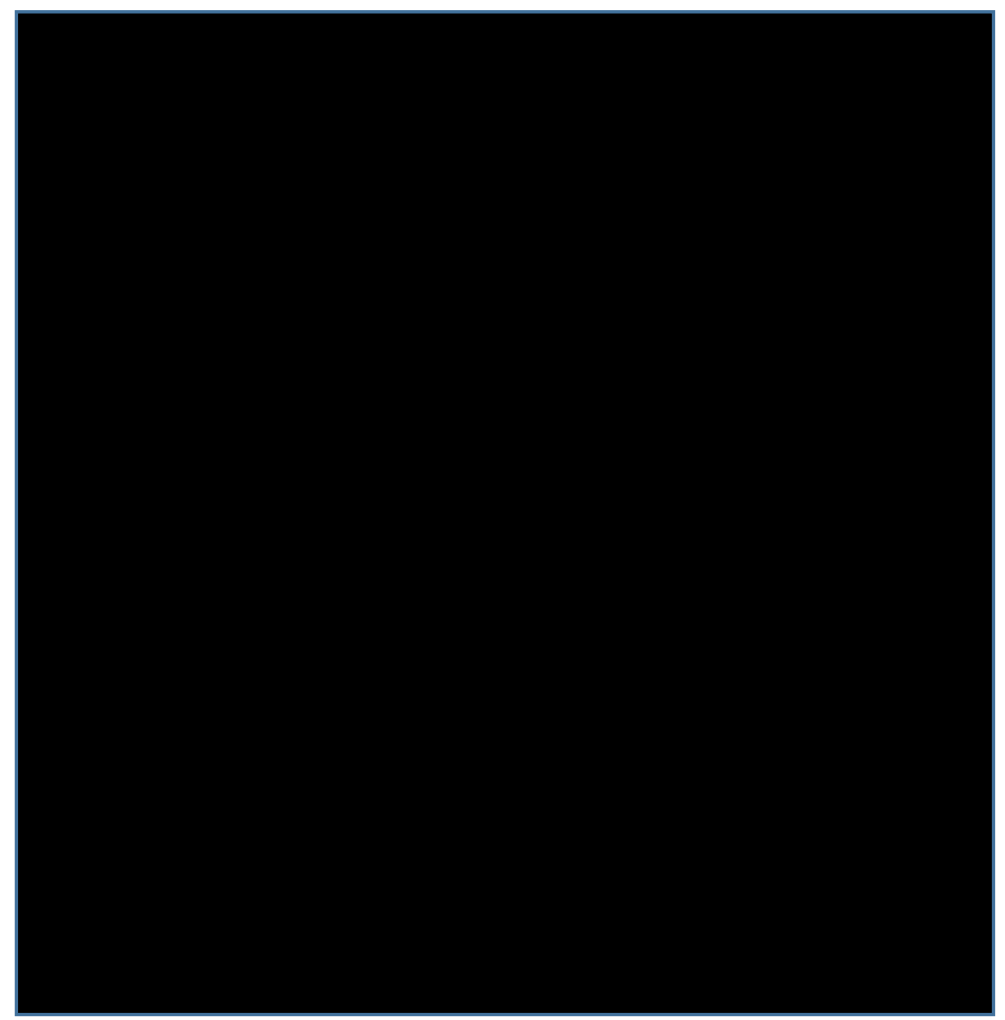

Fig. 15: Joanna Margaret Paul, Felix Sleeping III, 1980, conte. (location unknown) 


\section{Bibliography}

\section{Unpublished resources:}

\section{Alexander Turnbull Library, Wellington}

The Women's Gallery (Wellington): Ephemera: Eph-C-WOMENS-GALLERY-1980

The Women's Gallery (Wellington): Ephemera: Eph-C-WOMENS-GALLERY-1981

The Women's Gallery (Wellington): Ephemera: Eph-C-WOMENS-GALLERY-1982

The Women's Gallery (Wellington): Ephemera: Eph-C-WOMENS-GALLERY-1983

The Women's Gallery (Wellington): Photographs: PA 2004-174

The Women's Gallery (Wellington): Manuscripts and Archives:

84-072-01/1: Index for exhibition files

84-072-01/2: Exhibition file (EF), 1980

84-072-01/3: EF, 1980

84-072-01/4: EF, 1980-1981

84-072-02/01: EF, Mothers exhibition, 1981

84-072-02/02: EF, Mothers exhibition and Maori Women's Show, 1981

84-072-02/03: EF, 1981

84-072-03/01: EF, 1981

84-072-03/02: Events file, 1980-1981

84-072-04/07: Women in art information folder

84-072-04/08: Women's Art Movement information and newsletters

84-072-06/01: Women and Violence exhibition, forums and booklet, 19811982

84-072-06/02: Disarmament exhibition, 1981-1982 


\section{Museum of New Zealand Te Papa Tongarewa Archives}

Women's Art Archive. Information files: New Zealand Women Artists, 1971-1984. CA000047

Women's Art Archive. Oral Histories: Women Artists, 1984. CA000053

Women's Art Archive. Oral Histories: Interview with Lita Barrie, 1984. CA000053/001/0004

Women's Art Archive. Oral Histories: Interview with Juliet Batten, 1984. CA000053/001/0005

\section{Personal communication}

Batten, Juliet. Email correspondence with author, 2014-2015

Evans, Marian. Email correspondence with author, 2015

\section{Published resources:}

Awatere, Hinemoa, "Mauri Oho, Mauri Ora", In Toi Wahine: The Worlds of Maori Women, edited by Kathie Irwin and Irihapete Ramsden, Auckland: Penguin Books Ltd, 1995: 31-38.

Bachelard, Gaston, The Poetics of Space, Massachusetts: Beacon Press Books, 1969.

Barr, Mary (editor), Headlands: Thinking through New Zealand Art, Sydney: Museum of Contemporary Art, 1992.

Barrie, Lita, "Further toward a Deconstruction of Phallic Univocality: Deferrals", Antic 2, 1987: 19-47.

_ 1986: 87-103.

_, "The Female Imposter in Suburbia", in Alter/Image: Feminism and Representation in New Zealand Art 1973-1993, edited by Christina Barton and Deborah Lawler-Dormer, Wellington: City Gallery Wellington, 1993: 26-28.

Barrie, Lita, and Stuart Morgan, "Altared Positions: A Conversation between Stuart Morgan and Lita Barrie", Antic 1, 1986: 105-13.

Barry, Judith, and Sandy Flitterman-Lewis, "Textual Strategies: The Politics of ArtMaking", in Feminist Art Criticism: An Anthology, edited by Arlene Raven, Cassandra L Langer and Joanna Frueh, New York: Icon Editions: An Imprint of Harper Collins Publishers, 1991: 87-98. 
Barton, Christina, "Entries" in Now See Hear! Art, Language and Translation, edited by Ian Wedde and Gregory Burke, Wellington: Victoria University Press for the Wellington City Art Gallery, 1990: 215-222.

Barton, Christina, and Deborah Lawler-Dormer, Alter/Image: Feminism and Representation in New Zealand Art 1973-1993, Wellington: City Gallery Wellington, 1993.

, "'Unruly Practices' an Introduction to a Different View: 20 New Zealand Women Artists 1973-1993", in Alter/Image: Feminism and Representation in New Zealand Art 1973-1993, edited by Christina Barton and Deborah LawlerDormer, Wellington: City Gallery Wellington, 1993: 7-17.

Batten, Juliet, "Art and Identity", in Culture and Identity in New Zealand, edited by David Novitz and Bill Willmott, Wellington: Government Printing Office, 1989: 212-236.

—_, "The Edmonds Cookbook and the Ivory Tower" Antic 2, 1987: 5-17.

, "Emerging from the Underground: The Women's Art Movement in New Zealand", in Women's Studies Conference: Women's Studies Association of New Zealand, 1981.

Birdling, Bruce, "Emily Pace", Art New Zealand, no. 26 (1983): 38.

Broadhurst, Susan, Liminal Acts: A Critical Overview of Contemporary Performance and Theory, London: Cassell, 1999.

Broadsheet, "Collectively Speaking", Broadsheet 110, 1983.

Brodribb, Somer, Nothing Mat(t)ers: A Feminist Critique of Postmodernism, Melbourne: Spinifex Press, 1992.

Broud, Norma, and Garrard, Mary D, The Power of Feminist Art: The American Movement of the 1970s, History and Impact, New York: Harry N. Abrams, Inc, 1994.

Brown, Gordon $\mathrm{H}$, and Keith, Hamish, An Introduction to New Zealand Painting 1836 - 1967, Auckland: William Collins (New Zealand) Ltd., 1969.

Bugden, Emma, and Greg Donson, "Introduction", in Beauty, Even: A Tribute to Joanna Margaret Paul 1945 - 2003, Wellington: City Gallery Wellington, 2004: 5-7.

Bunkle, Phillida, "How the Level Playing Field Levelled Women", in Heading Nowhere in a Navy Blue Suit and Other Tales from the Feminist Revolution, edited by Sue Kedgley and Mary Varnham, Wellington: Daphne Brasell Associates Co Ltd, 1993: 85-101. 
Bunkle, Phillida, and Beryl Hughes (editors), Women in New Zealand Society, Auckland: George Allen \& Unwin Australia Pty Ltd., 1980.

Chadwick, Whitney, Women, Art and Society, New York: Thames and Hudson, 1990.

— , "Women Artists and the Politics of Representation", in Feminist Art Criticism: An Anthology, edited by Arlene Raven, Cassandra L Langer and Joanna Frueh, Icon Editions, 1991.

City Gallery Wellington, "beauty, even: Joanna Margaret Paul 1945 - 2003", Wellington: City Gallery Wellington, 2004.

Collard, Judith, "Spiral Women: Locating Lesbian Activism in New Zealand Feminist Art, 1975 - 1992", in Journal of the History of Sexuality, vol. 15, issue. 2, 2006: 292-320.

Coman, Mihai, "Liminality in Media Studies: From Everyday Life to Media Events", in Victor Turner and Contemporary Cultural Performance, edited by Graham St John, New York: Berghahn Books, 2008: 94-108.

Coney, Sandra, "Why the Women's Movement Ran out of Steam", in Heading Nowhere in a Navy Blue Suit and Other Tales from the Feminist Revolution, edited by Sue Kedgley and Mary Varnham, Wellington: Daphne Brasell Associates Co Ltd., 1993: 51-74.

Cottingham, Laura, "Are You Experienced? Feminism, Art and the Body Politic", in Seeing through the Seventies: Essays on Feminism and Art, edited by Laura Cottingham, The Gordon and Breach Publishing Group, 2000: 117-132.

, "L.A. Womyn: The Feminist Art Movement in Southern California, 19701979", in Seeing through the Seventies: Essays on Feminism and Art, edited by Laura Cottingham, The Gordon and Breach Publishing Group, 2000: 161174.

—_, "Shifting Ground: On the Critical Practice of Lucy R. Lippard", in Seeing through the Seventies: Essays on Feminism and Art, edited by Laura Cottingham, The Gordon and Breach Publishing Group, 2000: 1-46.

Culler, Jonathan, On Deconstruction: Theory and Criticism after Structuralism, London: Routledge, 1983.

Daley, Caroline, and Deborah Montgomerie, The Gendered Kiwi, Auckland: Auckland University Press, 1999.

Davies, Austin, "Women's Art," Nelson Mail, 1980.

Davis, Susan, Elizabeth Eastmond, and Priscilla Pitts, "Editor's Introduction", Antic 1, 1986. 
D'haen, Theo and Bertens, Hans, Liminal Postmodernisms: The Postmodern, the (Post-) Colonial and the (Post-) Feminist, Amsterdam: Editions Rodopi B. V., 1994.

Du Plessis, Rosemary, and Lynn, Alice (editors), Feminist Thought in Aotearoa/New Zealand: Connections and Difference, Oxford: Oxford University Press, 1998.

Eastmond, Elizabeth, and Merimeri Penfold, Women and the Arts in New Zealand: Forty Works: 1936 - 86, Auckland: Peguin Books (N.Z) Ltd, 1986.

Elam, Diane, Feminism and Deconstruction: Ms. En Abyme, London and New York: Routledge, 1994.

Else, Anne, "Women's Gallery Opens in Wellington", in Broadsheet 77, 1980: 32.

Else, Anne, and Rosslyn Noonan, "Unfinished Business", in Heading Nowhere in a Navy Blue Suit and Other Tales from the Feminist Revolution, edited by Sue Kedgley and Mary Varnham, Wellington: Daphne Brasell Associates Co Ltd, 1993: 190-203.

Evans, Marian, "Appendix: The Women's Gallery, December 1979 - February 1984", in A Women's Picture Book: 25 Women Artists of Aotearoa (New Zealand), Wellington: Government Printing Office, 1988: 247-254.

—, "The Women's Gallery 1979-", in Women Together: A History of Women's Organisations in New Zealand, edited by Anne Else, Wellington, New Zealand: Daphne Brasell Associates Press, 1993: 472-473.

—, the bone people, http://wellywoodwoman.blogspot.co.nz/2010/11/bonepeople.html, 2010. Accessed on 12/01/2015.

- They might have completely forgotten us, http://wellywoodwoman.blogspot.co.nz/2013/01/they-might-have-completelyforgotten-us.html, 2013. Accessed on 09/12/2013.

Evans, Marian, and Bridie Lonie, "Afterword 1", in A Women's Picture Book: 25 Women Artists of Aotearoa (New Zealand), edited by Marian Evans, Bridie Lonie and Tilly Lloyd, Wellington: Government Printing Office, 1988: 227240.

Evans, Marian, Bridie Lonie, and Tilly Lloyd, A Women's Picture Book: 25 Women Artists of Aotearoa (New Zealand), Wellington: Government Printing Office, 1988.

Fletcher, John, and Benjamin, Andrew, Abjection, Melancholia and Love: The Work of Julia Kristeva, Abingdon: Routledge, 1990.

Genz, Stephanie, and Brabon, Benjamin A., Postfeminism: Cultural Texts and Theories, Edinburgh: Edinburgh University Press Ltd, 2009. 
Green, Tony, "Modernism and Modernization", in Headlands: Thinking through New Zealand Art, edited by Mary Barr, Sydney: Museum of Contemporary Art, 1992: 147-160.

Grosz, Elizabeth, "Bodies and Knowledge: Feminism and the Crisis of Reason", in Space, Time and Perversion, edited by Elizabeth Grosz, New York: Routledge, 1995: 25-43.

— - "Sexual Signatures: Feminism After the Death of the Author", in Space, Time and Perversion, edited by Elizabeth Grosz, New York: Routledge, 1995: 9-24.

. "Women, Chora, Dwelling", in Space, Time and Perversion, edited by Elizabeth Grosz, New York: Routledge, 1995: 111-124.

Harris, Jocelyn, "Vulvas on Plates: Judy Chicago's Dinner Party", Broadsheet 72, 1979.

Hilliard, Hinemoa, "Mana Maori: The Art of Robyn Kahukiwa", in The Art of Robyn Kahukiwa, edited by Robyn Kahukiwa, Auckland: Reed Books, 2005: 10-17.

Ireland, Peter, "A Shape to Part the Space: Joanna Margaret Paul 1945 - 2003", Art New Zealand, no. 108, 2003: 58-59.

Irwin, Kathie, and Ramsden, Irihapete (editors), Toi Wāhine: The Worlds of Māori Women, Auckland: Penguin Books Ltd, 1995.

Jones, Amelia, "'Every Man Knows Where and How Beauty Gives Him Pleasure': Beauty Discourse and the Logic of Aesthetics", in The Art of Art History: A Critical Anthology, edited by Donald Preziosi, New York: Oxford University Press, 2009: 375-390.

Kahukiwa, Robyn, and Patricia Grace, Wahine Toa: Women of Maori Myth, Auckland: Viking Pacific, 1984.

Keir, Anna, and Marian McKay, "Women's Gallery Planned for Wellington", Broadsheet 76, 1980.

Kelsey, Jane, The New Zealand Experiment: A World Model for Structural Adjustment?, Auckland: Auckland University Press, 1995.

Kirker, Anne, "Di Ffrench: Activating Ideas. A Survey of Selected Works 19771997", Dunedin: Dunedin Public Art Gallery, 2009.

_ New Zealand Women Artists: A Survey of 150 Years, 2nd ed.: Craftsman House, BVI Ltd, 1993.

Kirker, Anne, and Eric Young, Eric, New Zealand's Women Painters, Auckland: Auckland City Art Gallery, 1975. 
Kristeva, Julia, "Women's Time", in The Kristeva Reader, edited by Toril Moi, Oxford: Basil Blackwell Ltd, 1986.

Langer, Cassandra L., "Against the Grain: A Working Gynergenic Art Criticism", in Feminist Art Criticism: An Anthology, edited by Arlene Raven, Cassandra L Langer and Joanna Frueh, New York: Icon Editions: An Imprint of Harper Collins Publishers, 1991.

Leslie, John, Kate McMillan, and Elizabeth McLeay (editors), Rethinking Women and Politics: New Zealand and Comparative Perspectives, Wellington: Victoria University Press, 2009.

Lonie, Bridie, "Exhibitions Wellington: Diaries", Art New Zealand no. 18, 1981.

, "The Subject of Motherhood as Treated in New Zealand Painting", in Mothers, edited by Marian Evans and Anna Keir, Wellington: Women's Gallery, 1981: 5-7.

Martin, John E., History of Parliament's buildings and grounds, http://www.parliament.nz/en-nz/about-parliament/how-parliament-works/factsheets/00PlibJMPBG1/history-of-parliaments-buildings-and-grounds. Accessed, October 2015.

Maxwell, Ian, "The Ritualization of Performance (Studies)", in Victor Turner and Contemporary Cultural Performance, edited by Graham St John, New York: Berghahn Books, 2008: 59-75.

Milburn, Felicity, "Di Ffrench: Light and Illusion", Christchurch: Robert McDougall Art Gallery \& Annex, 2001.

Mitchell, Alison, "Woman's Art: An Exhibition of Six Women Artists", Christchurch: Robert McDougall Art Gallery, 1975.

Moi, Toril, Sexual/Textual Politics, London: Methuen \& Co. Ltd., 1985.

Mulvey, Laura, "Visual Pleasure in Narrative Cinema", in The Norton Anthology of Theory and Criticism, edited by Peter Simon, New York: W. W. Norton and Company Inc, 2001: 982-989.

"Nancy Peterson from the Auckland Women's Community Video Inc, Interviews Anna Keir and Marian Evans at the Women's Gallery, 26 Harris Street Wellington." www.youtube.com/watch?v=-UZOLx83ADk. Accessed January 2014.

Neich, Roger, "Wood Carving", in Maori Art and Culture, edited by D. C. Starzecka, Auckland: David Bateman Ltd, 1996: 69-113.

Nochlin, Linda, Women, Art and Power And Other Essays, New York: Harper and Row, 1989. 
O'Connor, Mary Ellen, "We Will Work with You, Not for You", in We Will Work with You: Wellington Media Collective 1978-1998, edited by Mark Derby, Jennifer Rouse and Ian Wedde, Wellington: Victoria University Press, 2013: 84-108.

Owens, Craig, "The Allegorical Impulse: Toward a Theory of Postmodernism, Part 2", in Beyond Recognition: Representation, Power and Culture, edited by Scott Bryson, Barbara Kruger, Lynne Tillman and Jane Weinstock, Berkeley: University of California Press, 1994: 52-69.

, "The Discourse of Others: Feminists and Postmodernism", in Beyond Recognition: Representation, Power and Culture, edited by Scott Bryson, Barbara Kruger, Lynne Tillman and Jane Weinstock, Berkeley: University of California Press, 1994: 166-190.

Parker, Roszika, and Griselda Pollock (editors), Framing Feminism: Art and the Women's Movement 1970 - 1985, London: Pandora Press (Routledge \& Kegan Paul Ltd), 1987.

Parker, Roszika, and Griselda Pollock, "Fifteen Years of Feminist Action: From Practical Strategies to Strategic Practices", in Framing Feminism: Art and the Women's Movement, edited by Roszika Parker and Griselda Pollock, London: Pandora Press, 1987: 3-78.

Paul, Janet, "Women Artists", in Women in New Zealand Society, edited by Phillida Bunkle and Beryl Hughes, Auckland: George Allen \& Unwin Australia Pty Ltd., 1980: 184-216.

Phelan, Peggy, "Survey", in Art and Feminism, edited by Peggy Phelan and Helena Reckitt, London: Phaidon, 2001: 14-49.

Pitts, Priscilla, "The Unquiet Earth: Reading Landscape and the Land in New Zealand Art", in Headlands: Thinking through New Zealand Art, edited by Mary Barr, Sydney: Museum of Contemporary Art, 1992: 87-98.

_ Practice", in Alter/Image: Feminism and Representation in New Zealand Art 1973-1993, edited by Christina Barton and Deborah Lawler-Dormer, Wellington: City Gallery Wellington and Auckland City Art Gallery, 1993: $18-21$.

Pollock, Griselda, Vision and Difference: Feminism, Femininity and the Histories of Art, New York: Routledge Classics, 2003.

Pound, Francis, "Nationalist Antitheses: A Compendium", Antic 1, 1986,: 73-84.

, "The Words and The Art: New Zealand Art Criticism c.1950-c.1990", in Headlands: Thinking through New Zealand Art, edited by Mary Barr, Sydney: Museum of Contemporary Art, 1992: 185-202. 
Raven, Arlene, "The Last Essay on Feminist Criticism", in Feminist Art Criticism: An Anthology, edited by Arlene Raven, Cassandra A. Langer and Joanna Frueh, New York: Icon Editions: Harper Collins Publishers, 1991.

Reckitt, Helena, "Preface", in Art and Feminism, edited by Peggy Phelan and Helena Reckitt, London: Phaidon, 2001: 10-13.

Rosier, Pat, Been Around For Quite a While. Broadsheet: Twenty Years of Broadsheet Magazine, Auckland: New Women's Press Ltd., 1992.

Schechner, Richard, Between Theater and Anthropology, Philadelphia: University of Pennsylvania Press, 1985.

- , Performance Studies: An Introduction, New York and London: Routledge, 2006.

Seidman, Stephen, The Postmodern Turn: New Perspectives on Social Theory, Cambridge: Cambridge University Press, 1994.

Simmons, Laurence, Speaking Truth to Power: Public Intellectuals Rethink New Zealand, Auckland: Auckland University Press, 2007.

Skinner, Damian, "The Eye of an Outsider: A Conversation with Ans Westra", Art New Zealand no. 100, 2001: 94-100.

Sotheran, Cheryll, "Replacing Women in Art History", Art New Zealand, no. 26, 1983: 15-17.

St John, Graham, "Victor Turner and Contemporary Cultural Performance: An Introduction", in Victor Turner and Contemporary Cultural Performance, edited by Graham St John, New York: Berghahn Books, 2008: 1-40.

Tasker, Yvonne, and Diane Negra, "Introduction: Feminist Politics and Postfeminist Culture", in Interrogating Postfeminism: Gender and the Politics of Popular Culture, edited by Yvonne Tasker and Diane Negra, Durham and London: Duke University Press, 2007: 1-26.

Te Awekotuku, Ngahuia, "Maori: People and Culture", in Maori Art and Culture, edited by D. C. Starzecka, Auckland: David Bateman Ltd., 1996: 26-49.

The Women's Gallery, Mothers, Wellington: The Women's Gallery, 1981.

$\longrightarrow$, Pamphlet, Alexander Turnbull Archive, 1980.

—, Why a Women's Gallery?, Alexander Turnbull Archive, 1980.

Trevelyan, Jill, "'To See the Moment Is to Farewell It.' The Drawings of Joanna Margaret Paul", in Joanna Margaret Paul: Drawing, edited by Jill Trevelyan and Sarah Treadwell, Auckland: Auckland University Press, 2006: 7-24. 
Turner, Victor, "Are There Universals of Performance in Myth, Ritual, and Drama?", in By Means of Performance: Intercultural Studies of Theatre and Ritual, edited by Richard Schechner and Willa Appel, Cambridge: Cambridge University Press, 1990: 8-18.

— Forest of Symbols: Aspects of Ndembu Ritual, edited by Victor Turner, Ithaca and London: Cornell University Press, 1967.

— The Forest of Symbols: Aspects of Nbemdu Ritual, Ithaca and London: Cornell University Press, 1967.

— , "Liminal to Liminoid, in Play, Flow, and Ritual: An Essay in Comparative Symbology", in From Ritual to Theatre: The Human Seriousness of Play, edited by Victor Turner, New York: Performing Arts Journal Publications, 1982 .

Vogel, Lisa, "Fine Arts and Feminism: The Awakening Consciousness", in Feminist Art Criticism: An Anthology, edited by Arlene Raven, Cassandra A. Langer and Joanna Frueh, New York: Icon Editions: Harper Collins Publishers, 1991.

West, Cornel, "The New Cultural Politics of Difference", in The Postmodern Turn: New Perspectives on Social Theory, edited by Stephen Seidman, Cambridge: Cambridge University Press, 1994: 65-81.

Whitford, Margaret (editor), The Irigaray Reader: Luce Irigaray, Oxford: Blackwell Publishers Limited, 1991. 
Appendix I

\section{Exhibition History of the Women's Gallery, Wellington}

1980

\section{January \\ Women only opening \\ 21 January - 29 February \\ Opening Show}

Exhibiting artists: Juliet Batten, Allie Eagle, Claudia Eyley, Keri Hulme, Bridie Lonie, Heather McPherson, Joanna Paul, Nancy Peterson, Helen Rockel, Carole Stewart, Tiffany Thornley

$$
17 \text { March - } 7 \text { April }
$$

Fabric Show

$$
14 \text { April - } 10 \text { May }
$$

Print Show

Exhibiting artists: Linda James, Janet Paul, Tiffany Thornley

15 May - 15 June

\section{Edith Collier Exhibition}

Drawings and preparatory sketches for paintings in the retrospective exhibition organised by the Sargeant Gallery

\section{June - 19 July \\ Womenspirit}

$$
14-30 \text { July }
$$

\section{Beehive Exhibition}

22 July - 22 August

\section{Diaries}

Exhibiting artists: Juliet Batten, Allie Eagle, Miro Billbrough, Di Ffrench, Keri Hulme,

$$
\begin{gathered}
26 \text { August - } 20 \text { September } \\
\text { Art Archive Show } \\
3 \text { October - } 11 \text { October } \\
\text { Lesbiana }
\end{gathered}
$$

28 October -6 December

Women and Violence

$$
\begin{gathered}
9-23 \text { December } \\
\text { Stock Show }
\end{gathered}
$$




\section{$6-17$ January \\ Sculpture Project}

\section{February - 7 March}

\section{Mothers}

Exhibiting Artists: Sharon Alston, Juliet Batten, Jo Cornwall, Claudia Pond Eyley, Jacqueline Fahey,

Di Ffrench, Keri Hulme, Linda James, Robyn Kahukiwa, Anna Keir, Robin McKinlay, Joanna Paul,

Helen Rockel, Jill Stewart, Barbara Strathdee, Tiffany Thornley, Robin White

$$
\begin{gathered}
23 \text { March }-6 \text { April } \\
\text { Maori Women's Show }
\end{gathered}
$$

\section{April - 9 May \\ Political Posters}

\section{May - 13 June \\ Self Image}

23 June - 25 July

Sexxuality

$$
\begin{gathered}
4-29 \text { August } \\
\text { Spirituality }
\end{gathered}
$$

\section{September - 10 October}

Group Show

3 November - 12 December

Women and the Environment 
1982

Gallery relocated to new premises at 323 Willis Street

$$
\begin{gathered}
2-31 \text { March } \\
\text { Silk and Pottery }
\end{gathered}
$$

Exhibiting artists: Lani Morris, Sharon Kennedy, Valeska Campion

$$
\begin{aligned}
& 13 \text { April - 8 May } \\
& \text { Portraits }
\end{aligned}
$$

Exhibiting artists: Adrienne Martyn, Lnn Culy

11 May - 5 June

Janet de Wagt

Exhibiting artist: Janet de Wagt

14 June -10 July

Mothers

As part of a national tour

10 September -6 October

The First Women's Gallery

Exhibiting artists: Fiona Clark, Allie Eagle, Marian Evans, Claudia Pond Eyley, Keri Hulme, Anna Keir, Bridie Lonie, Heather McPherson, Joanna Paul, Carole Stewart, Tiffany Thornley

$$
12 \text { - } 30 \text { October }
$$

\section{Mothers}

At the Antares Gallery in Sydney, as part of the Women and Arts Festival

9 October - 20 November

\section{Women's Disarmament Exhibition}


27 February - 18 March

Painted Works

Exhibiting artists: Linda Grey, Caroline Campbell

25 March - 22 April

Craft Show: Fabrics, Pottery

$$
\begin{gathered}
1-21 \text { May } \\
10 \text { Women Artists }
\end{gathered}
$$

Exhibiting artists: Betty Clegg, Betty Eaton, Claire Jennings, Helen Seresin, Rosie Little, Dwyliss Powell, Pat Fry, Lara Seresin, Caroline Campbell, Linda Hubbard

\section{June - 13 August \\ Images of Women: 11 Photographers}

Exhibiting artists: Bub Bridger, Carole Shepheard, Gail Wright, Rhonda Bosworth, Victoria

Ginn, Janet Bayly, Ans Westra, Gillian Chaplin, Stella Daniell, Margaret Jones, Angela Gunn

$$
23 \text { August - } 10 \text { September }
$$

Children and Childhood

Exhibiting artists: Robyn Belton, Miro Bilbrough, kids from Brandon Intermediate School, Robyn Kahukiwa, Anna Keir, Barbara Strathdee

25 September - 16 October

Paintings and Graphics

Exhibiting artists: Frantze Meikle, Melanie Walker, Petina-Jane Alley

1 November - 17 December

Workbooks/Diaries

Exhibiting artists: Anne Morris, Ans Westra \& Sylvia Bowen, Carole Shepheard, Di Ffrench, Heather McPherson, Janet de Wagt, Jo Cornwall, Joanna Paul, Juliet Batten, Keri Hulme, Lani Morris, Lynnsay Francis, Robin White, Sarah Parkinson, Shirley Cameron, Sky Isaacs 
